\title{
A virtual-reality system for interacting with three-dimensional models using a haptic device and a head-mounted display
}

\author{
Elie Saad
}

Department of BioMedical Engineering

McGill University, Montréal, Québec

A thesis submitted to McGill University

In partial fulfillment of the requirements of the degree of

Master of Engineering

(C) Elie Saad, 2016 


\section{A virtual-reality system for interacting with three-dimensional models using a haptic device and a head-mounted display.}

\section{ABSTRACT}

Visualizing and simulating the real world by means of three-dimensional (3D) models is important for many fields of science, technology, engineering and medicine (STEM). Exploiting the human senses, such as the sense of sight with head-mounted displays (HMDs) and the sense of touch with haptic devices, has helped in creating immersive virtual-reality (VR) experiences. However, HMDs and haptics have seldom been combined in STEM applications, and recently the technology has been advancing rapidly in both areas.

The objective of this research was to develop a VR system which combines both a consumer-level HMD and a mid-level haptic device using a game-development platform. A proof-of-concept system was developed using the Oculus Rift HMD and the Phantom Premium 1.5 High Force haptic device. The system was implemented using the Unity 3D game engine and was tested with two 3D human anatomical models, a heart and part of a skull. The technical performance of the system was evaluated, and a small preliminary user evaluation was performed. Particular challenges and limitations of currently available hardware and software are also discussed.

The combination of HMDs and haptics promises to be beneficial for educational, training and rehabilitation purposes. Future work should include more in-depth evaluation, as well as extension of the system beyond 3D model visualizations and simple haptic interactions to include more complex 
features such as material deformation and cutting, which are useful for many applications in STEM and beyond. 


\section{Un système de réalité virtuelle pour interagir avec des modèles en trois dimensions en utilisant un appareil haptique et un visiocasque.}

\section{RÉSUMÉ}

Simuler et visualiser le monde par des modèles en trois dimensions (3-D) est primordial pour de nombreux domaines de la science, la technologie, l'ingénierie et la médecine (STIM). Solliciter les différents sens de l'être humain à travers des appareils divers, comme par exemple les visiocasques pour solliciter le sens de la vue et les appareils haptiques pour solliciter le sens du toucher, a permis de susciter le sentiment d'immersion dans un environnement virtuel. De nos jours, la technologie derrière les visiocasques et les appareils haptiques a évolué très rapidement mais les deux sont rarement combinés pour servir dans des applications STIM.

L'objectif de cette recherche était de développer un système de réalité virtuelle qui combine à la fois un visiocasque pour consommateurs et un appareil haptique de niveau intermédiaire en utilisant un moteur de jeu. Un système de preuve de concept a été développé en utilisant le visiocasque Oculus Rift et l'appareil haptique Phantom Premium 1.5 High Force. Ce système a été développé en utilisant le moteur de jeu Unity 3D et testé avec deux modèles anatomiques du corps humain, un coeur et une partie d'un crâne. L'évaluation de la performance technique du système a été établie et une petite évaluation préliminaire de l'utilisateur a été effectuée. Les défis et limites des matériels et logiciels informatiques disponibles sont également discutés. 
La combinaison des visiocasques et des appareils haptiques promet d'être bénéfique pour des fins éducatives, d'entraînement et de réhabilitation. Les travaux futures doivent inclure une évaluation plus approfondie ainsi qu'une extension du système au-delà des visualisations des modèles $3 \mathrm{D}$ et des simples interactions haptiques pour inclure des fonctions plus complexes telles que la déformation de la matière et la coupe, utiles pour de nombreuses applications STIM et au-delà. 


\section{ACKNOWLEDGMENTS}

Foremost, I would like to express my sincere gratitude to my supervisor Dr W. Robert J. Funnell for his guidance, motivation and patience throughout the learning process of my master's degree. His valuable comments, remarks and feedback helped me in putting all the pieces together and presenting this work.

I would also like to thank my co-supervisor Dr Paul Kry from the School of Computer Science for his continuous support throughout this project and for granting me access to his lab and providing me with the required equipment. I am also grateful to Dr Nicole Ventura from the Department of Anatomy \& Cell Biology for her valuable assistance with the user evaluation.

Special thanks to my friends and colleagues in the McGill Auditory Mechanics Laboratory and the McGill BioMedical Engineering Department, in particular Pina Sorrini, Nancy Abate and Daniel Caron.

My sincere thanks go to my Mom and Dad for all their encouragement, motivation and support. I would also like to thank all of my family, friends and loved ones, in particular my brother Joseph and the Lebanese Maronite Order, for their continuous encouragement and help throughout my academic career. 


\section{Table of Contents}

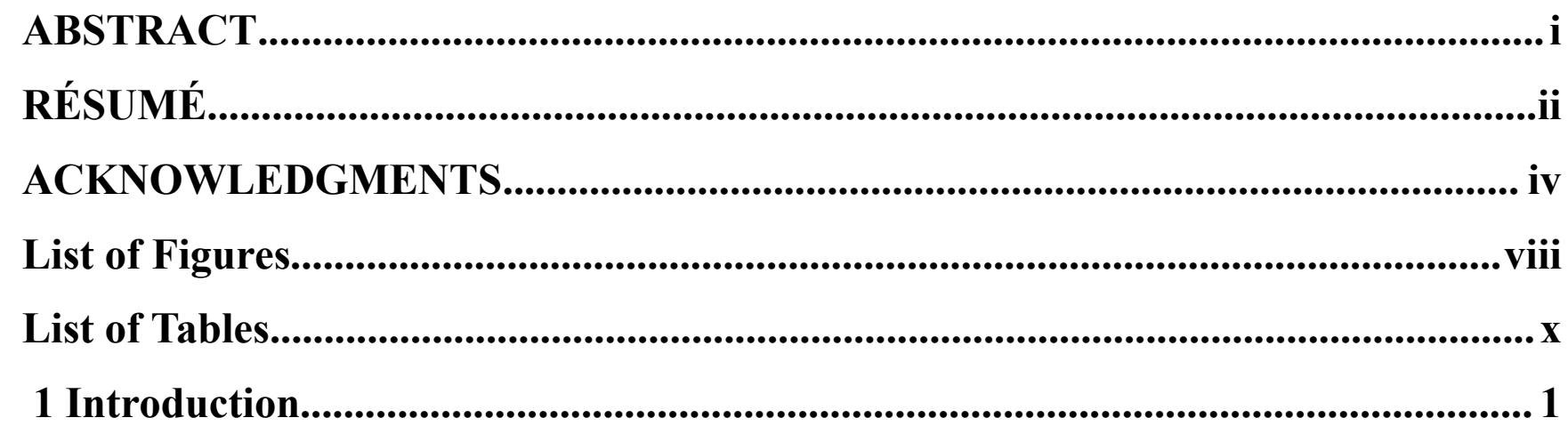

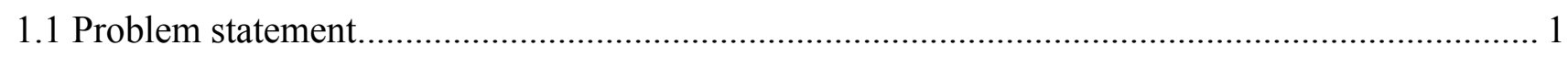

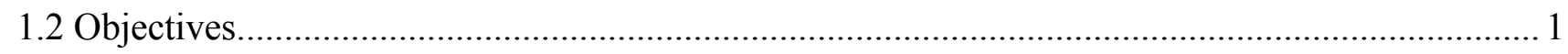

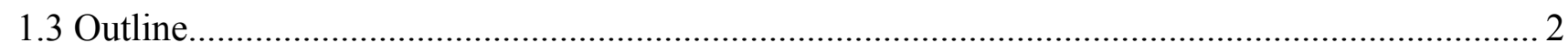

2 Background......................................................................................................................................... 3

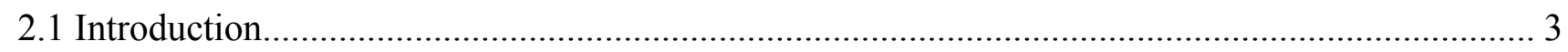

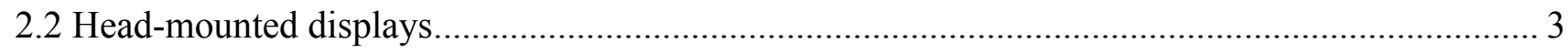

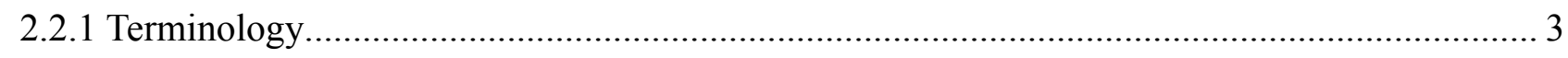

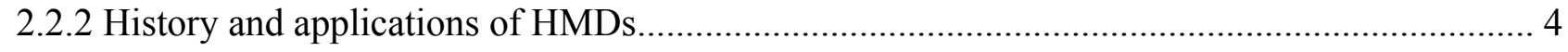

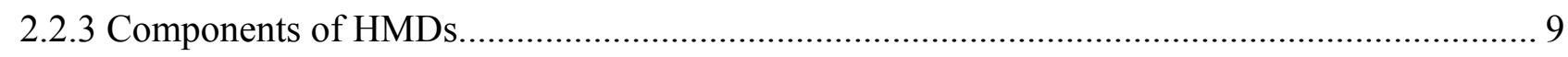

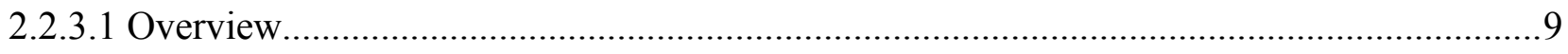

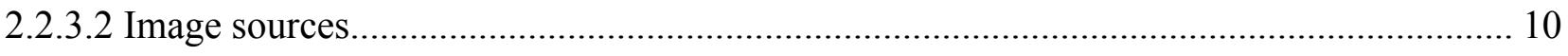

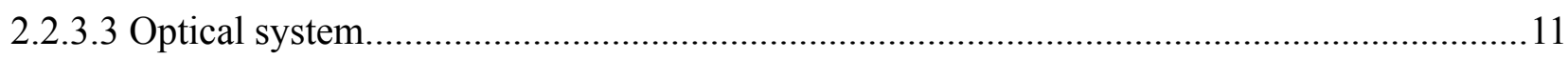

2.2.4 Summary of available and upcoming consumers HMDs............................................... 12

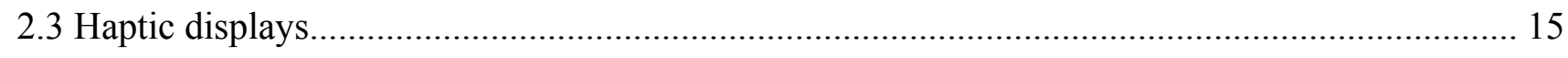

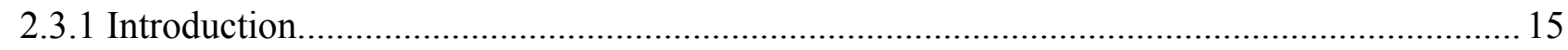




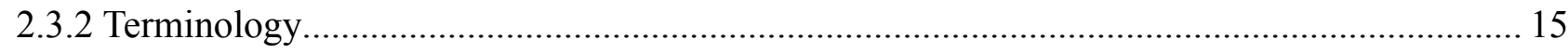

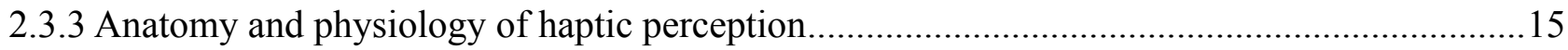

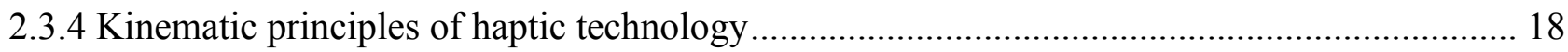

2.3.5 Tactile-feedback and force-feedback haptic technologies......................................................

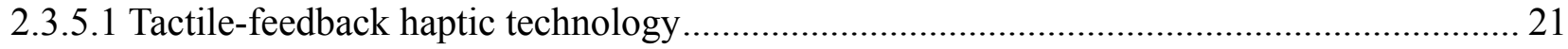

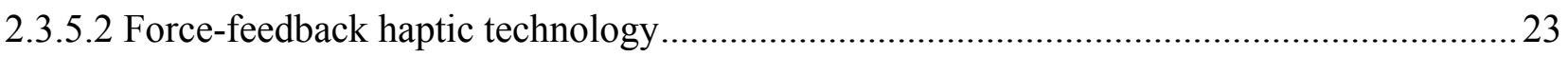

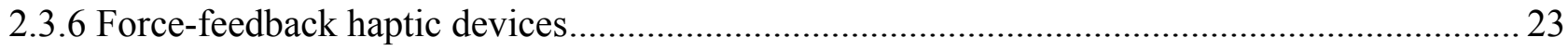

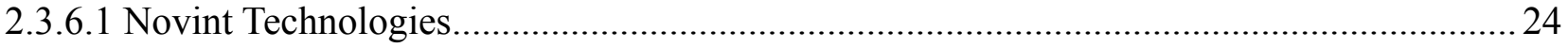

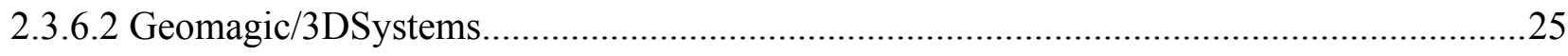

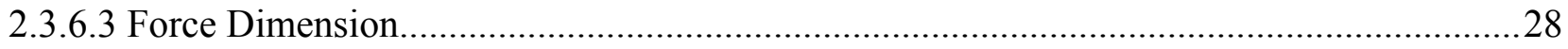

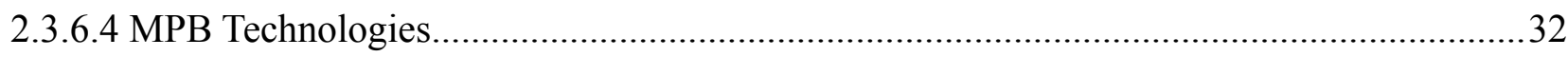

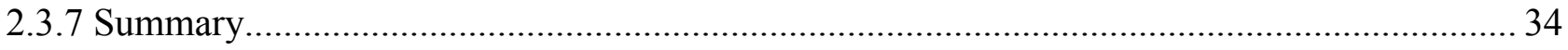

3 A virtual-reality system with HMD and haptics...................................................... 38

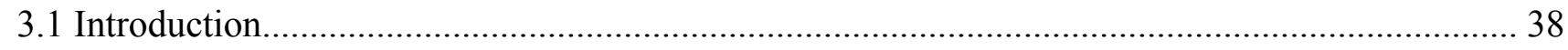

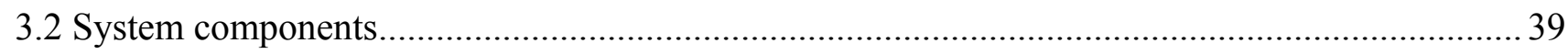

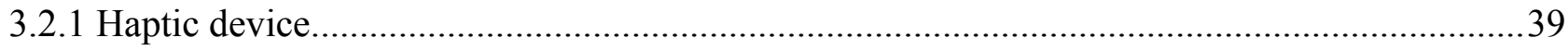

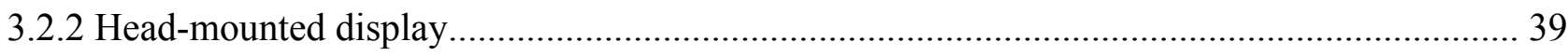

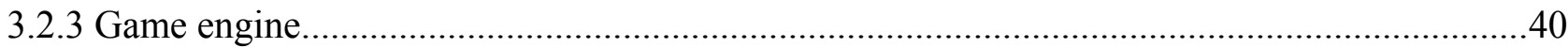

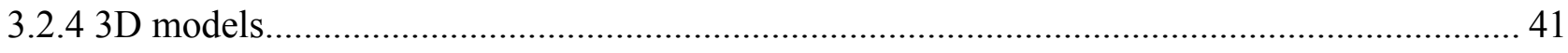

3.2.5 Operating system and computer graphics........................................................................... 43

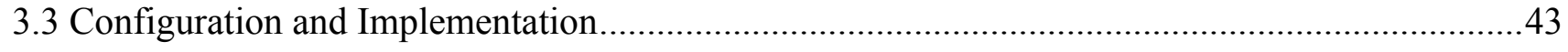

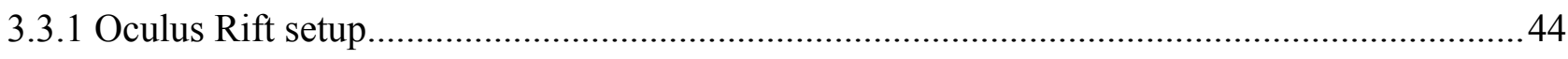

3.3.2 Phantom Premium 1.5 haptic setup....................................................................................45

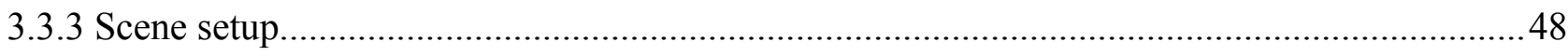




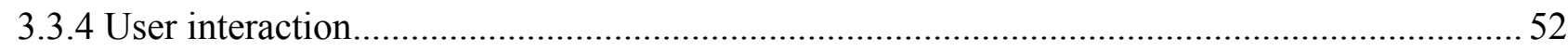

4 System evaluation and challenges...................................................................55

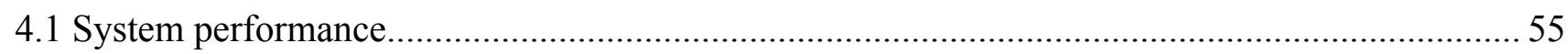

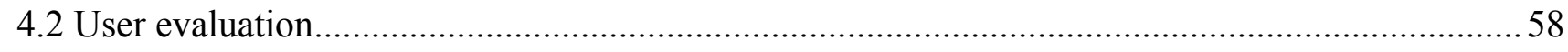

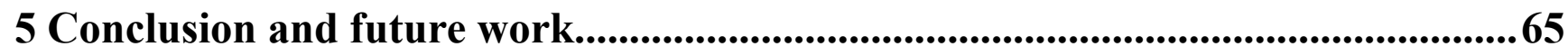

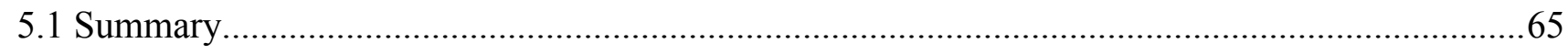

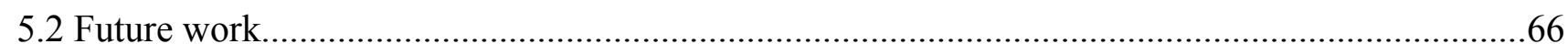

6 References........................................................................................................... 68

Appendix A: Consent Form...................................................................................................75

Appendix B: Instructions for using the HMD-Haptics Demo........................................76

Appendix C: Questionnaire for participants.......................................................... 78 


\section{List of Figures}

Figure 2.1: Ocularity of HMD.

Figure 2.2: Partially overlapped field of view with a central binocular region and two monocular regions. 4

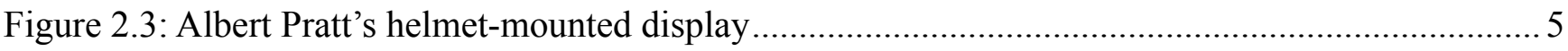

Figure 2.4: Visual Target Acquisition System (VTAS) helmet-mounted display................................6

Figure 2.5: The Virtual Interactive Environment Workstation VIEW system.................................. 6

Figure 2.6: Opaque stereoscopic medical HMD from Viking systems...........................................

Figure 2.7: Sony HMS-3000MT HMD device in a surgical setting ............................................ 8

Figure 2.8: Some of the consumer head-mounted displays..................................................... 8

Figure 2.9: Annotated illustration of a currently available HMD showing its different components.......9

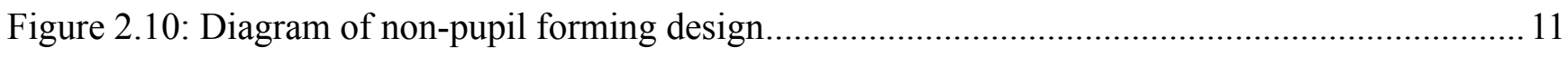

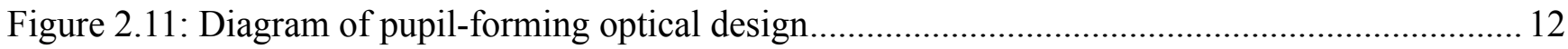

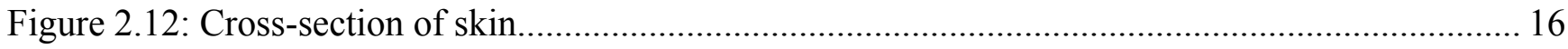

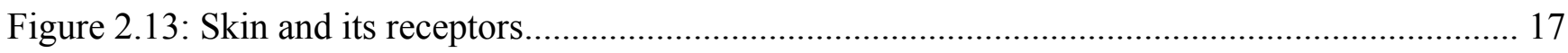

Figure 2.14: Comparison of the function of muscle spindles and Golgi tendon organs...................... 18

Figure 2.15: Haptic displays: kinematics design principles..................................................... 19

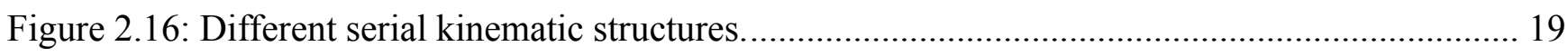

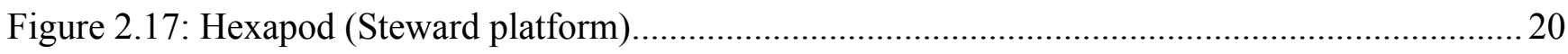

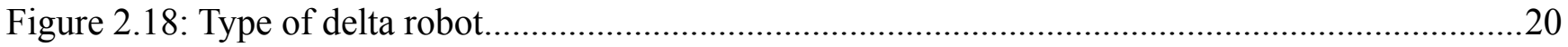

Figure 2.19: CyberTouch vibrotactile glove for generating touch sensations .................................21

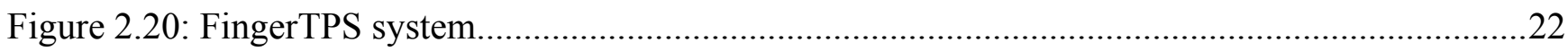

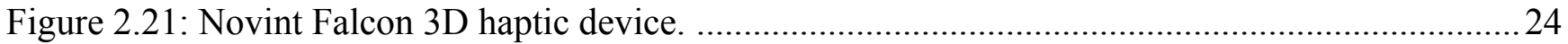

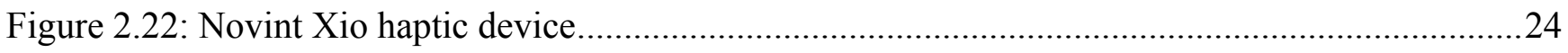

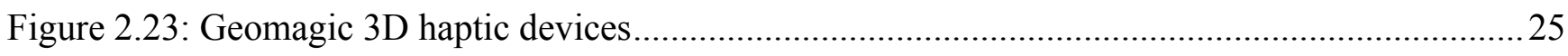

Figure 2.24: Thumb-pad (left) and scissors (right) snap-on end effectors......................................22

Figure 2.25: Force Dimension delta.x force-feedback haptic devices...........................................29

Figure 2.26: Force Dimension omega.x force-feedback haptic devices........................................ 30 
Figure 2.27: Force Dimension sigma.7 force-feedback haptic device with 7 DOF .30

Figure 2.28: MPB Technologies Freedom 7S haptic device with scissors grip to provide 7 DOFs........32

Figure 2.29: Comparison of haptic devices based on position resolution $(\mu \mathrm{m})$ and price (USD)..........35

Figure 2.30: Comparison of haptic devices based on maximum force $(\mathrm{N})$ and price (USD)................36

Figure 2.31: Comparison of haptic devices based on numbers of DOFs and price (USD)..................36

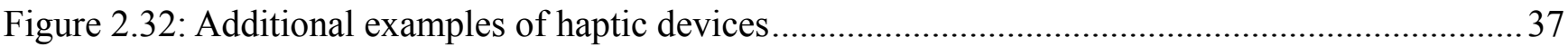

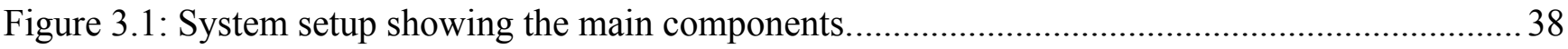

Figure 3.2: Phantom Premium 1.5 High Force haptic device..........................................................39

Figure 3.3: Oculus Rift Development Kit 2 with a positional tracker.............................................. 40

Figure 3.4: Skull model with 35,013 triangles and heart model with 11,812 triangles......................42

Figure 3.5: Resampled skull with 10,501 triangles and heart with 3,543 triangles.........................43

Figure 3.6: Oculus Configuration Utility main screen and Demo Scene running at $75 \mathrm{fps}$..................44

Figure 3.7: Phantom Configuration Utility tool.........................................................................45

Figure 3.8: Using the Sensable Haptics Phantom test tool to calibrate the device and check its forces

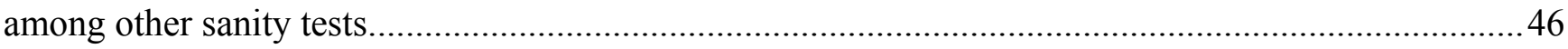

Figure 3.9: UML Class diagram showing the system haptic interaction....................................... 47

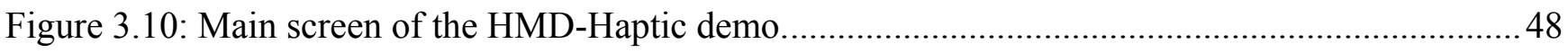

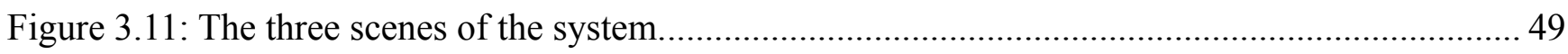

Figure 3.12: Haptic scenes showing the initial 3D models of the skull and the heart with a 2D

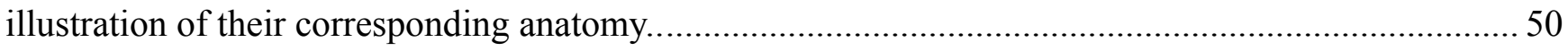

Figure 3.13: 3D skull model disassembled using the haptic device............................................ 51

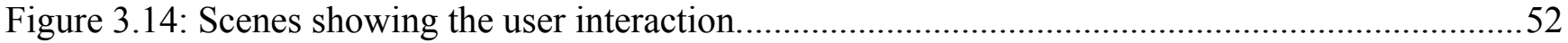

Figure 3.15: Heart scene where the user is interacting with the left ventricle structure while the remaining parts are faded (semitransparent).

Figure 4.1: Frame rate of $15 \mathrm{fps}$ when interacting with the skull model (35,021 triangles) on a PC with

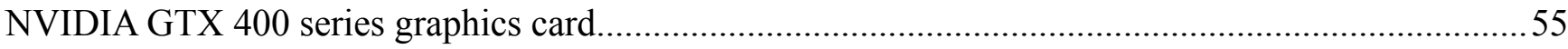

Figure 4.2: Sample scene showing the resampled heart 3D model...............................................56

Figure 4.3: Scenes showing the user interaction with the temporal bone and the mandible of the 3D simplified skull model using the haptic virtual pointer...............................................................5

Figure 4.4: Questionnaire results for the system evaluation. ....................................................63

Figure 4.5: Timings for completing the tasks for the user evaluation study....................................64 


\section{List of Tables}

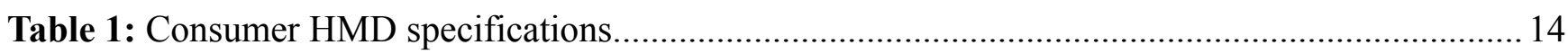

Table 2: Geomagic 3D Systems haptic device specifications for Touch 3D Stylus, Geomagic Touch and Geomagic Touch X

Table 3: Geomagic 3D Systems Phantom haptic device specifications for Phantom Premium 1.0, 1.5,

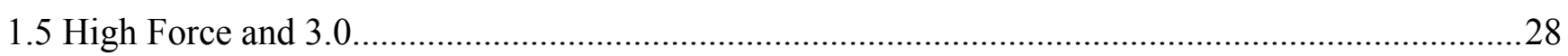

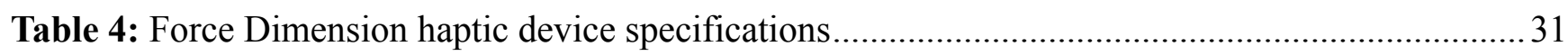

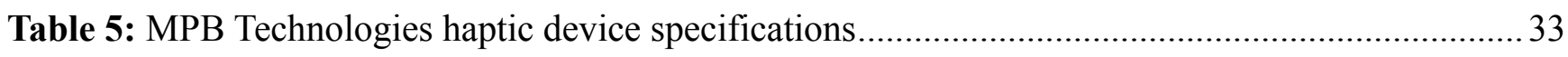

Table 6: Characteristics of some commercially available low-end to high-end force-feedback haptic

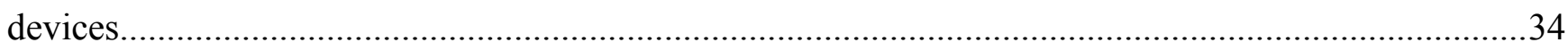

Table 7: Questionnaire results: Learning methods for anatomy...........................................................59

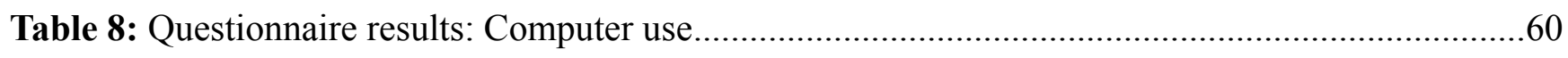

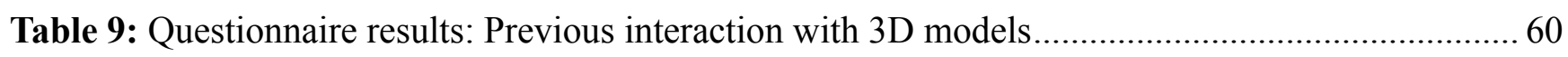

Table 10: Individual times to complete each task for the five participants.............................................64 


\section{Introduction}

\subsection{Problem statement}

Replicating the real world by means of three-dimensional (3-D) models is important for many fields of science, technology, engineering and medicine (STEM) (e.g., Zachmann 1998; Nicholson, Funnell, and Daniel 2006; Auweraer et al. 2008; Talabă 2008). Interacting with these models in a realistic way is made possible with the emergence of various systems and displays which use one or more of our senses to immerse us in a virtual reality (VR) experience. Head-mounted displays (HMDs) are an example of systems that take advantage of the sense of sight to immerse users in a virtual environment (e.g., Hezel and Veron 1993). Haptic (force-feedback) devices, on the other hand, allow users to interact with 3-D models through the sense of touch (e.g., Adams and Hannaford 1999). To create a more fully immersive and realistic user experience, several works have combined two or more elements of the human sensory system into one interface to obtain a "multi-modal virtual reality system" (Fritschi et al. 2008). However, very little has been done so far to combine recent consumer-level HMDs with haptic devices.

\subsection{Objectives}

The emergence of multiple affordable head-mounted displays and haptic devices is changing the whole VR interaction experience. The main goal of this project was to develop a prototype which combines a consumer-level HMD (the Oculus Rift) and a mid-level haptic device (the Phantom Premium 1.5 High Force) using a game-development platform (the Unity 3D game engine), to offer users the ability to 
touch, feel and manipulate 3-D models by means of a haptic device while being immersed in the virtual world using an HMD. The secondary objectives were to evaluate the technical performance of the system and perform a small preliminary user evaluation.

\subsection{Outline}

Chapter 2 of this thesis presents background information related to head-mounted displays and haptic devices. Chapter 3 gives the technical details and design specs of the implemented virtual reality system. Chapter 4 summarizes the results of evaluating the tool and Chapter 5 contains the conclusions and a discussion of future work. 


\section{Background}

\subsection{Introduction}

In this chapter we will give an overview of the head-mounted displays used for immersing the user into a virtual environment through the sense of sight, followed by a section on haptic displays which allow the user to interact with $3 \mathrm{D}$ objects through the sense of touch.

\subsection{Head-mounted displays}

\subsubsection{Terminology}

Head-mounted displays (HMDs) are "visual display(s) covering the eyes, sometimes having position tracking to provide a computer with the location and orientation of the head" (Blade and Padgett 2015). An HMD device can have (1) an immersive design, in which the view of the real world is blocked to replicate "the way we view, navigate through, and explore the world" (Melzer 2001); or (2) a seethrough design, in which the view of the real world is augmented by virtual images (e.g., Rolland and Hua 2005).

As illustrated in Figure 2.1, these devices can be (1) monocular, with the virtual image being viewed by only one eye; (2) biocular, with the same image and perspective being received by each eye; and (3) binocular, with a scene from a different perspective being seen by each eye (e.g., Melzer 2001; Bayer, Rash, and Brindle 2009). In the latter case, a larger field of view can be obtained by partially overlapping the images received from the two optical channels to create three regions: one central 
binocular region seen by both eyes, and two monocular regions each seen by a different eye (Figure 2.2).

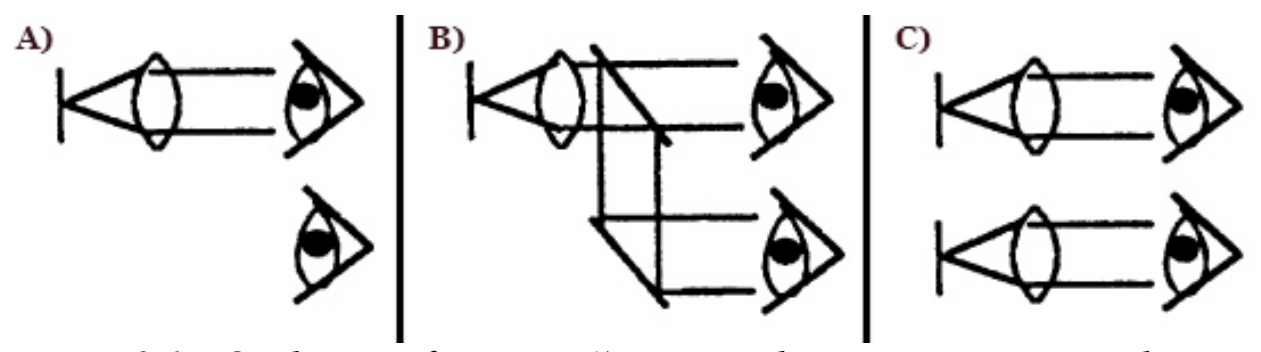

Figure 2.1: Ocularity of HMD. A) Monocular: one eye views the image source; B) Biocular: both eyes view the image source; C) Binocular: each eye views an independent image source (Melzer 2001)

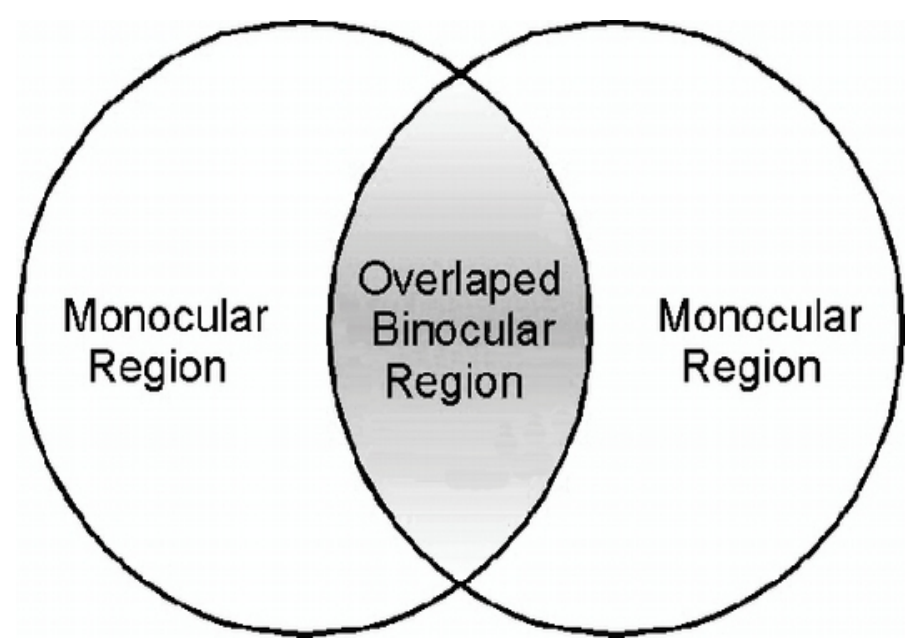

Figure 2.2: Partially overlapped field of view with a central binocular region and two monocular regions (Bayer et al. 2009)

\subsubsection{History and applications of HMDs}

During World War I, in 1916, Pratt invented a see-through helmet-mounted display (Figure 2.3) to serve as an "aiming and weapon delivery system for a marksman" (Marshall 1989, mentioned by Bayer et al. 2009). 


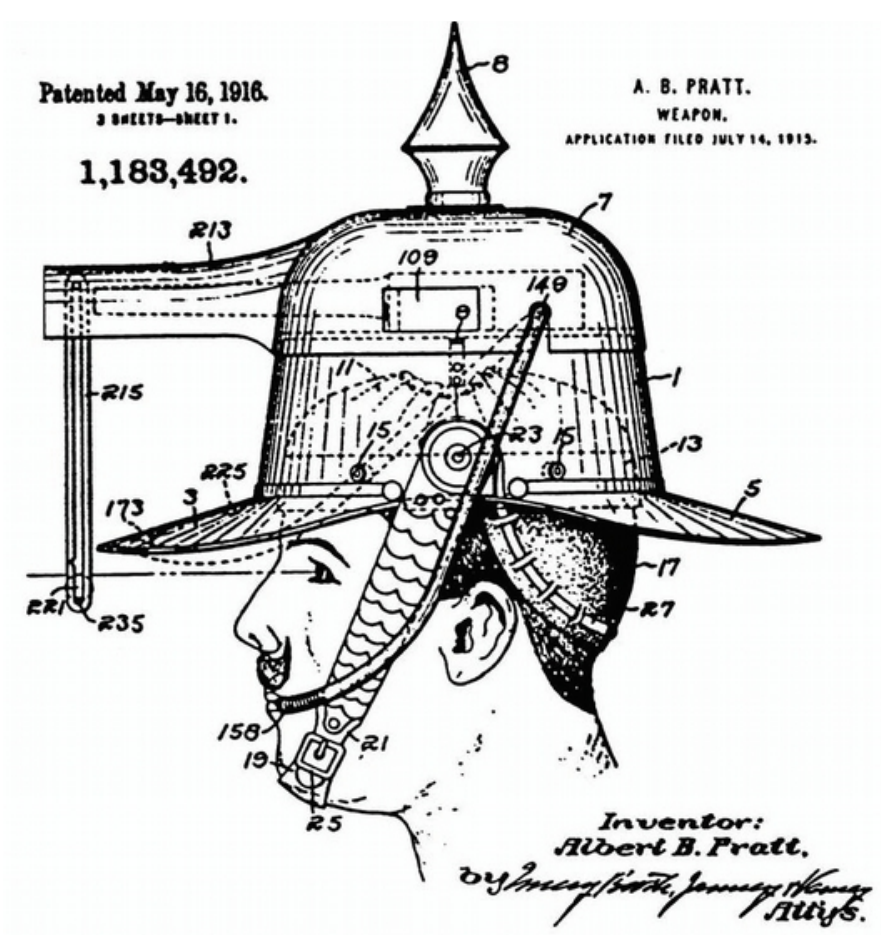

Figure 2.3: Albert Pratt's helmet-mounted display (Bayer et al. 2009)

The first HMD with a tracking device appeared in the 1960s "to present the user with a perspective image which changes as he moves" (Sutherland 1968). In the 1970s, the United States military developed a head-tracking helmet sighting system (i.e, Figure 2.4) for applications such as directing the fire of a helicopter-mounted gun and firing missiles (e.g., Bayer et al. 2009). Later on, the Visually Coupled Airborne Systems Simulator (VCASS) HMD was used in military flight simulators (e.g. Gigante 1993). The objective was to augment the cockpit view with graphics containing valuable information for the training pilot such as the optimal flight path, and targeting and threat information . Over the years, HMDs were used for military training and linked to various systems and teleoperator applications such as radars, sensors, aircrafts and vehicles (e.g., Bayer et al. 2009). 


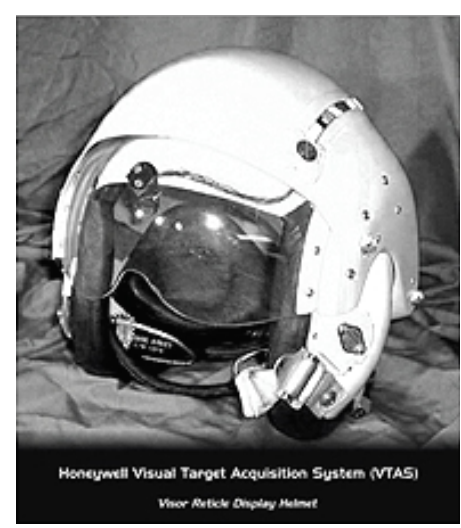

Figure 2.4: Visual Target Acquisition System (VTAS) helmet-mounted display (Bayer et al. 2009).

In the 1980s, NASA Ames Research Center developed (1) the Virtual Visual Environment Display (VIVED) to evaluate, for astronauts, the potential of a monochrome HMD; and (2) the Virtual Interactive Environment Workstation (VIEW) (Figure 2.5) which included an HMD with a head and hand tracking system (Gigante 1993).

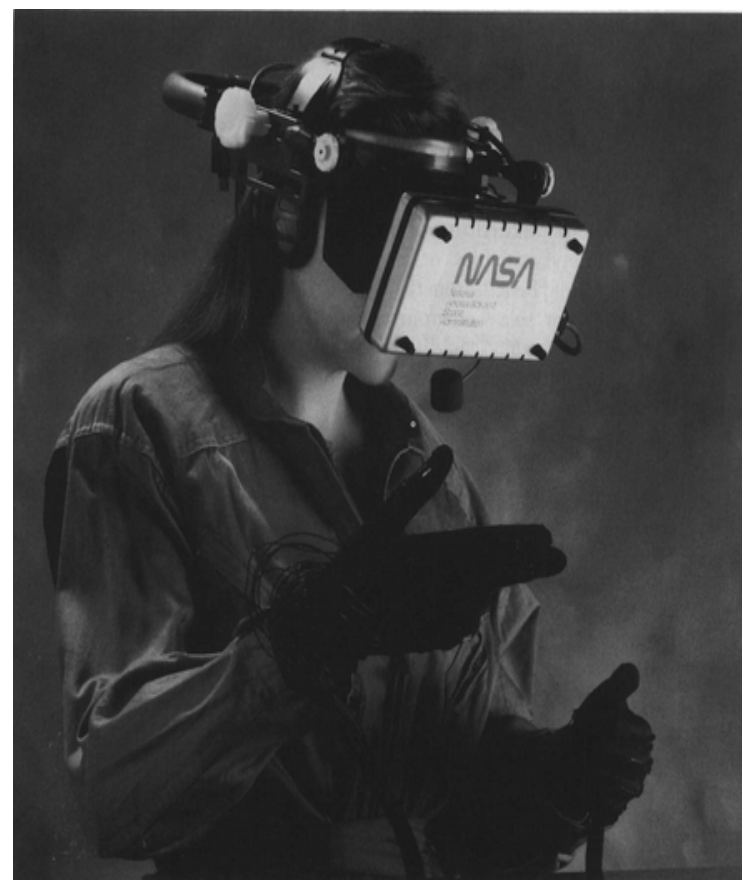

Figure 2.5: The Virtual Interactive Environment Workstation VIEW system, developed at the NASA Ames Research Center (Gigante 1993) 
In the commercial area, HMDs are used in many engineering and scientific applications (e.g., Zachmann 1998; Talabă 2008; Auweraer et al. 2008).

In the medical field, Keller et al. (2008) noted that HMDs were not very successful at the beginning due to the limitations of the display technology, such as low resolution and cumbersome hardware. It was around 2001 that affordable devices with $800 \times 600$ pixel displays became available, such as the Viking Systems HMD (Figure 2.6) which evolved from $640 \times 480$ to $800 \times 600$ at that time then reached $1280 \times 1024$ pixels later on. HMDs have also shown potential in virtual rehabilitation systems (e.g., Peli et al. 2007; Fidopiastis, Rizzo, and Rolland 2010) and as a surgical aid (e.g., Bayer et al. 2009).

A more recent HMD for surgeons was introduced by Sony in 2014, with an enhanced version in September 2015: the Sony HMS-3000MT (Figure 2.7). This device offers an immersive view of high definition images from 3D surgical endoscopic cameras and other imaging systems (Sony 2015). By combining HMS-3000MT with a high-definition 3D endoscope for minimally invasive surgery, a team in Tokyo created a RoboSurgeon which provides 3D imagery of the operative field combined with imagery of the cystoscopy (Fujii et al. 2014).

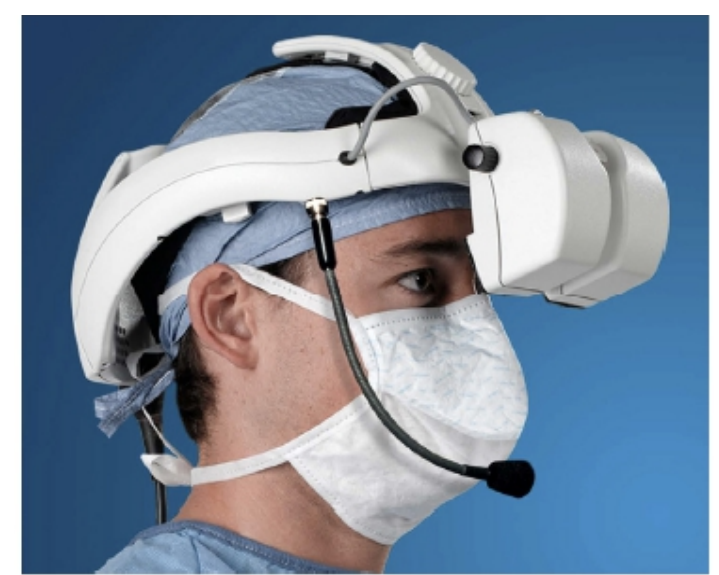

Figure 2.6: Opaque stereoscopic medical HMD from Viking systems (Keller et al. 2008) 


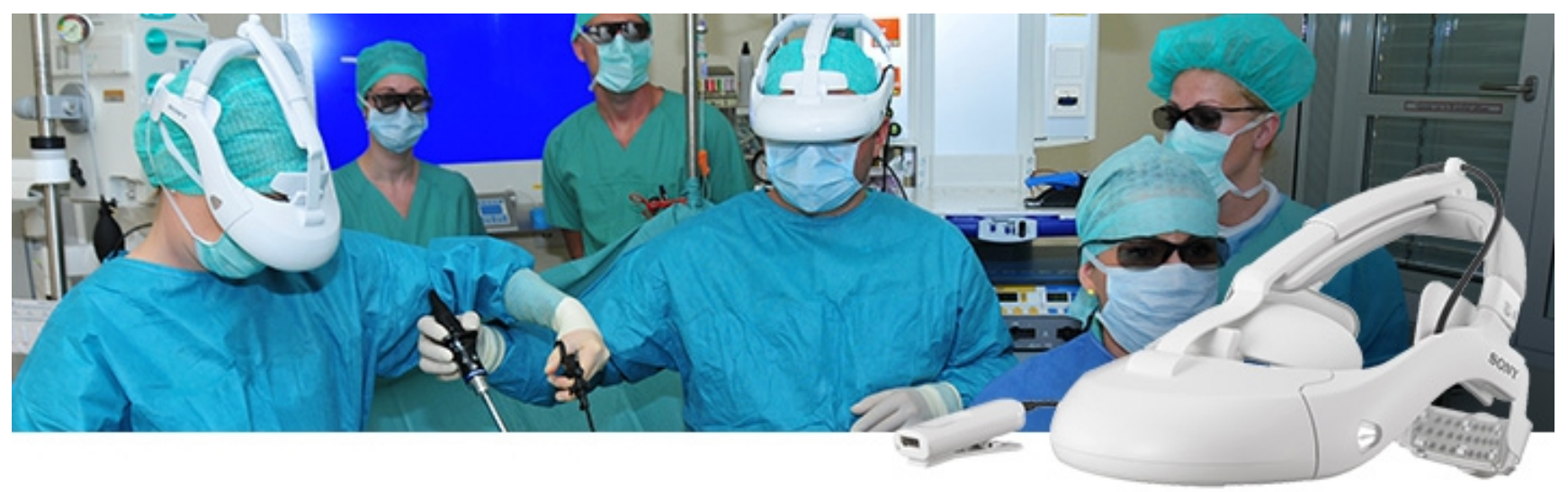

Figure 2.7: Sony HMS-3000MT HMD device in a surgical setting (Sony 2015).

Over the past few years, HMDs have been investigated for their use as consumer electronics products by being integrated into sports and gaming applications (e.g., Kress and Starner 2013; Kayatt and Nakamura 2015). This has been facilitated by the emergence of many devices costing from 200 to 450 USD, and others are planned for the near future. Five such devices are shown in Figure 2.8.

In the next sections, we will discuss the key components of HMD devices and provide an overview of the state of the art in HMD technology.
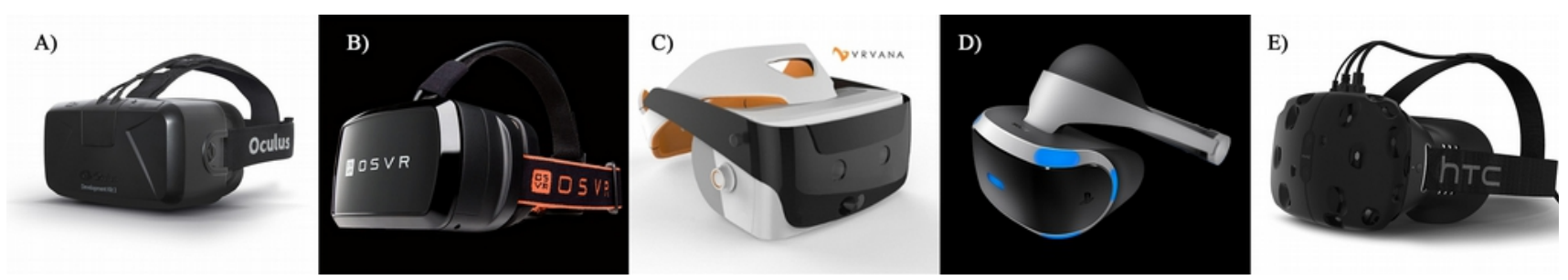

Figure 2.8: Some of the consumer head-mounted displays: A) Oculus rift (Oculus 2015) - B) OSVR Hacker kit (OSVR 2015) - C) Vrvana Totem, not yet available (Vrvana 2015) - D) Project Morpheus by Sony, not yet available (PlayStation 2015) - E) HTC Vive, not yet available (HTC 2015) 


\subsubsection{Components of HMDs}

\subsubsection{Overview}

In its basic design, an HMD is composed of (1) one or more image sources or displays to present an image to the viewer; (2) an optical system to provide a wide field of view and allow the screen to be placed close to the eyes; and (3) a platform to mount these components to the head (e.g., Melzer 2001). In order to allow freedom of movement while exploring the virtual environment, a tracking system responsible for monitoring the head position and/or eye movements can be added to the HMD (e.g., Bayer et al. 2009). Figure 2.9 shows an annotated prototype of one particular HMD, the Open Source Virtual Reality developer kit.
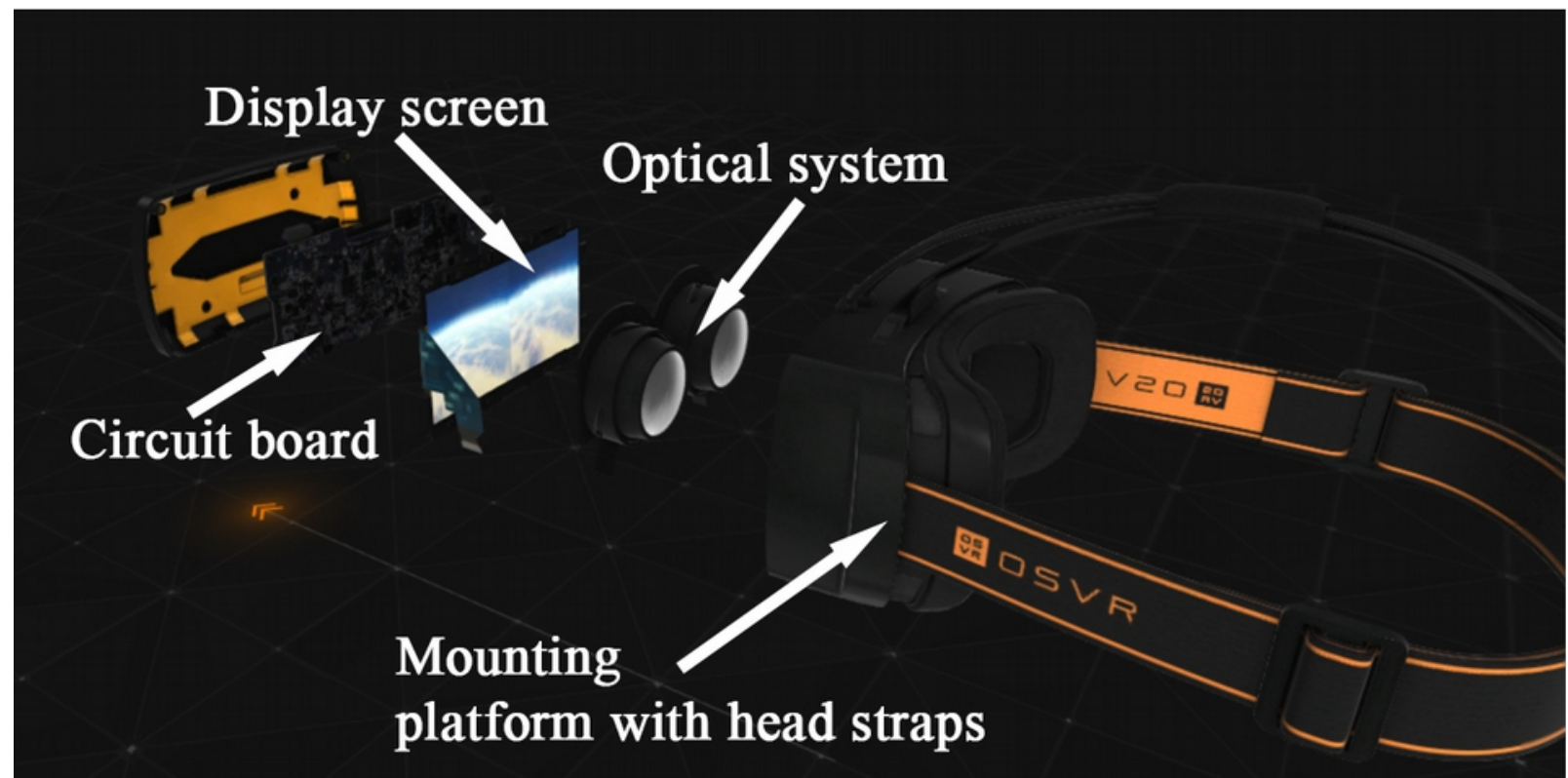

Figure 2.9: Annotated illustration of a currently available HMD showing its different components (After OSVR 2015) 
Design choices for an HMD are influenced by many factors related to the requirements of each application and its intended users. For example, when designing for consumer electronics like gaming applications, the final product should be attractive, light, small and comfortable, with an affordable price and very low power consumption. However, when designing for military applications, the quality of the optics will be the main focus with special attention paid to the field of view, the eye box and the eye relief (e.g., Kress and Starner 2013). In the following sections we review the image sources and optical systems of HMDs and discuss how they can influence the design.

\subsubsection{Image sources}

When developing an HMD, the main challenge is to obtain a display which provides a high-resolution image while having an acceptable size and weight so it fits well on the head and can be used comfortably.

Image sources can be separated into two categories: emissive and nonemissive (e.g., Melzer 2001). The emissive category includes, but is not limited to, (1) the cathode ray tube (CRT) and (2) the organic light emitting diode (OLED). A CRT contains an electron gun and a phosphor screen on opposite ends of a vacuum tube, and the phosphor emits visible light after being excited by a modulated beam from the electron gun. With OLED technology, a visible light is emitted by a thin layer of organic (carbon based) material driven by a low voltage. The nonemissive category includes, for example, the transmissive liquid crystal displays (LCDs), where the source image is illuminated from the rear. Each of these three technologies (CRT, OLED and LCD) has been used as the image source in HMDs, but in 2015 most of the currently released consumer HMDs use OLED displays (e.g., Oculus 2015; OSVR 2015). An OLED does not require the backlight and filters that LCDs do, which leads to a light-weight display (e.g., Melzer 2001). 


\subsubsection{Optical system}

The role of the optics in an HMD is to collimate and magnify the image source to create a virtual image which appears far away from the user's face and larger than the actual image size (e.g., Melzer et al. 2009).

An optical system for an HMD can have either (1) a magnifying system (e.g., Hezel and Veron 1993), also known as non-pupil-forming design (e.g., Melzer et al. 2009); or (2) an infinity optics system (e.g., Hezel and Veron 1993), also know as pupil-forming design (e.g., Melzer et al. 2009). While the nonpupil-forming technique uses a "simple" (possibly compound) magnifying lens (Figure 2.10), the pupil-forming technique has a more complex architecture resembling that of a submarine periscope. The pupil technique creates an intermediate image of the image source using a set of lenses then relays the produced image to form a pupil using a second set of lenses (Figure 2.11).

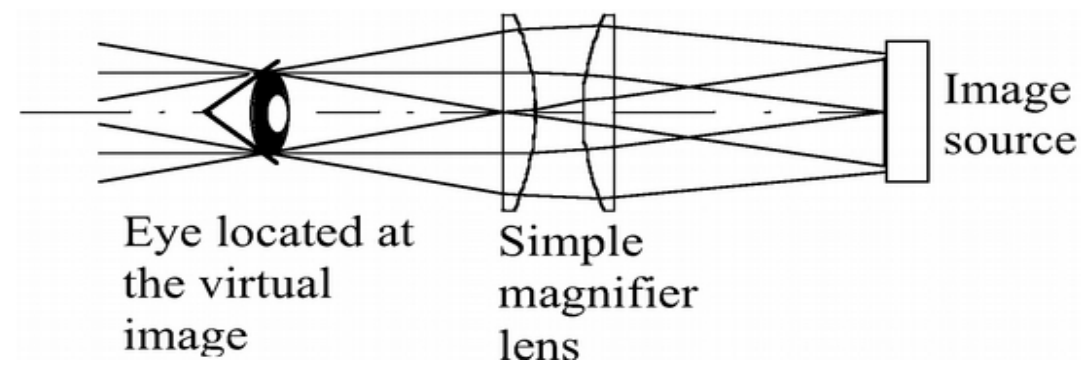

Figure 2.10: Diagram of non-pupil forming design (Melzer 2001) 


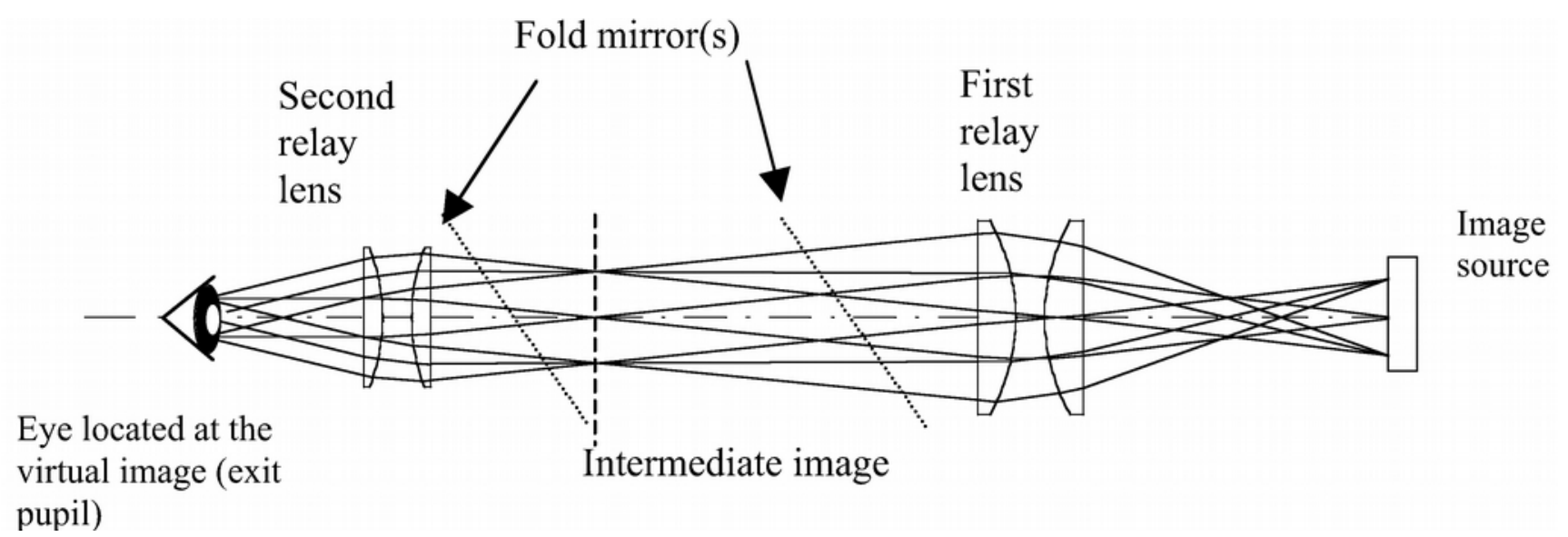

Figure 2.11: Diagram of pupil-forming optical design (Melzer 2001)

Due to its complex design, the pupil-forming technique can lead to heavier and more costly HMDs, depending on the number of inserted mirrors (e.g., Melzer et al. 2009). As for the non-pupil-forming technique, it is currently used to produce compact and inexpensive HMDs because it offers a simpler, cheaper, lighter and smaller design (e.g., Kress and Starner 2013).

\subsubsection{Summary of available and upcoming consumers HMDs}

In this part we give an overview of current HMD consumer devices and some of the upcoming ones. Table 1 provides a comparison based on their specifications. Having a price range between 200 and 450 USD, these devices are affordable not only for gaming purposes but also for other cost-sensitive applications, like teaching, and for prototyping and testing new ideas. As for the Google Cardboard (Google 2015) with a price range from 20-120 USD, it is designed for experiencing VR using a compatible mobile phone and can be built using the kit provided by Google.

All these devices have a weight of around $400 \mathrm{~g}$ and use an OLED display with a field of view from 96 to 110 degrees. Their frame-rate requirements range from 60 to $120 \mathrm{fps}$. The latter is needed in order to quickly change the displayed image and avoid simulator sickness whenever the users move their heads. 
This requires a high-performance graphics card to redraw the VR scene twice for every frame, once for each eye. For example, for the upcoming Project Morpheus HMD requiring a frame rate of $120 \mathrm{fps}$ (PlayStation 2015), the graphics card has to draw 240 frames every second, which is 4 times higher than a $60-\mathrm{Hz}$ monitor.

To satisfy the frame-rate requirement, new graphics cards are being developed to provide a satisfying VR experience, such as the GeForce GTX series by NVIDIA, with the 970 card being the minimum recommended by Oculus (2015) and the 980 Ti currently being the top of the GeForce line (GeForce 2016). However, having the best graphics card does not guarantee that the system's performance will be as good as desired, and a system can still run, albeit perhaps slowly, even without meeting the above requirements.

Most of these consumer devices provide support for the Unity and/or Unreal game engines and are compatible with the Microsoft Windows operating system (OS).

Further development and research are needed to produce more advanced HMDs in order to provide a better, more immersive VR experience. 
Table 1: Consumer HMD specifications (Google 2015; Oculus 2015; HTC 2015; FOVE 2016;

PlayStation 2015; Vrvana 2015; Razer 2015).

\begin{tabular}{|c|c|c|c|c|c|c|c|c|c|c|c|}
\hline HMD device & Platform(s) & Supported engine(s) & $\begin{array}{c}\text { OLED Display } \\
\text { size (inch) }\end{array}$ & $\begin{array}{c}\text { Latency } \\
(\mathrm{ms})\end{array}$ & $\begin{array}{c}\text { Resolution } \\
\text { (pixels) }\end{array}$ & $\underset{\text { (fps) }}{\text { Frame rate }}$ & $\begin{array}{c}\text { Field of view } \\
\text { (degrees) }\end{array}$ & $\begin{array}{c}\text { Dimensions } \\
\text { (inches) }\end{array}$ & $\underset{\text { (g) }}{\text { Weight }}$ & Availability** & Price \\
\hline Google Cardboard & $\begin{array}{l}\text { Android and iOS } \\
\text { devices }\end{array}$ & Unity & $\mathrm{N} / \mathrm{S}$ & $\mathrm{N} / \mathrm{S}$ & $1920 \times 1080$ & N/A & 80 & $\mathrm{~N} / \mathrm{S}$ & $\mathrm{N} / \mathrm{S}$ & 2014 & 20-120 USD \\
\hline Samsung Gear VR & $\begin{array}{l}\text { Mobile (Galaxy } \\
\text { Note 4, S6 \& S6 } \\
\text { edge) }\end{array}$ & $\mathrm{N} / \mathrm{S}$ & 5.7 & $<20$ & $2560 \times 1440$ & 60 & 96 & $\mid \begin{array}{c}7.72 \times 3.88 \times \\
3.26\end{array}$ & 403 & 2014 & 199.99 USD \\
\hline Oculus Rift & Windows & Unreal and Unity & $\mathrm{N} / \mathrm{S}$ & low* & $1920 \times 1080$ & 70 & 100 & $\mathrm{~N} / \mathrm{S}$ & 440 & 2014 & 350 USD \\
\hline $\begin{array}{l}\text { Razer OSVR } \\
\text { Hacker Dev kit }\end{array}$ & $\begin{array}{l}\text { Windows, Mac, } \\
\text { Linux and } \\
\text { Android }\end{array}$ & Unreal and Unity & 5.5 & low* & $1920 \times 1080$ & 60 & 100 & $\mathrm{~N} / \mathrm{S}$ & $\mathrm{N} / \mathrm{S}$ & 2015 & 299.99 USD \\
\hline Vrvana Totem & $\begin{array}{l}\text { Windows, Mac, } \\
\text { Linux, Playstation } \\
3 \text { \& } 4 \text { and Xbox } \\
\text { One \& } 360\end{array}$ & $\begin{array}{l}\text { OSVR, Unreal and } \\
\text { Unity }\end{array}$ & $\mathrm{N} / \mathrm{S}$ & low* & $\mathrm{N} / \mathrm{S}$ & 75 & 105 & $6.6 \times 4.4 \times 5.4$ & 400 & $2016^{*}$ & 450 USD \\
\hline Project Morpheus & Playstation 4 & $\mathrm{~N} / \mathrm{S}$ & 5.7 & $<18$ & $1920 \times 1080$ & 120 & 100 & $\mathrm{~N} / \mathrm{S}$ & $\mathrm{N} / \mathrm{S}$ & $2016^{*}$ & $\mathrm{~N} / \mathrm{S}$ \\
\hline HTC's Vive & $\begin{array}{l}\text { Windows, Mac } \\
\text { and Linux }\end{array}$ & $\begin{array}{l}\text { Steam, Unity and } \\
\text { Unreal }\end{array}$ & $\mathrm{N} / \mathrm{S}$ & low* & $2400 \times 1080$ & 90 & 110 & $\mathrm{~N} / \mathrm{S}$ & $\mathrm{N} / \mathrm{S}$ & Spring $2016^{*}$ & $\mathrm{~N} / \mathrm{S}$ \\
\hline FOVE & $\begin{array}{l}\text { Windows, Mac } \\
\text { and Linux }\end{array}$ & $\begin{array}{l}\text { CryEngine, Unreal } \\
\text { and Unity }\end{array}$ & 5.7 & low* & $2560 \times 1440$ & 60 & 100 & $\mathrm{~N} / \mathrm{S}$ & 400 & Spring $2016^{*}$ & $\mathrm{~N} / \mathrm{S}$ \\
\hline
\end{tabular}

N/S Not specified

* as specified by the manufacturer.

** as prototypes 


\subsection{Haptic displays}

\subsubsection{Introduction}

The haptic sense, or sense of touch, plays an important role in our perception of different characteristics and material properties of the objects in our environment, such as surface roughness, texture, shape, size, temperature and weight, as well as forces in general (e.g., Bresciani, Drewing, and Ernst 2008). Stimulating this sense of touch by means of haptic display interfaces allows users to touch, feel and manipulate objects, not only in a virtual-reality environment but also in a real-world setting using teleoperated systems (e.g., Samur 2012). In this part of the background chapter we will briefly cover the anatomy and physiology of the sense of touch and then discuss the state of the art of the haptic technology used in virtual reality environments.

\subsubsection{Terminology}

The term haptics refers to the sense of touch. It has its origin in the Greek verb ä $\pi \tau \omega$ (hapto) meaning "to touch" (among other meanings) (Liddell and Scott 1990).

\subsubsection{Anatomy and physiology of haptic perception}

In this section we will simplistically discuss the anatomy and physiology of human haptic perception based on Bracewell et al. (2008), Proske and Gandevia (2009), Kolarsick et al. (2011), Samur (2012) and Riener and Harders (2012).

Sensing is one of the main functions of the human skin, along with protection, thermoregulation, water balance, immune defence and communication. As illustrated in Figure 2.12, the human skin is composed of different layers including (1) the epidermis; (2) the dermis; and (3) the subcutaneous tissue. The epidermis is the outermost layer and consists of keratinocytes, cells which synthesize 
keratin protein with a protective role. The second layer, the dermis, provides pliability and elasticity to the skin. As for the subcutaneous tissue, it acts as a fat storage.

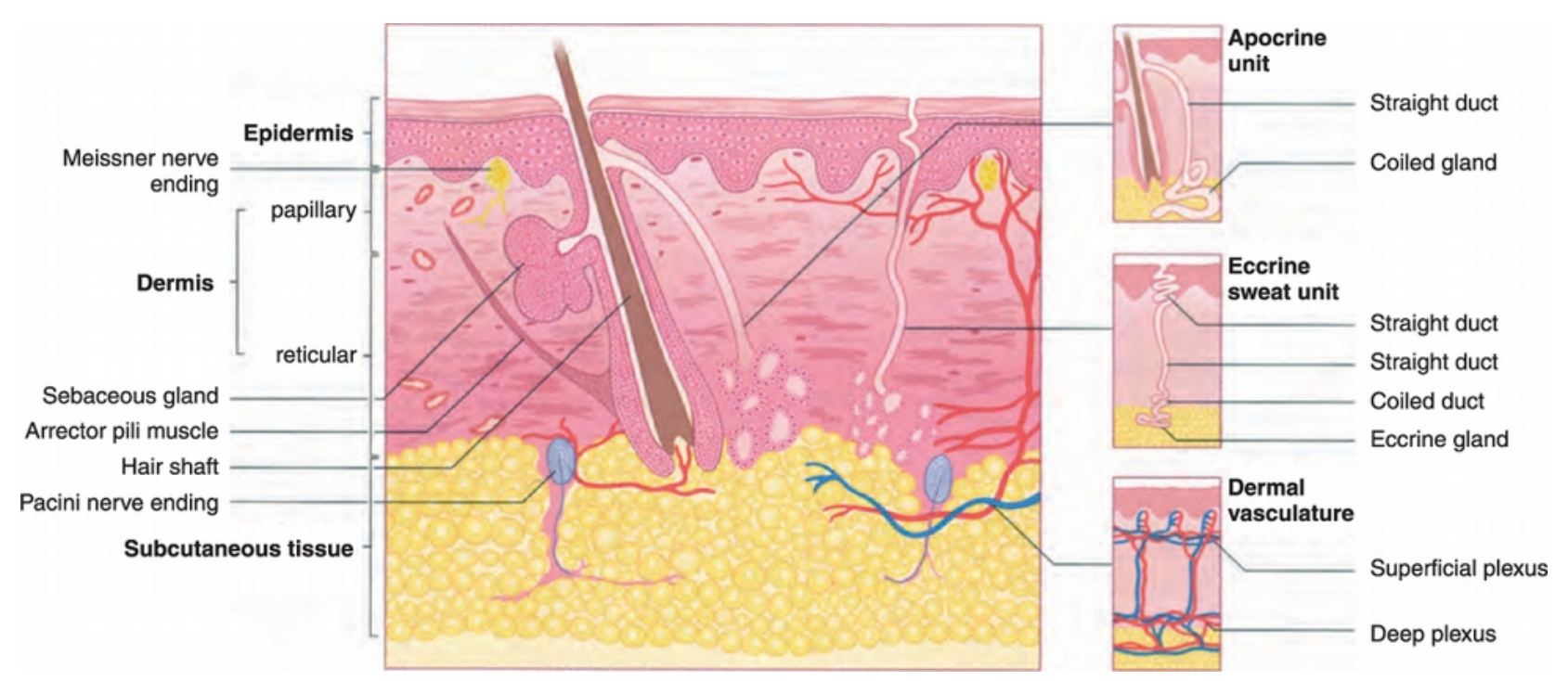

Figure 2.12: Cross-section of skin (Figure 1.1 in Kolarsick et al. 2011)

Tactile perception is provided by skin receptors responsible for sensing pressure, vibration, texture, shape, temperature and pain. Known receptors include thermoreceptors and mechanoreceptors. Thermoreceptors are nerve endings which can be divided into two classes: (1) for sensing cold temperatures, between 8 and $28^{\circ} \mathrm{C}$; and (2) for sensing warm temperatures, between 29 and $44^{\circ} \mathrm{C}$. As for mechanoreceptors (Figure 2.13), they include (1) Merkel cells; (2) Meissner corpuscles; (3) Ruffini nerve endings; and (4) Pacinian corpuscules. Merkel cells are located in the epidermis. These cells are sensitive to vibrations of low frequencies (around $30 \mathrm{~Hz}$ ) and are responsible for pattern detection, texture and tactile flow perception. Meissner corpuscles are located in the dermis layer and are responsible for grip control and motion detection. Ruffini nerve endings are found in the dermis and play a role in controlling finger position and ensuring a stable grasp. Finally, Pacinian corpuscules are 
located between the dermis layer and the subcutaneous tissue and are responsible for detecting vibrations of high frequencies (around $250 \mathrm{~Hz}$ ).

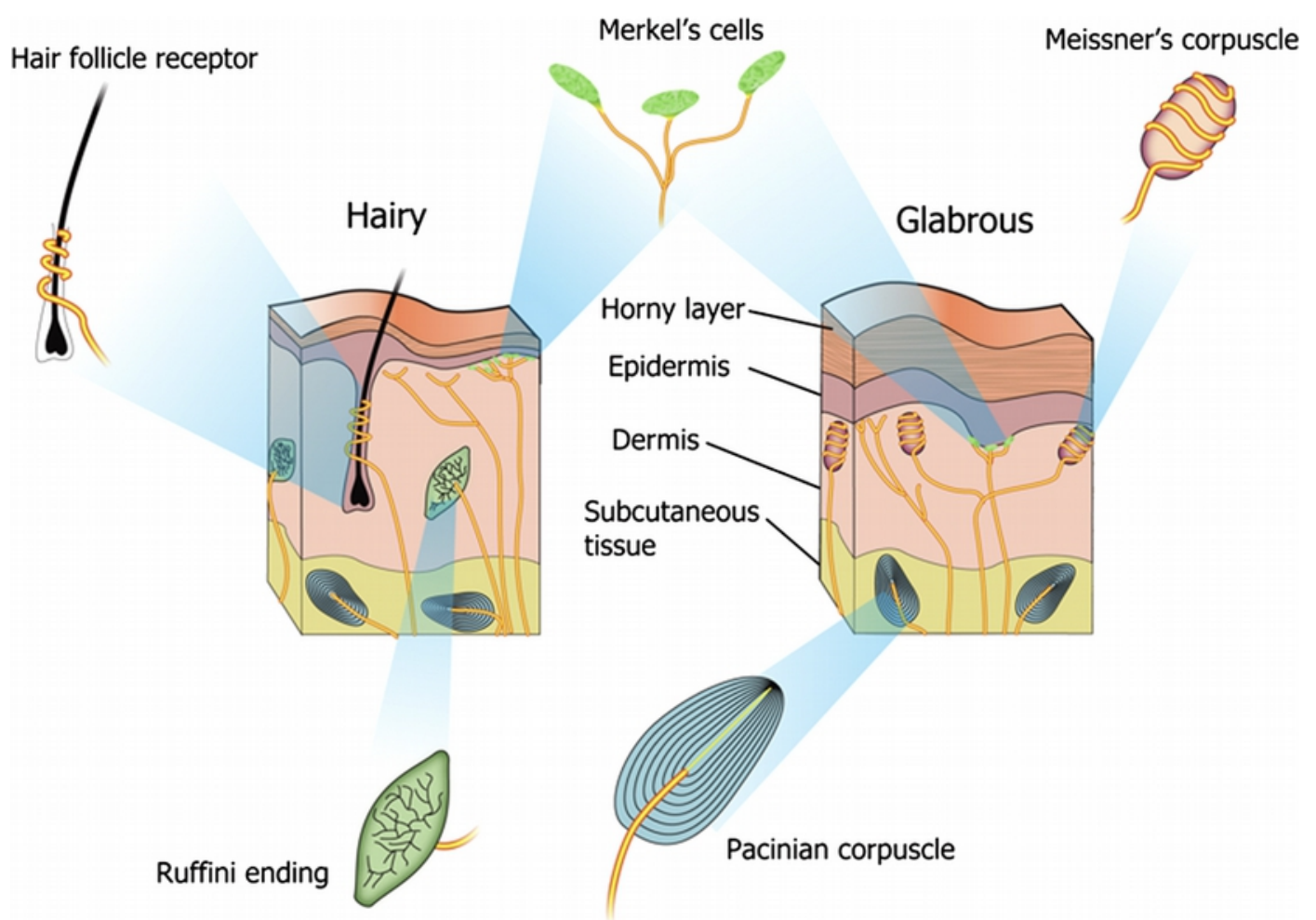

Figure 2.13: Skin and its receptors (Figure 4.2 in Riener and Harders 2012, p. 82)

Kinaesthetic stimuli, on the other hand, are detected by a collection of receptors present in the body's muscles and joints. Receptors located in the muscles, the Goldi tendon organs and muscle spindles (Figure 2.14), are sensitive to muscle tension and length respectively. Receptors located in the joints, known as joint receptors, are responsible for sensing deformation of the joint capsules and stretch of the ligaments. In summary, kinesthetic receptors are responsible for detecting the position and movement of the limbs along with the force exerted by the muscles. 

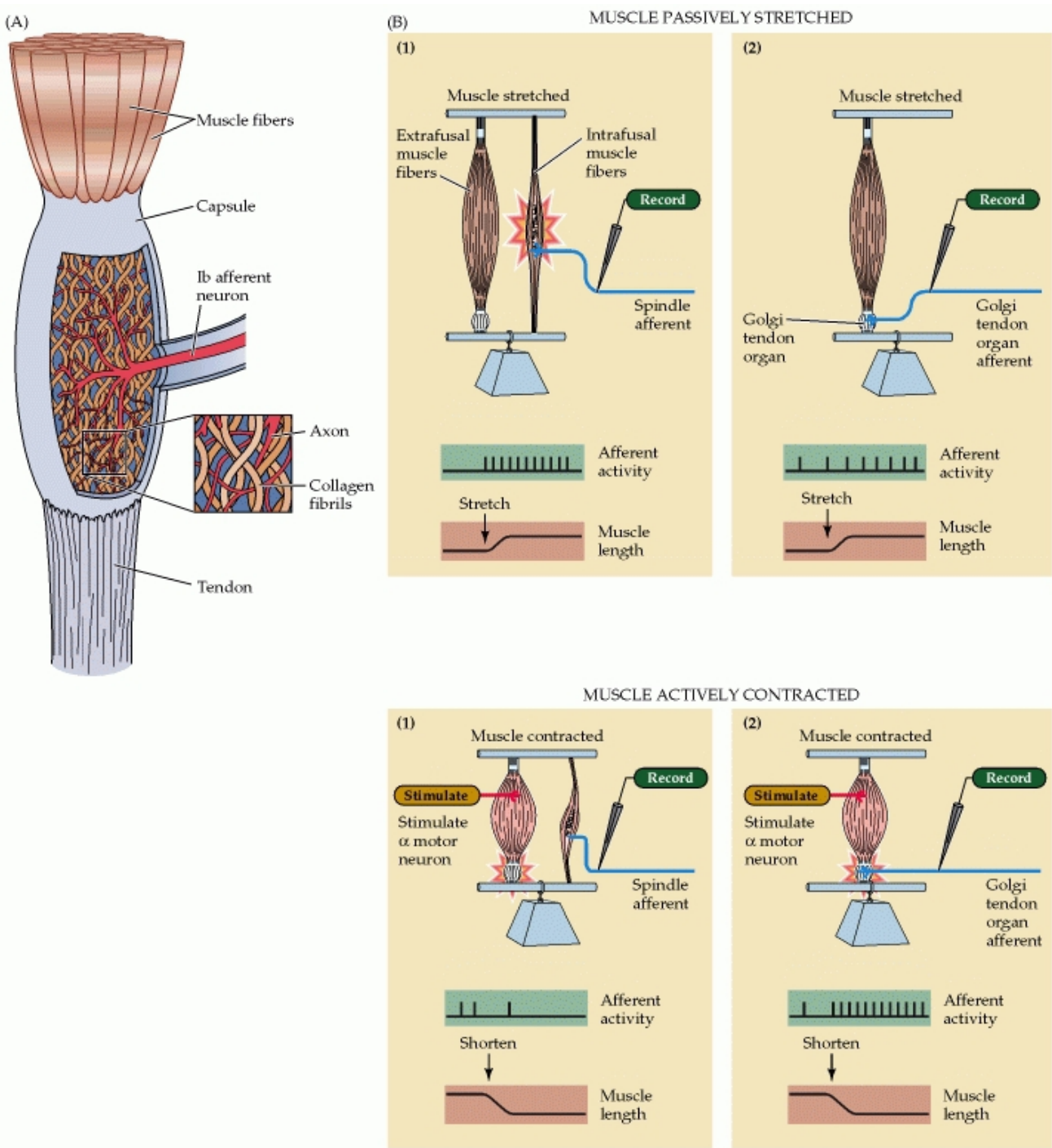

Figure 2.14: Comparison of the function of muscle spindles and Golgi tendon organs. (A) Golgi tendon organs are arranged in series with extrafusal muscle fibers because of their location at the junction of muscle and tendon. (B) The two types of muscle receptors, the muscle spindles (1) and the Golgi tendon organs (2), have different responses to passive muscle stretch (top) and active muscle contraction (bottom). Both afferents discharge in response to passively stretching the muscle, although the Golgi tendon organ discharge is much less than that of the spindle.(Figure 16.11 in Purves et al. 2001).

\subsubsection{Kinematic principles of haptic technology}

Serial and parallel kinematic designs (Figure 2.15) are alternatives for generating forces and movements in a haptic system (e.g., Riener and Harders 2012). 


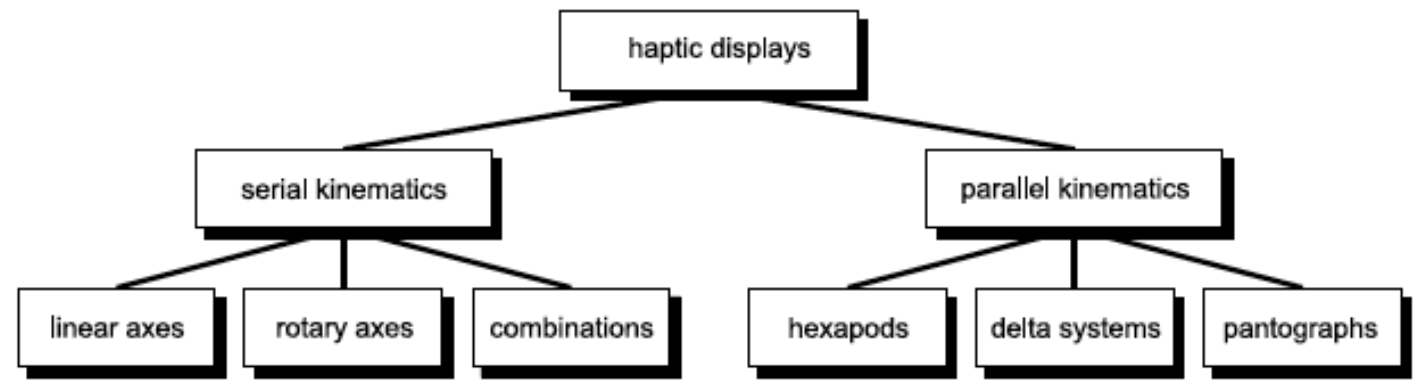

Figure 2.15: Haptic displays: kinematics design principles (Figure 4.5 in Riener and Harders 2012, p. 87)

A serial kinematic structure is designed like a chain of actuators and links to produce different types of movements (1) along translational or linear axes (Figure 2.16-a); (2) around rotary axes (Figure 2.16b); or (3) with a combination of both types of axis (Figure 2.16-c). Serial mechanisms lead to a relatively large workspace and are used in industrial robots (e.g., Lenarčič, Bajd, and Stanišić 2013).

In a parallel kinematic design, two or more linear or rotary links are arranged in parallel to influence the position and orientation of a moving platform connected to the base (e.g., Riener and Harders 2012).

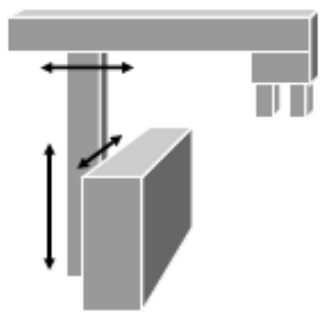

(a)

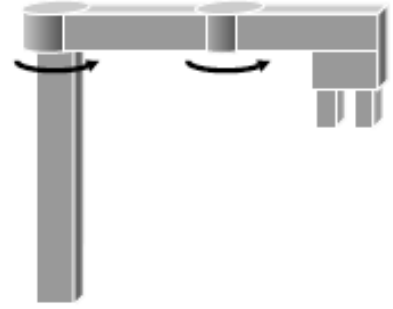

(b)

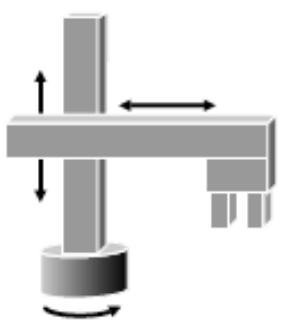

(c)

Figure 2.16: Different serial kinematic structures. (a) Linear axes; (b) Rotary axes; (c) Combination of linear and rotary axes. (Figure 4.6 in Riener and Harders 2012 p. 87)

Parallel designs have the disadvantage of offering a smaller workspace. However, these designs are able to support higher loads, which is why they are included in most of today's industrial robots (e.g., Lenarčič, Bajd, and Stanišić 2013). 
The hexapod shown in Figure 2.17 is an example of a parallel design having six linear actuators for connecting two platforms to generate a motion with six degrees of freedom (DOFs), with three translations and three rotations. A similar structure was suggested by Steward in the 1960s for designing a flight simulator (e.g., Lenarčič, Bajd, and Stanišić 2013). Another example is shown in Figure 2.18: a "delta" robot, with a parallel 3-DOF translational design (e.g., Riener and Harders 2012). This mechanism is used in industrial robotics for sorting and packaging and in medical robotics for surgical procedures (e.g., Lenarčič, Bajd, and Stanišić 2013).

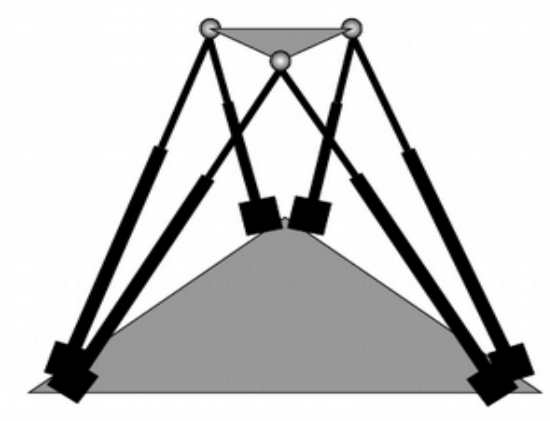

Figure 2.17: Hexapod (Steward platform) (Figure 4.7 in Riener and Harders 2012, p. 88)

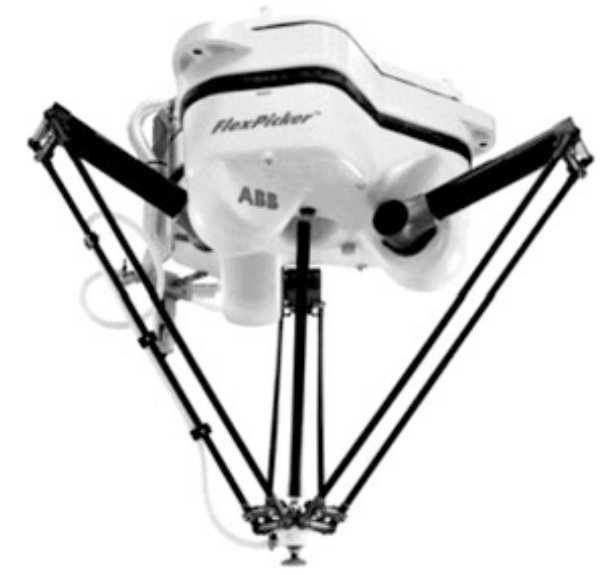

Figure 2.18: Type of delta robot introduced in production by ABB in 1999 under the name FlexPicker (Figure 7.1 in Lenarčič, Bajd, and Stanišić 2013, p. 240) 
Both structures, serial and parallel, are currently used in designing haptic devices. For example, of the devices described in section 2.3.6 below, the MPB and Geomagic products have a series kinematic structure while the Novint and Force Dimension devices have a parallel kinematic structure.

\subsubsection{Tactile-feedback and force-feedback haptic technologies}

"Tactile-feedback" and "force-feedback" displays represent two classes of haptic feedback technology. Tactile-feedback haptic displays are mechanical devices designed to exploit the skin receptors in order to offer tactile sensations to users (e.g., Chouvardas, Miliou, and Hatalis 2008; Riener and Harders 2012). Force-feedback haptic displays, on the other hand, are mechanical devices which mainly exploit the kinaesthetic receptors in the muscles and limbs to offer users sensations of force while interacting with objects in the environment (e.g., Riener and Harders 2012). In the following sections we will discuss both technologies and provide examples for each.

\subsubsection{Tactile-feedback haptic technology}

As noted earlier in this chapter, tactile sensations help us in recognizing an object's shape, texture and temperature while also providing us with information about its elasticity and viscosity (e.g., Mihelj, Novak, and Begus 2014).

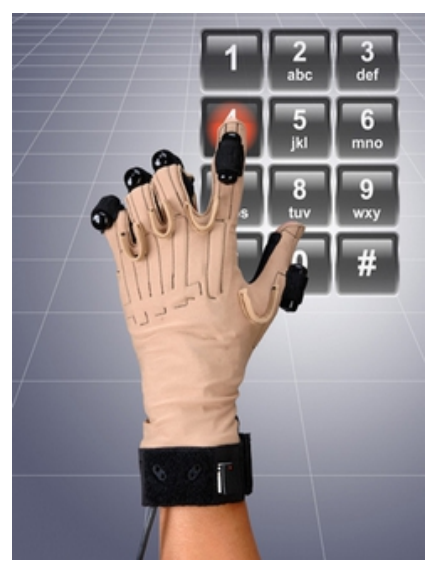

Figure 2.19: CyberTouch vibrotactile glove for generating touch sensations (CyberGlove Systems 2015) 
Tactile technology exploits the skin receptors to develop a wide variety of haptic displays. These displays can be based on different modalities, such as (1) vibration, like the CyberTouch vibrotactile glove shown in Figure 2.19 (CyberGlove Systems 2015); (2) pressure, like the tactile finger-pressure sensor system shown in Figure 2.20 (e.g., Pressure Profile Systems 2015); (3) electro-tactile (e.g., Pamungkas and Ward 2016); and (4) temperature (e.g., Yong Fu et al. 2010).

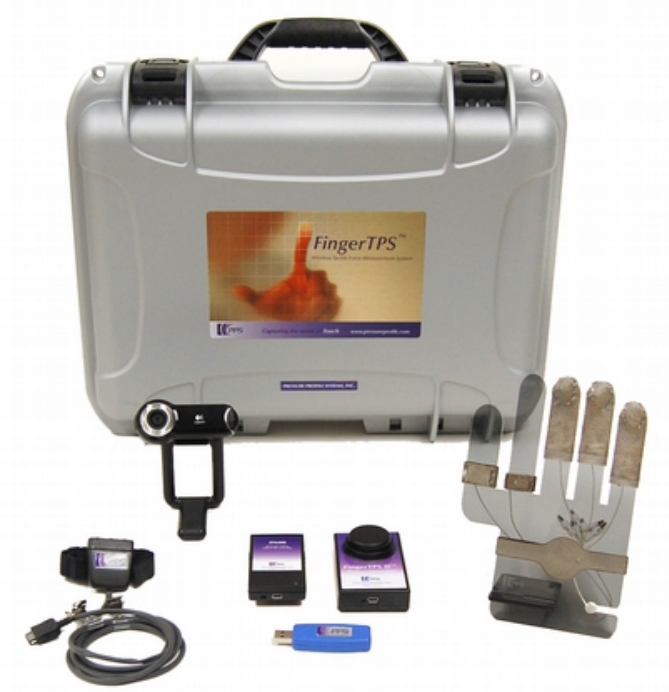

Figure 2.20: FingerTPS system: finger tactile pressure sensing system for measuring exerted hand pressure on an object. (Pressure Profile Systems 2015)

There are various applications for tactile-feedback systems. They can be used as assistive tools and communication aids for people with disabilities, for example, visually impaired persons (e.g., "Braille" 2015; Jansson 2008; Xu et al. 2011) and hearing-impaired persons (e.g., Kaczmarek KA et al. 1991). Tactile properties are also integrated in computer games (e.g., Foottit et al. 2014) and simulators (e.g., Coles et al. 2011; Mako Surgical Corp. 2015) as well as in gamepads for therapeutic aids (e.g., Changeon et al. 2012). Recently, touch screens and mobile devices have also started providing tactile 
features through mechanical and/or vibration feedback for notifying users of a call, a message or other events (e.g., Coles et al. 2011; Pyo et al. 2015; Senseg 2015; Apple 2015).

In order to create a more complete realistic haptic experience, the challenge remains in designing a portable system which provides (1) a realistic tactile experience; and (2) can be easily integrated with force-feedback interfaces (e.g., Coles, Meglan, and John 2011; Riener and Harders 2012) which we will cover in the next section.

\subsubsection{Force-feedback haptic technology}

As mentioned earlier in this chapter, kinaesthetic sensations are related to our perception of the movements and positions of the limbs along with the forces exerted by the muscles (e.g., Proske and Gandevia 2009). Force-feedback technology exploits the modalities of kinaesthetic receptors to design various high-end to low-end haptic devices (e.g., Riener and Harders 2012). These devices differ in their number of DOFs, force and torque, workspace size, software interface and price (e.g., Coles, Meglan, and John 2011).

Force-feedback technology is mainly used in surgical simulators (e.g., Basdogan et al. 2004; Varshney et al. 2014; CAE Healthcare 2015), for telesurgery (e.g., Avusoglu et al. 2001), for teleoperator systems (e.g., Lederman and Klatzky 1999; Ueberle, Mock, and Buss 2004), for data visualization (e.g., Panëels et al. 2013; Soukal, Purchart, and Kolingerová 2014) and for gaming (e.g., Razer 2015; Thrustmaster 2015).

\subsubsection{Force-feedback haptic devices}

In the remaining sections of this Chapter we will provide a review of some of the currently available force-feedback devices, from least expensive to most expensive, and provide their characteristics. 


\subsubsection{Novint Technologies}

Novint Technologies offer two haptic devices. The Novint Falcon (Figure 2.21), sold for 249.95 USD, is the least expensive force-feedback haptic device on the market today (Novint Technologies Inc. 2012a). This device has a parallel kinematic structure with 3-DOF translational sensing, a position resolution of $400 \mathrm{dpi}$ and a maximum force of approximately $8.9 \mathrm{~N}$. It weighs around $2.8 \mathrm{~kg}$ with an approximate workspace $(\mathrm{W} \times \mathrm{H} \times \mathrm{D})$ of $4 \times 4 \times 4$ inches. It also offers two types of grip: (1) a ball grip for standard applications; and (2) a pistol grip for Falcon-enabled first-person-shooter games. Novint's second device, the Xio (Figure 2.22), was announced in 2012 as "a revolution in gaming" with promises that it would also be used in scientific and medical applications, but as of early 2016 the company has not released it yet nor provided its specifications (Novint Technologies Inc. 2012b).
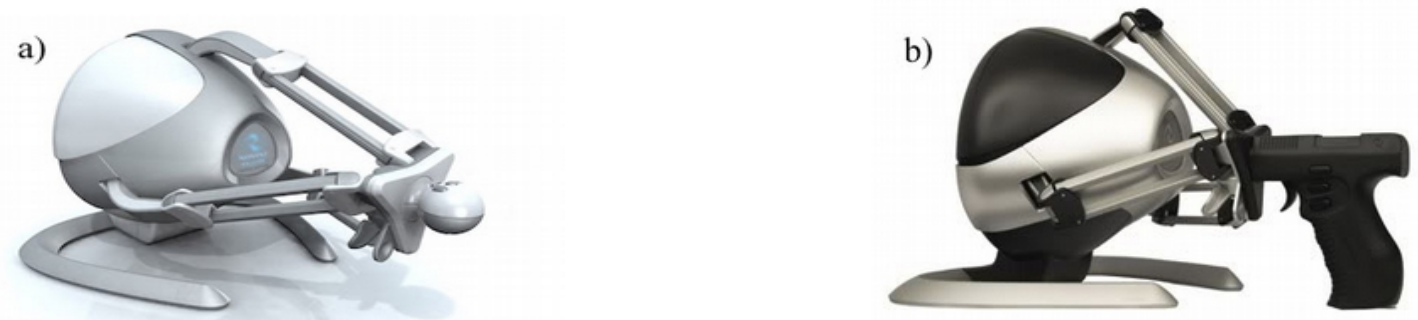

Figure 2.21: Novint Falcon 3D haptic device. a) with a ball grip for standard applications; b) with a gun grip for falcon enabled games. (Novint Technologies Inc. 2012a)

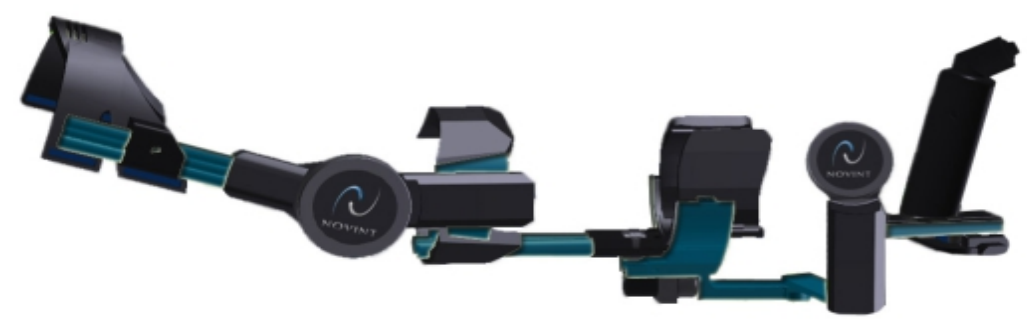

Figure 2.22: Novint Xio haptic device (Novint Technologies Inc. 2012b) 


\subsubsection{Geomagic/3DSystems}

Geomagic (Figure 2.23) offers four haptic product lines having a serial kinematic structure: (1) Touch 3D stylus; (2) Geomagic Touch, formerly the Sensable Omni; (3) Touch X, formerly the Sensable Phantom Desktop; and (4) the 3D Systems Phantom Premium models (3D Systems Corporation 2015). All four groups offer 3-DOF position sensing and 3-DOF force feedback, with differences related to their workspace capabilities, maximum force, position resolution and maximum stiffness.

A summary of the specifications of the first three products is shown in Table 2. Touch $3 \mathrm{D}$ stylus is the latest generation of Geomagic products and is intended for gaming and digital design in particular (3D Systems Corporation 2015). This device costs 600 USD and has a large workspace of $10.45 \times 9.5 \times 3.5$ inches with a position resolution of $0.084 \mathrm{~mm}$ and a maximum force of $3.4 \mathrm{~N}$.
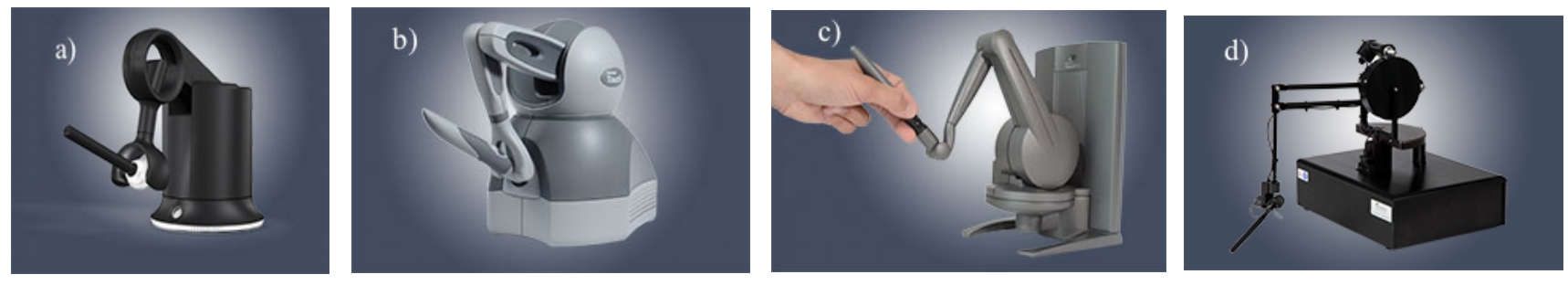

Figure 2.23: Geomagic 3D haptic devices: a) Touch 3D Stylus; b) Geomagic Touch; c) Geomagic Touch X; and d) 3D Systems Phantom Premium (3D Systems Corporation 2015)

The Geomagic Touch product, selling for 2,800 USD, is considered by its designers as a mid-range professional haptic device. It has a position resolution of $0.055 \mathrm{~mm}$ with a maximum force of $3.3 \mathrm{~N}$ and a workspace of $6.4 \times 4.8 \times 2.8$ inches.

The third product, Geomagic Touch X, selling for 4,400 USD, has a larger workspace $(6.4 \times 4.8 \times 4.8$ inches $)$, a better position resolution $(0.023 \mathrm{~mm})$ and a higher maximum force $(7.9 \mathrm{~N})$. 
Table 2: Geomagic 3D Systems haptic device specifications for Touch 3D Stylus, Geomagic Touch and Geomagic Touch X ( based on our communication with 3DSystems sales representatives and $3 D$ Systems Corporation 2015)

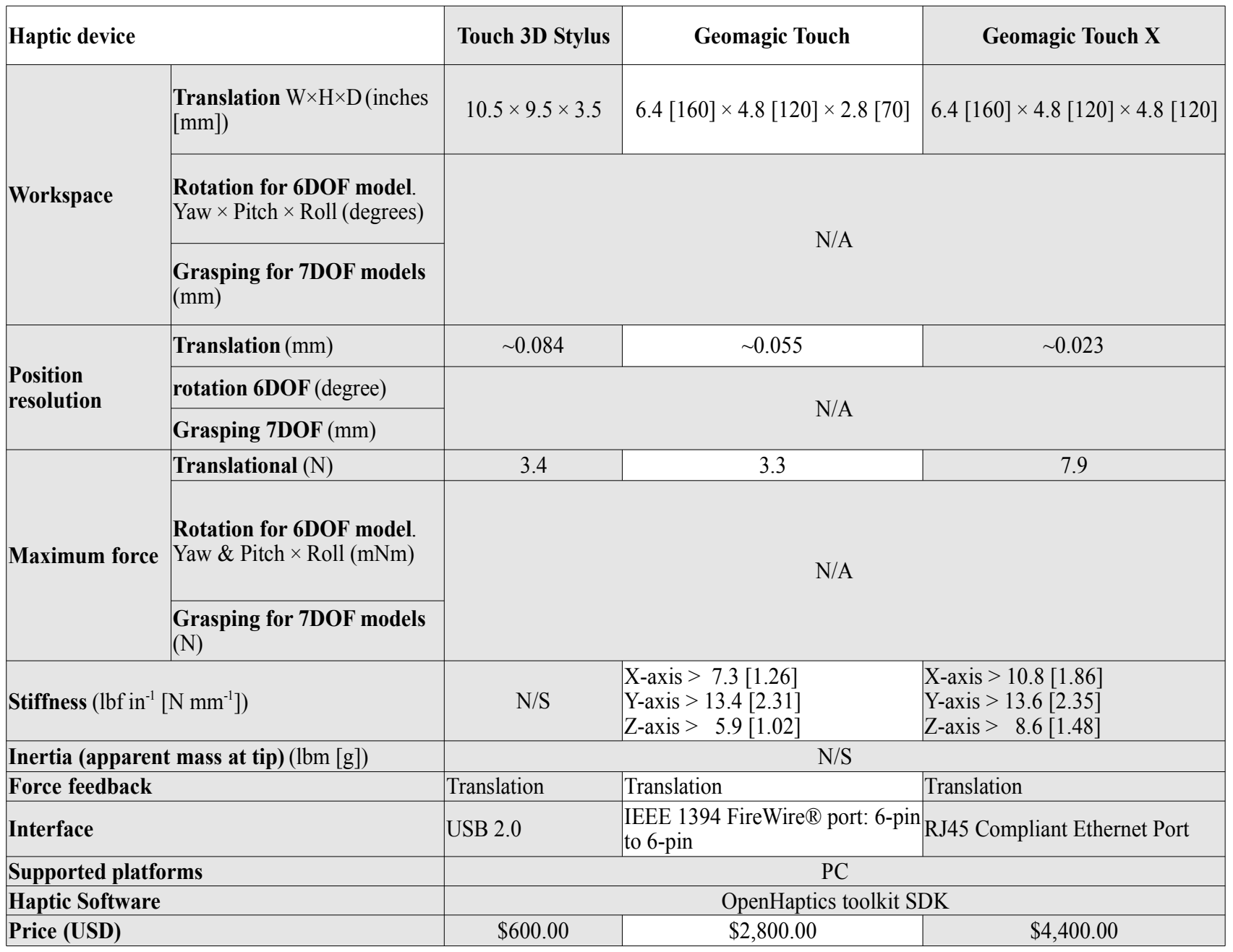

N/A: not applicable

N/S: not specified

As for the fourth group, it comprises a line of higher-precision haptic devices summarized in Table 3 (Sensable Technologies 2007; Geomagic 2015). This group contains the Phantom Premium 1.0, 1.5, 1.5 High Force and 3.0. The 3.0 model was discontinued in 2014 (Geomagic 2015). The 1.5 model has 
6 DOFs of force feedback with an optional seventh sensing DOF related to pinch functionality obtained by attaching an end effector, such as a thumb-pad or scissors (Figure 2.24). These Phantom devices differ in their stiffnesses and workspace ranges. For example, the workspace of the 1.0 devices corresponds roughly to the volume swept by the hand pivoting at the wrist, whereas the workspace of the $1.5 \& 1.5$ High Force devices corresponds to the volume swept by the lower arm pivoting at the elbow.
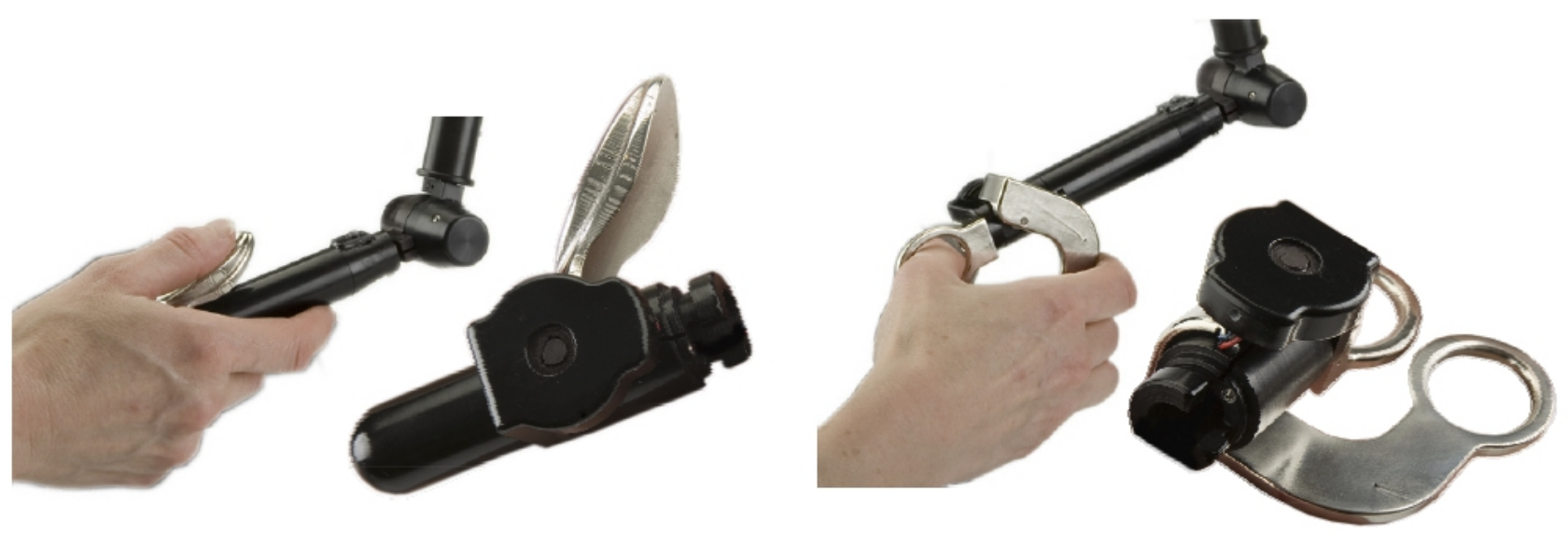

Figure 2.24: Thumb-pad (left) and scissors (right) snap-on end effectors for Phantom 6-DOF devices. These end effectors provide an additional degree of freedom in positional sensing (Sensable technologies 2007). 
Table 3: Geomagic 3D Systems Phantom haptic device specifications for Phantom Premium 1.0, 1.5, 1.5 High Force and 3.0 (based on our communication with 3DSystems sales representatives and $3 D$ Systems Corporation 2013a, 2013b, 2013c)

\begin{tabular}{|c|c|c|c|c|c|}
\hline \multicolumn{2}{|l|}{ Haptic device } & \multirow{2}{*}{$\begin{array}{c}\text { Phantom Premium 1.0 } \\
10[254] \times 7[178] \times 5[127]\end{array}$} & \begin{tabular}{|c|} 
Phantom Premium \\
1.5 \\
\end{tabular} & $\begin{array}{c}\text { Phantom Premium } \\
1.5 \text { High Force }\end{array}$ & \multirow{2}{*}{$\begin{array}{c}\text { Phantom Premium 3.0 } \\
33[838] \times 23[584] \times 16[406]\end{array}$} \\
\hline \multirow{3}{*}{ Workspace } & $\begin{array}{l}\text { Translation } \mathrm{W} \times \mathrm{H} \times \mathrm{D} \\
\text { (inches }[\mathrm{mm}] \text { ) }\end{array}$ & & $15[381] \times 10.5$ & {$[267] \times 7.5[191]$} & \\
\hline & $\begin{array}{l}\text { Rotation for 6DOF model. } \\
\text { Yaw } \times \text { Pitch } \times \text { Roll (degrees) }\end{array}$ & \multirow{2}{*}{$\mathrm{N} / \mathrm{A}$} & \multicolumn{2}{|c|}{$\mathrm{N} / \mathrm{S}$} & $297 \times 260 \times 335$ \\
\hline & $\begin{array}{l}\text { Grasping for } 7 \mathrm{DOF} \\
\text { models }(\mathrm{mm})\end{array}$ & & \multicolumn{2}{|c|}{$\mathrm{N} / \mathrm{A}$} & $\mathrm{N} / \mathrm{S}$ \\
\hline \multirow{3}{*}{$\begin{array}{l}\text { Position } \\
\text { resolution }\end{array}$} & Translation (mm) & 0.03 & 0.03 & 0.007 & 0.02 \\
\hline & rotation 6DOF (degree) & \multirow{2}{*}{ N/A } & \multicolumn{2}{|c|}{$\mathrm{N} / \mathrm{S}$} & $\mathrm{N} / \mathrm{S}$ \\
\hline & Grasping 7DOF (mm) & & \multicolumn{2}{|c|}{$\mathrm{N} / \mathrm{A}$} & N/A \\
\hline \multirow{3}{*}{ Maximum force } & Translation $(\mathrm{N})$ & 8.5 & 8.5 & 37.5 & 22 \\
\hline & $\begin{array}{l}\text { Rotation for 6DOF model. } \\
\text { Yaw \& Pitch } \times \text { Roll }(\mathrm{mNm})\end{array}$ & \multirow{2}{*}{ N/A } & \multicolumn{2}{|c|}{$\mathrm{N} / \mathrm{S}$} & $188 \times 48$ \\
\hline & $\begin{array}{l}\text { Grasping for 7DOF } \\
\operatorname{models}(\mathrm{N})\end{array}$ & & \multicolumn{2}{|c|}{$\mathrm{N} / \mathrm{A}$} & $\mathrm{N} / \mathrm{S}$ \\
\hline \multicolumn{2}{|c|}{ Stiffness $\left(\mathrm{lbf} \mathrm{in}^{-1}\left[\mathrm{~N} \mathrm{~mm}^{-1}\right]\right)$} & $20[3.5]$ & \multicolumn{2}{|c|}{$20[3.5]$} & $5.7[1]$ \\
\hline \multicolumn{2}{|c|}{ Inertia (apparent mass at tip) (lbm [g]) } & $<0.17[75]$ & $<0.17[75]$ & $<0.33[150]$ & $<0.35[159]$ \\
\hline \multicolumn{2}{|l|}{ Force feedback } & translation & \multicolumn{2}{|l|}{ Translation and rotation } & Translation and rotation \\
\hline \multicolumn{2}{|l|}{ Interface } & \multicolumn{4}{|c|}{ Parallel port } \\
\hline \multicolumn{2}{|c|}{ Supported platforms } & \multicolumn{4}{|c|}{$\mathrm{PC}$} \\
\hline \multicolumn{2}{|c|}{ Haptic Software } & \multicolumn{4}{|c|}{ OpenHaptics toolkit SDK } \\
\hline \multicolumn{2}{|l|}{ Price } & $\$ 24,200.00$ & $\$ 28,880.00$ & $\$ 34,150.00$ & $\begin{array}{l}\text { Not sold anymore! (was around } \\
70,000 \$ \text { ) }\end{array}$ \\
\hline
\end{tabular}

N/A: not applicable

N/S: not specified

\subsubsection{Force Dimension}

Force Dimension manufactures three groups of haptic devices with parallel kinematic structure (Force Dimension 2015). Their characteristics are summarized in Table 4.

The first group contains two devices: delta.3 and delta.6 (Figure 2.25). Both devices offer a translation resolution of $0.02 \mathrm{~mm}$, a workspace of $400 \mathrm{~mm}$ diameter and $260 \mathrm{~mm}$ height, and a maximum force of 
20 N. The delta. 6 devices have 6 DOFs and offer a rotational resolution of $<0.04$ degrees, torques of $150 \mathrm{mNm}$ and a rotational workspace of \pm 22 degrees around each axis.
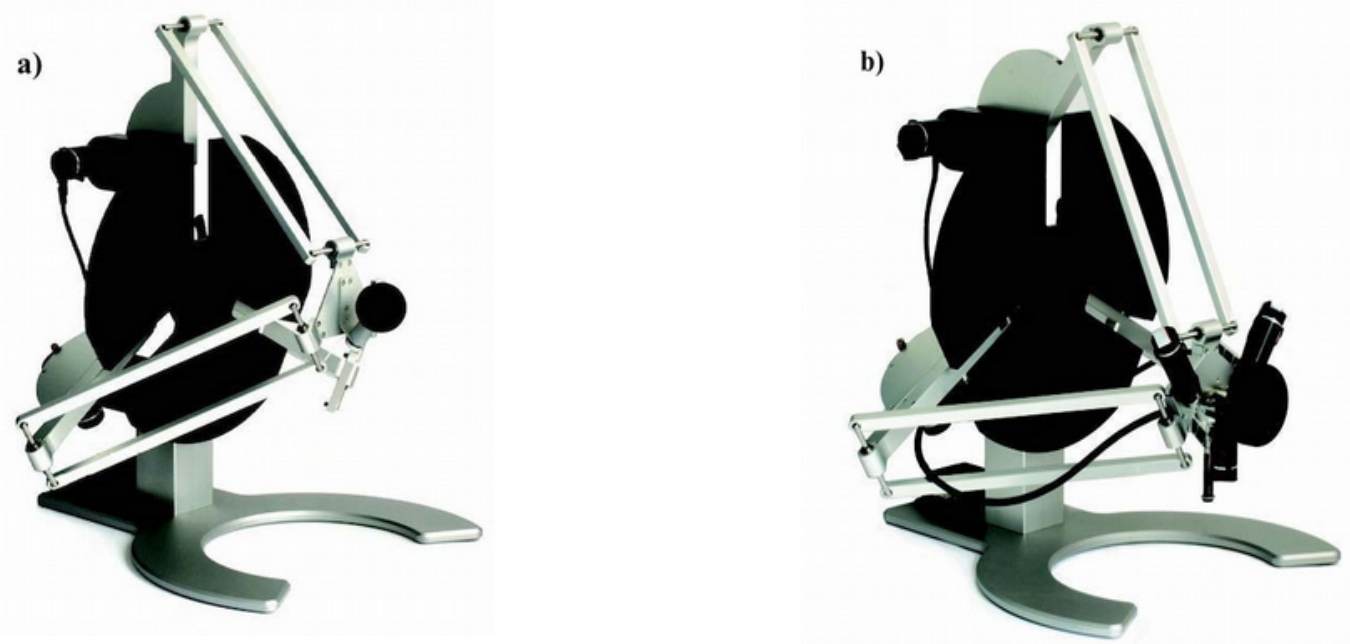

Figure 2.25: Force Dimension delta.x force-feedback haptic devices. a) delta.3 with 3 DOF translations; b) delta.6 with 6 DOF translations and rotations (Force Dimension 2015)

The second group contains three devices: (1) omega.3 with 3 DOFs; (2) omega.6 with 6 DOFs; and (3) omega.7 having a grasping extension to provide 7 DOFs (Figure 2.26). Omega devices have a workspace of $160 \mathrm{~mm}$ diameter and $110 \mathrm{~mm}$ height with translation resolution $<0.01 \mathrm{~mm}$, translation forces of $12 \mathrm{~N}$ and stiffness of $14.5 \mathrm{~N} / \mathrm{mm}$. In addition, omega. 6 and omega. 7 models provide a rotation resolution of 0.09 degrees with a rotation workspace of $240 \times 140 \times 320$ degrees. With the grasping feature, omega. 7 has $25 \mathrm{~mm}$ of grasping workspace and $0.006 \mathrm{~mm}$ in grasping resolution.

The third Force Dimension line consists of the sigma.7 device with 7 DOFs (Figure 2.27). It has a workspace of $90 \mathrm{~mm}$ diameter and $130 \mathrm{~mm}$ height in translation, $235 \times 140 \times 200$ degrees in rotation and $25 \mathrm{~mm}$ grasping. Its translation resolution is $0.0015 \mathrm{~mm}$ with a rotation resolution of 0.013 degrees and 
a grasping resolution of $0.006 \mathrm{~mm}$. As for the forces, sigma.7 has $20 \mathrm{~N}$ in translation, $400 \mathrm{mNm}$ in rotation and $\pm 8 \mathrm{~N}$ in grasping.

a)

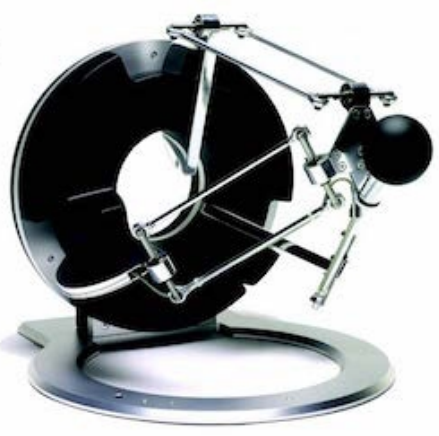

b)

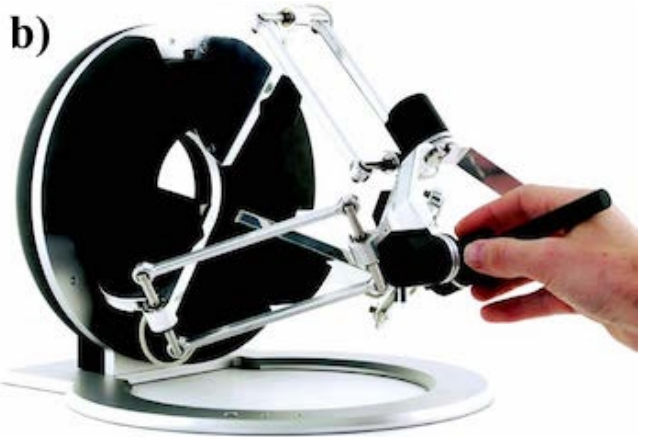

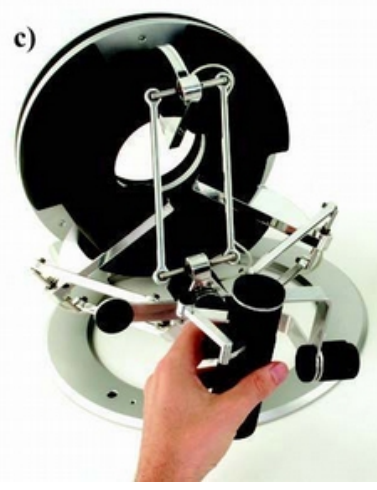

Figure 2.26: Force Dimension omega.x force-feedback haptic devices. a) omega.3 with 3 DOF in translations; b) omega.6 with 6 DOF: 3 translations and 3 rotations; c) omega. 7 with 7 DOF: 3 translations, 3 rotations and 1 grasping (Force Dimension 2015).

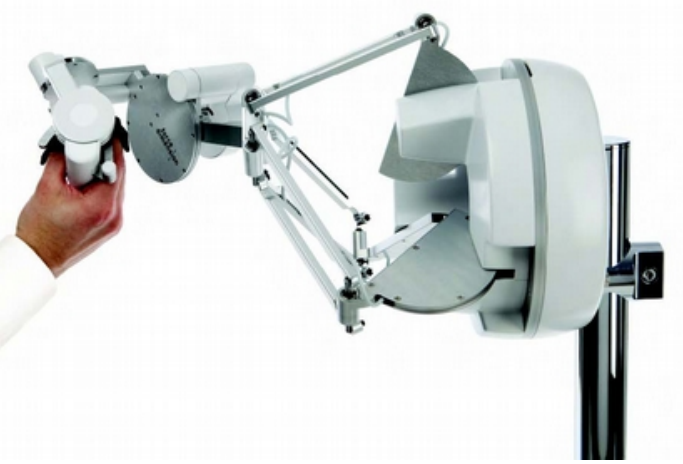

Figure 2.27: Force Dimension sigma. 7 force-feedback haptic device with 7 DOF: 3 translations, 3 rotations and 1 grasping (Force Dimension 2015) 
Table 4: Force Dimension haptic device specifications for delta, omega and sigma models (based on Force Dimension 2015)

\begin{tabular}{|c|c|c|c|c|}
\hline \multicolumn{2}{|l|}{ Haptic device } & \multirow{2}{*}{$\begin{array}{c}\text { Delta.x } \\
(.3 \& .6 \text { models }) \\
\varnothing \times[400] \times[260]\end{array}$} & \multirow{2}{*}{$\begin{array}{c}\text { Omega.x } \\
(.3-.6 \& .7 \text { models }) \\
\varnothing \times[160] \times[110]\end{array}$} & \multirow{2}{*}{$\begin{array}{c}\text { Sigma.7 } \\
\varnothing \times[190] \times[130]\end{array}$} \\
\hline \multirow{3}{*}{ Workspace } & $\begin{array}{l}\text { Translation } \mathrm{W} \times \mathrm{H} \times \mathrm{D} \\
\text { (inches }[\mathrm{mm}] \text { ) }\end{array}$ & & & \\
\hline & $\begin{array}{l}\text { Rotation for 6DOF } \\
\text { model. Yaw } \times \text { Pitch } \times \text { Roll } \\
(\text { degrees) }\end{array}$ & \pm 22 & $240 \times 140 \times 180$ & $235 \times 140 \times 200$ \\
\hline & $\begin{array}{l}\text { Grasping for } 7 \mathrm{DOF} \\
\text { models }(\mathrm{mm})\end{array}$ & $\mathrm{N} / \mathrm{A}$ & 25 & 25 \\
\hline \multirow{3}{*}{$\begin{array}{l}\text { Position } \\
\text { resolution }\end{array}$} & Translation $(\mathrm{mm})$ & 0.02 & $<0.01$ & 0.0015 \\
\hline & rotation 6DOF (degree) & $<0.04$ & 0.09 & 0.013 \\
\hline & Grasping 7DOF (mm) & $\mathrm{N} / \mathrm{A}$ & 0.006 & 0.006 \\
\hline \multirow{3}{*}{ Maximum force } & Translational (N) & 20 & 12 & 20 \\
\hline & $\begin{array}{l}\text { Rotation for 6DOF } \\
\text { model. Yaw \& Pitch } \times \\
\text { Roll }(\mathrm{mNm})\end{array}$ & \multicolumn{3}{|c|}{$\mathrm{N} / \mathrm{S}$} \\
\hline & $\begin{array}{l}\text { Grasping for 7DOF } \\
\text { models }(\mathrm{N})\end{array}$ & $\mathrm{N} / \mathrm{A}$ & \pm 8 & \pm 8 \\
\hline \multicolumn{2}{|c|}{ Stiffness $\left(\mathrm{lbf} \mathrm{in}^{-1}\left[\mathrm{~N} \mathrm{~mm}^{-1}\right]\right)$} & $\mathrm{N} / \mathrm{S}$ & {$[14.5]$} & $\mathrm{N} / \mathrm{S}$ \\
\hline \multicolumn{2}{|c|}{ Inertia (apparent mass at tip) (lbm [g]) } & \multicolumn{3}{|c|}{$\mathrm{N} / \mathrm{S}$} \\
\hline \multicolumn{2}{|l|}{ Force feedback } & translation and rotation & translation and rotation & $\begin{array}{l}\text { translation, rotation and } \\
\text { grasping }\end{array}$ \\
\hline \multicolumn{2}{|l|}{ Interface } & \multicolumn{3}{|c|}{ USB 2.0} \\
\hline \multicolumn{2}{|c|}{ Supported platforms } & \multicolumn{3}{|c|}{ PC / Linux / Mac / QNX / WindRiver } \\
\hline \multicolumn{2}{|c|}{ Haptic Software } & \multicolumn{3}{|c|}{ Haptic SDK \& robotic SDK } \\
\hline \multicolumn{2}{|l|}{ Price } & $\begin{array}{l}\text { Delta.3: 45,833 CAD } \\
\text { Delta.6: } 83,194 \text { CAD }\end{array}$ & $\begin{array}{l}\text { Omega.3: 30,139 CAD } \\
\text { Omega.6: 38,611 CAD } \\
\text { Omega.7: 48,472 CAD }\end{array}$ & $110,139 \mathrm{CAD}$ \\
\hline
\end{tabular}

N/A: not applicable

N/S: not specified 


\subsubsection{MPB Technologies}

MPB Technologies (MPB Technologies 2014) offer two haptic devices with serial kinematic structure: (1) the Freedom 6S with 6 DOFs sold for 54,400 USD; and (2) the Freedom 7S with a scissors grip to provide a 7th DOF sold for 62,150 USD (Figure 2.28). Both devices have a workspace of $170 \times 220 \times 330 \mathrm{~mm}$ with a maximum force of $2.5 \mathrm{~N}$ and a stiffness of $2 \mathrm{~N} / \mathrm{mm}$. Having a position resolution of $2 \mu \mathrm{m}$ makes such devices suitable for very precise applications like medical simulation, for example.

The scissors added to the Freedom 7S model provide a range of $40^{\circ}$ with a maximum force of 450 $\mathrm{mNm}$, a position resolution of $14 \mathrm{rad}$ and a stiffness of $20 \mathrm{~N} . \mathrm{m} / \mathrm{rad}$. Table 5 shows the specifications of these two devices.

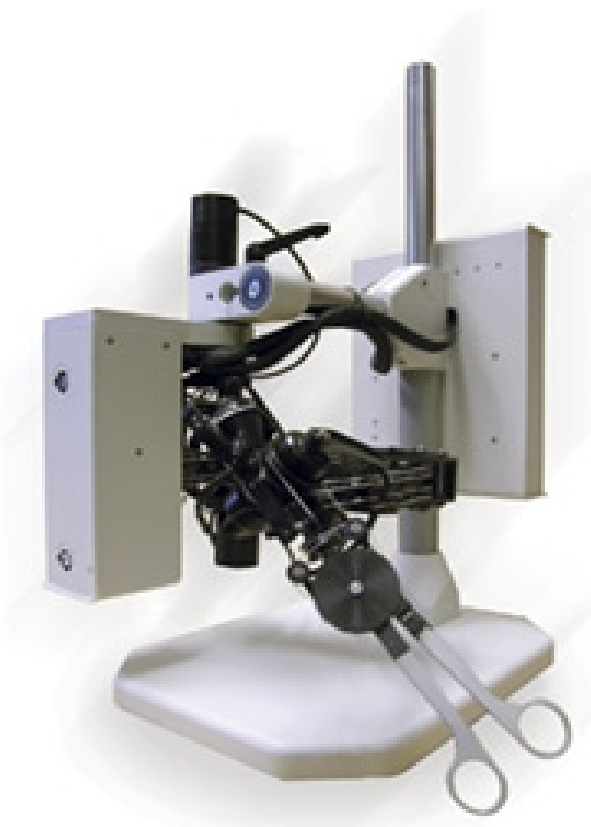

Figure 2.28: MPB Technologies Freedom $7 S$ haptic device with scissors grip to provide 7 DOFs. (MPB Technologies 2014) 
Table 5: MPB Technologies haptic device specifications for Freedom 6S and Freedom 7S (based on MPB Technologies 2014)

\begin{tabular}{|c|c|c|c|}
\hline \multirow{2}{*}{\multicolumn{2}{|c|}{ Haptic device }} & \multicolumn{2}{|c|}{ MPB Technologies } \\
\hline & & Freedom 6S (6DOF) & Freedom 7S (7DOF) \\
\hline \multirow{3}{*}{ Workspace } & Translation $\mathrm{W} \times \mathrm{H} \times \mathrm{D}($ inches $[\mathrm{mm}])$ & \multicolumn{2}{|c|}{$[170] \times[220] \times[330]$} \\
\hline & $\begin{array}{l}\text { Rotation for 6DOF model. Yaw } \times \text { Pitch } \\
\times \text { Roll (degrees) }\end{array}$ & \multicolumn{2}{|c|}{$170 \times 130 \times 340$} \\
\hline & Grip for 7DOF models (mm [degree]) & N/A & {$[40]$} \\
\hline \multirow{3}{*}{$\begin{array}{l}\text { Position } \\
\text { resolution }\end{array}$} & Translation $(\mathrm{mm})$ & \multicolumn{2}{|c|}{0.002} \\
\hline & rotation 6DOF (degree $[\mu \mathrm{rad}])$ & [20] & $\begin{array}{l}\text { Yaw: [13] } \\
\text { Pitch: [17] } \\
\text { Roll: [14] }\end{array}$ \\
\hline & Grip 7DOF (mm $[\mu \mathrm{rad}])$ & N/A & [14] \\
\hline \multirow{3}{*}{ Maximum force } & Translational (N) & \multicolumn{2}{|r|}{2.5} \\
\hline & $\begin{array}{l}\text { Rotation for 6DOF model. Yaw } \times \text { Pitch } \\
\times \text { Roll }(\mathrm{mNm})\end{array}$ & \multicolumn{2}{|c|}{$310 \times 370 \times 150$} \\
\hline & Grip for 7DOF models (N [mNm]) & N/A & {$[450]$} \\
\hline \multicolumn{2}{|c|}{ Stiffness (lbf in $\left.{ }^{-1}\left[\mathrm{~N} \mathrm{~mm}^{-1}\right]\right)$} & \multicolumn{2}{|r|}{ [2] } \\
\hline \multicolumn{2}{|c|}{ Inertia (apparent mass at tip) (lbm [g]) } & [125] & {$[175]$} \\
\hline \multicolumn{2}{|l|}{ Force feedback } & Translation and rotation & translation, rotation and grip \\
\hline \multicolumn{2}{|l|}{ Interface } & \multicolumn{2}{|c|}{$\begin{array}{l}\text { Two PCI or PCIe cards installed in a computer with } \\
\text { cable connection to device }\end{array}$} \\
\hline \multicolumn{2}{|c|}{ Supported platforms } & \multicolumn{2}{|c|}{ PC / Linux } \\
\hline \multicolumn{2}{|l|}{ Haptic Software } & \multicolumn{2}{|c|}{$\mathrm{N} / \mathrm{S}$} \\
\hline \multicolumn{2}{|c|}{$\begin{array}{l}\text { Price (including a signal conditioning unit, a current } \\
\text { amplifier and } \mathrm{A} / \mathrm{D} \text { and } \mathrm{D} / \mathrm{A} \text { cards). }\end{array}$} & 54,400 USD & 62,150 USD \\
\hline
\end{tabular}

\section{N/A: not applicable}

N/S: not specified 


\subsubsection{Summary}

In the previous section we described some of the commercially available low-end to high-end forcefeedback haptic devices, as summarized in Table 6. Comparing such devices by plotting their position resolutions and numbers of DOFs against price (Figure 2.29 and Figure 2.31) shows that the price generally increases for a finer position resolution and for a larger number of DOFs. Plotting the maximum force against price (Figure 2.30) shows that in general the price increases for a higher maximum force. However, the Phantom Premium 1.5 HF, although it is in the middle of the range of haptic devices in terms of its price, position resolution and number of DOFs, provides the highest maximum force $(37.5 \mathrm{~N})$, which makes it suitable for a wide range of applications. The MPB Freedom devices have high prices but low maximum forces; on the other hand, they have a finer position resolution than any but the even higher-priced sigma.7 device.

Table 6: Characteristics of some commercially available low-end to high-end force-feedback haptic devices

\begin{tabular}{|c|c|c|c|c|c|c|c|}
\hline Company & Device Name & Abbreviation & $\begin{array}{c}\text { Position } \\
\text { resolution }(\mu \mathrm{m})\end{array}$ & $\begin{array}{l}\text { Max Force } \\
\text { (N) }\end{array}$ & DOFs & $\begin{array}{l}\text { Kinematic } \\
\text { structure }\end{array}$ & $\begin{array}{l}\text { Price } \\
\text { (USD) }\end{array}$ \\
\hline \multirow{6}{*}{$\begin{array}{l}\text { Force } \\
\text { Dimension }\end{array}$} & Omega.3 & Om3 & 10 & 12 & 3 & Parallel & $\$ 21,800.00$ \\
\hline & Omega.6 & Om6 & 10 & 12 & 6 & Parallel & $\$ 28,000.00$ \\
\hline & Omega.7 & Om7 & 10 & 12 & 7 & Parallel & $\$ 35,100.00$ \\
\hline & Delta.3 & Del3 & 20 & 20 & 3 & Parallel & $\$ 33,158.00$ \\
\hline & Delta.6 & Del6 & 20 & 20 & 6 & Parallel & $\$ 60,185.00$ \\
\hline & Sigma.7 & Sig7 & 1.5 & 20 & 7 & Parallel & $\$ 79,680.00$ \\
\hline \multirow{6}{*}{ Geomagic } & Touch 3D stylus & Tch3DS & 84 & 3.4 & 3 & Serial & $\$ 600.00$ \\
\hline & Touch (Omni) & Tch & 55 & 3.3 & 3 & Serial & $\$ 2,800.00$ \\
\hline & Touch X & TchX & 23 & 7.9 & 3 & Serial & $\$ 4,400.00$ \\
\hline & \begin{tabular}{|l} 
Phantom \\
Premium 1.0
\end{tabular} & Ph1.0 & 30 & 8.5 & 3 & Serial & $\$ 24,200.00$ \\
\hline & $\begin{array}{l}\text { Phantom } \\
\text { Premium } 1.5\end{array}$ & $\mathrm{Ph} 1.5$ & 30 & 8.5 & 6 & Serial & $\$ 28,880.00$ \\
\hline & $\begin{array}{l}\text { Phantom } \\
\text { Premium 1.5 HF }\end{array}$ & $\mathrm{Ph} 1.5 \mathrm{HF}$ & 7 & 37.5 & 6 & Serial & $\$ 34,150.00$ \\
\hline \multirow{2}{*}{ MPB } & Freedom 6S & Fr6S & 2 & 2.5 & 6 & Serial & $\$ 54,400.00$ \\
\hline & Freedom 7S & Fr7S & 2 & 2.5 & 7 & Serial & $\$ 62,150.00$ \\
\hline Novint & Novint Falcon & Fal & 60 & 8.9 & 3 & Parallel & $\$ 250.00$ \\
\hline
\end{tabular}




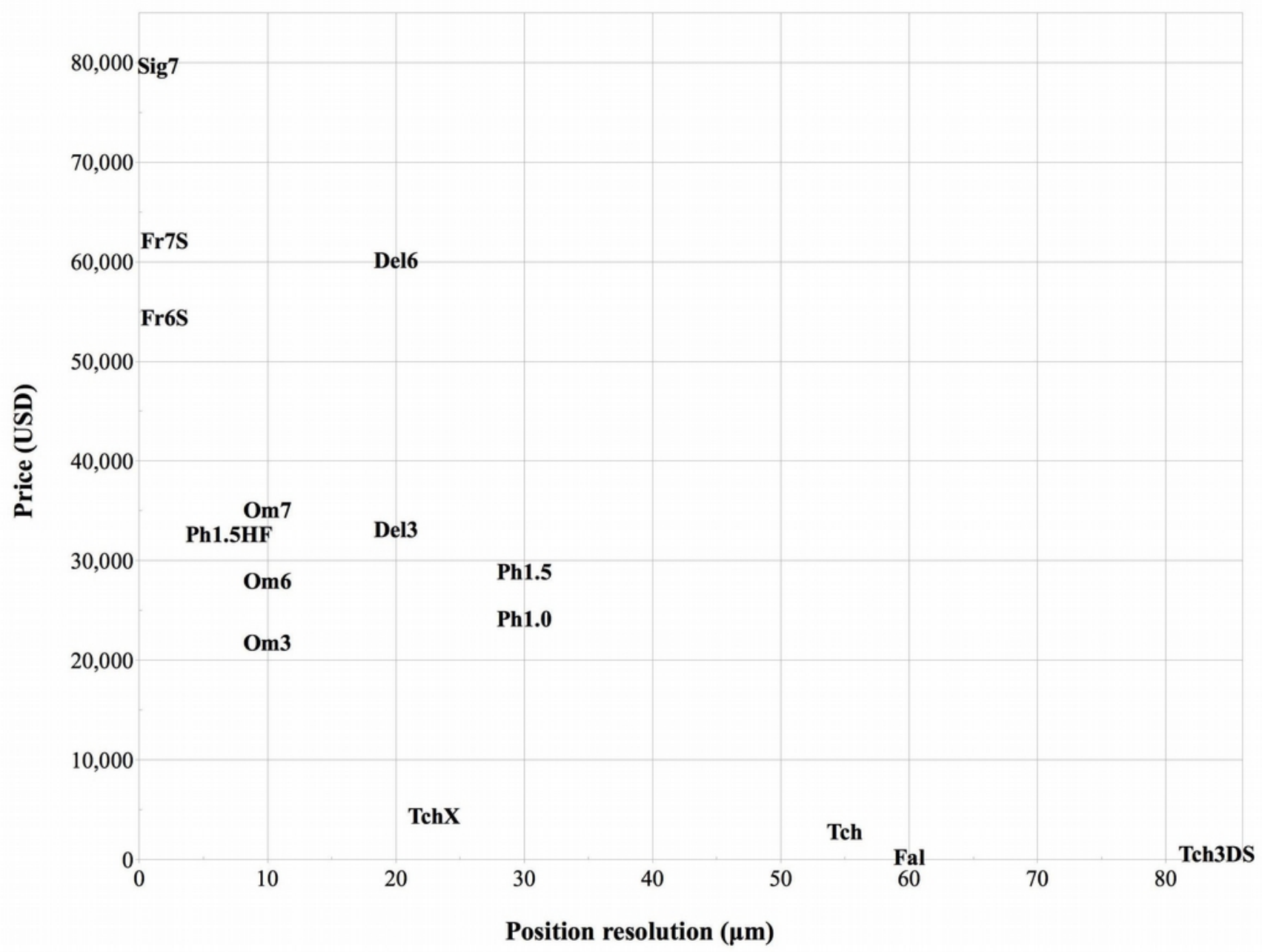

Figure 2.29: Comparison of haptic devices based on position resolution ( $\mu m$ ) and price (USD). The abbreviations are defined in Table 6. 


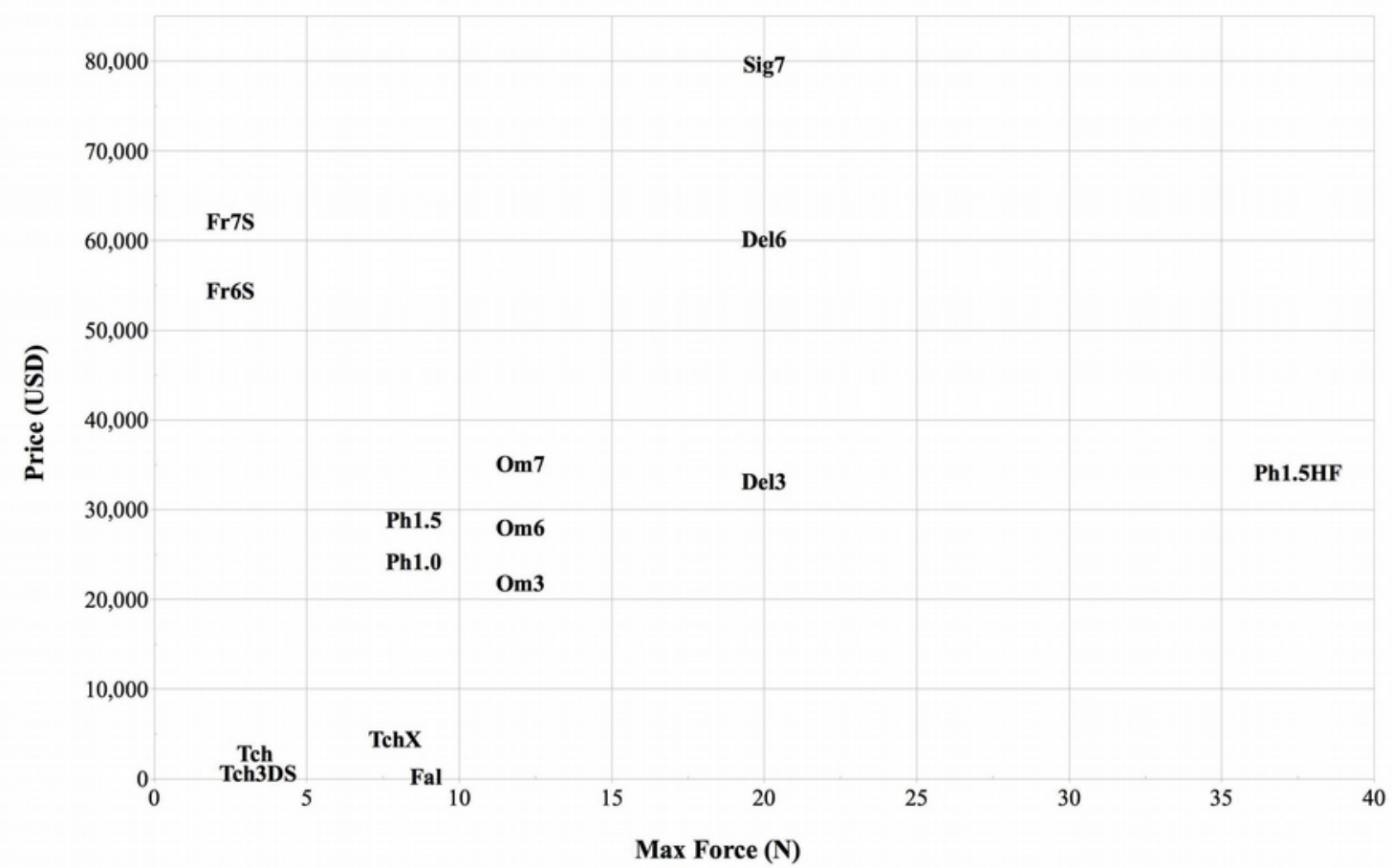

Figure 2.30: Comparison of haptic devices based on maximum force (N) and price (USD). The abbreviations are defined in Table 6.

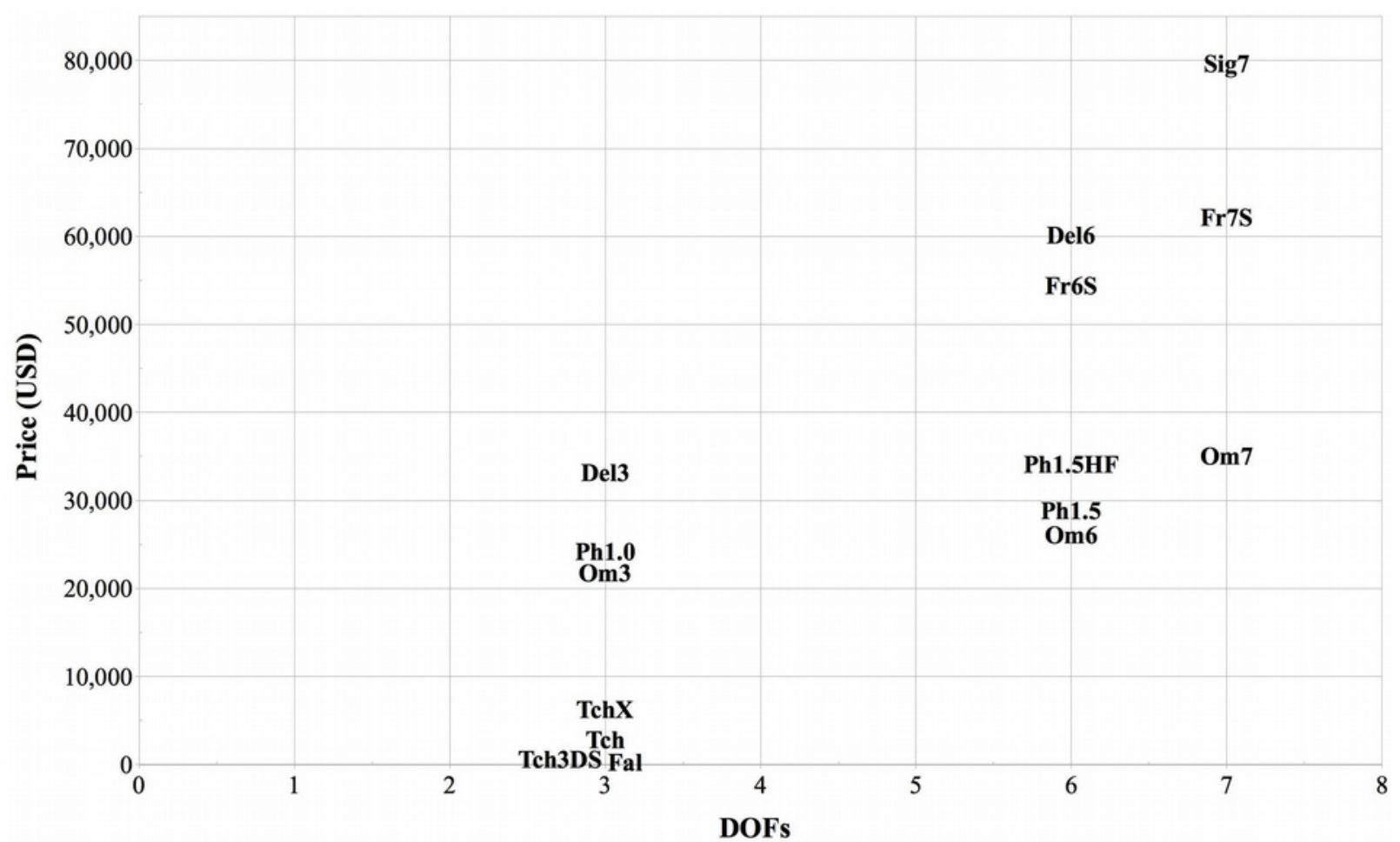

Figure 2.31: Comparison of haptic devices based on numbers of DOFs and price (USD). The abbreviations are defined in Table 6. 
Additional haptic devices could be added, such as (1) the HD² High Definition haptic device (Quanser 2015); (2) the W3D and W6D haptic devices (Entact 2015); (3) the Maglev 200 (Butterfly Haptics 2014); (4) and the Virtuose 3D and 6D products (Haption 2015). These devices are shown in Figure 2.32 .

Selecting a haptic device to meet the requirements of a specific application such as physical rehabilitation or medical simulation, for example, can be done based on the common characteristics shown in tables 2, 3, 4 and 5 . These include the workspace size, position resolution, price and number of DOFs. However, other important characteristics are often not specified by the manufacturers, such as the force resolution, stiffness and frequency response. In any case, testing devices from different manufacturers is generally required to finally decide which one is better suited for a given application. The testing process is itself challenging because these devices are expensive and each of the mentioned manufacturers has its own device-dependent application program interface (API).

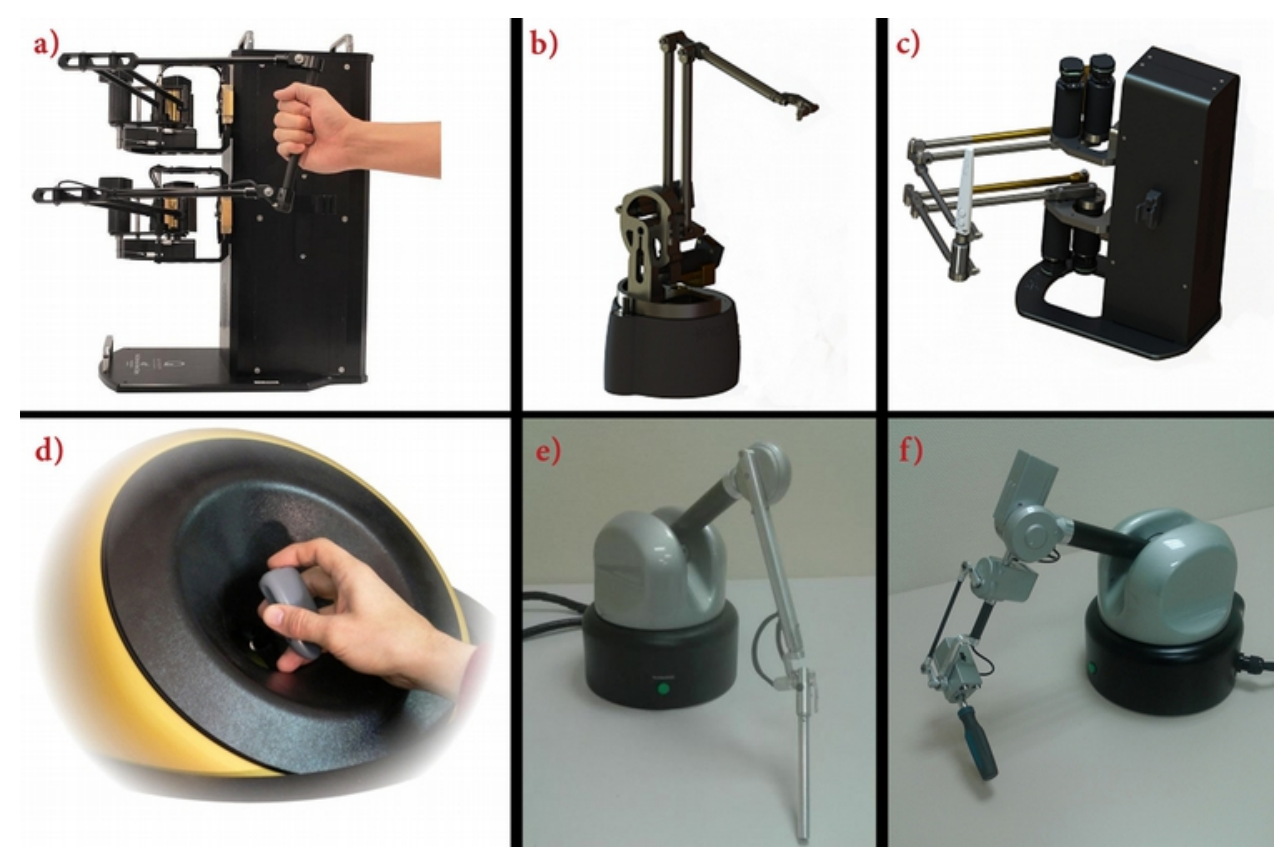

Figure 2.32: Additional examples of haptic devices: a) $H^{2}$ High Definition Haptic Device (Quanser 2015); b) \& c) W3D and W6D devices (Entact 2015); d) Maglev 200 device (Butterfly Haptics 2014); e) \& f) Virtuose $3 D$ and $6 D$ devices (Haption 2015) 


\section{A virtual-reality system with HMD and haptics}

\subsection{Introduction}

As mentioned earlier, the main objective of this research was to develop a proof-of-concept system which combines both HMD and haptics. The system setup of our prototype is shown in Figure 3.1. We tested our prototype with anatomical models as a simple preliminary test case. In the following sections of this chapter we will cover the system components, configuration and implementation.

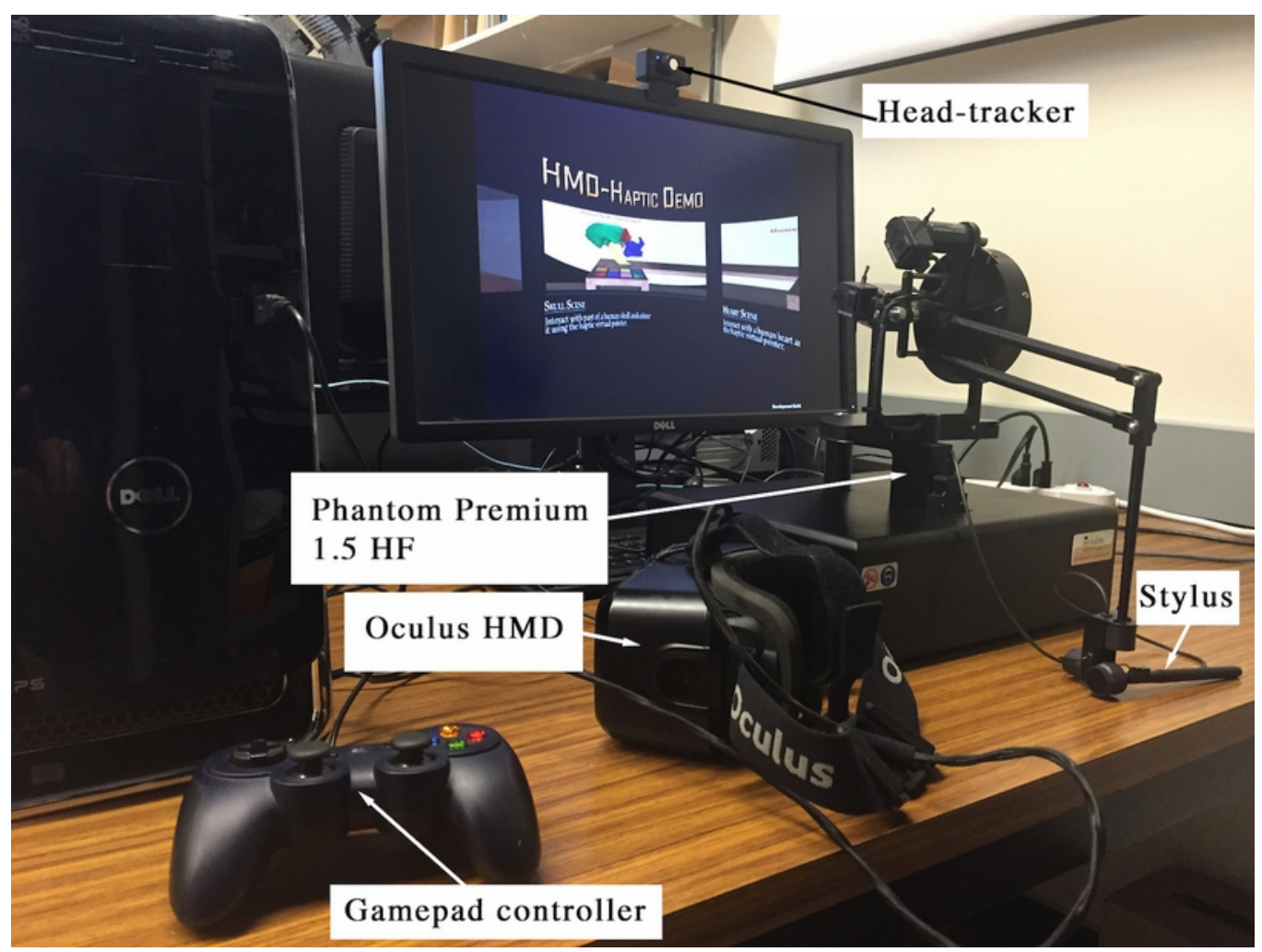

Figure 3.1: System setup showing the main components: the Phantom Premium 1.5 HF haptic device, the Oculus HMD, the gamepad controller, the head-tracker and the haptic stylus. 


\subsection{System components}

\subsubsection{Haptic device}

Haptic devices already available in the lab included a Novint Falcon, a Phantom Premium 1.5 High Force and an MPB Freedom 7S. The Phantom device (Figure 3.2) was selected for this project because it is in the middle of the range in terms of performance and price as discussed in section 2.3 .7 , and because it is compatible with the Unity game engine that we adopted for developing the system. This device includes a stylus with a switch and provides 6 DOFs in both position sensing and force feedback.

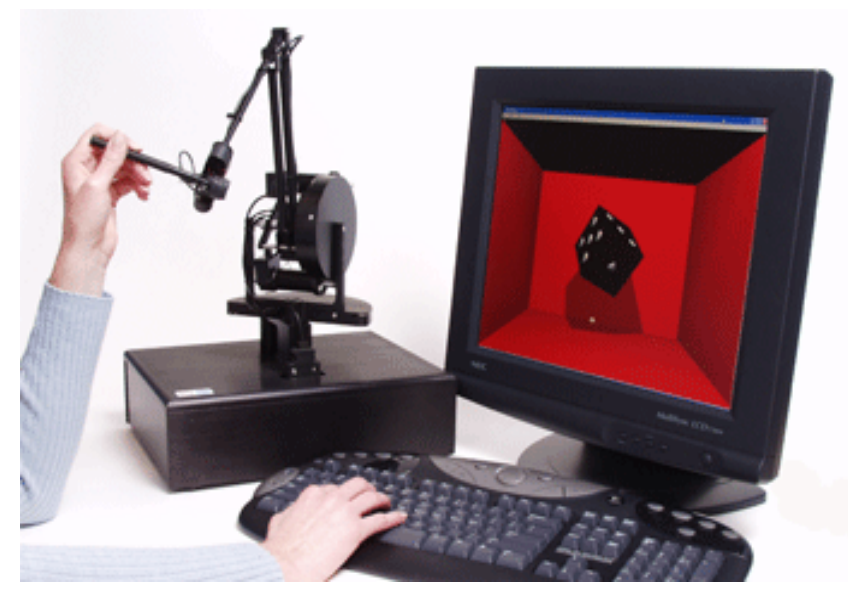

Figure 3.2: Phantom Premium 1.5 High Force haptic device (Geomagic 2015)

\subsubsection{Head-mounted display}

The Oculus Rift Development Kit 2 (DK2) HMD is another major component of this system. We bought it in 2015 as a developer version for 350 USD. It has a resolution of $1920 \times 1080(960 \times 1080$ per eye), a maximum refresh rate of $75 \mathrm{~Hz}$ and a head-position tracker (Figure 3.3). 
Being a recent product, its software development kit (SDK) and engine integration plugin are still in the beta version. We started with the Oculus SDK for Windows version 0.6.0.1-beta and its corresponding Unity integration version 0.1.0-beta. The latter was known for its instability and caused the system to crash several times when we were using it. In August 2015 we updated the SDK to version 0.7.0.0-beta, followed by Unity integration version 0.1.2.0-beta in October 2015. With this version we still experienced some system crashes but it was more stable than the previous version. Most recently we switched to SDK version 0.8.0.0-beta with its corresponding engine integration version 0.1.3.0-beta, released around the end of October 2015. This one has the known issue of causing the system to crash when gathering diagnostic logs but otherwise has been solid.

Note that throughout the project we had to update the graphics card drivers with each Oculus release

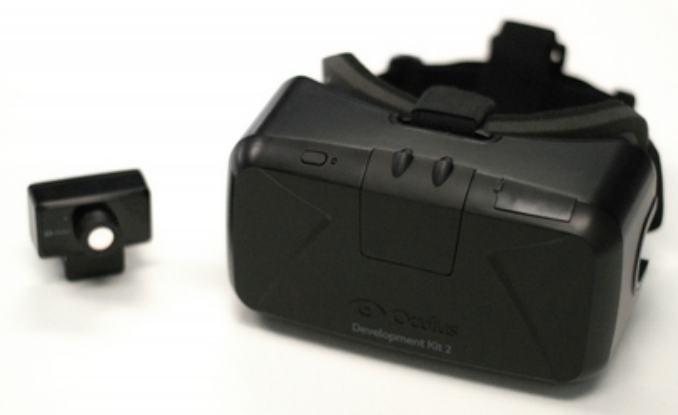

Figure 3.3: Oculus Rift Development Kit 2 (right) with a positional tracker (left) (Oculus 2015).

and we kept checking for new ones to stay up to date with the graphics enhancements. This was done nine times since we started using Unity version 5.

\subsubsection{Game engine}

Unity (2015) is one of the most popular game development platforms on the market today along with Unreal Engine 4 (Epic Games 2015) and CryEngine (Crytek 2015). Unity and Unreal Engine 4 both 
became freely accessible in 2015 and provide support for the Oculus VR HMD, whereas CryEngine offers only a free license for educational purposes and has no support for the Oculus headset. Haptics support was only provided by Unity by means of a haptic plugin for Geomagic devices (Poyade et al. 2014). This plugin is compatible with Geomagic devices and was tested by its authors on the Touch haptic device (formerly known as the Phantom Omni).

From these three engines we selected Unity 5 for being compatible with both Oculus HMD and Geomagic haptic devices and because we were already familiar with its interface, which made it easier for us to import and interact with the 3D models described later in this chapter. Note that Unity 5 was constantly updated after its release in 2015 , with 17 versions from 5.0.0 to 5.3.1, and we had to follow these updates, especially those related to Oculus dependencies upgrades, VR stabilization and performance optimization. These updates were very time consuming and required us to modify a few things in the scene, such as lighting and textures, but without any code changes.

\subsubsection{D models}

In this study, we used a model of part of a skull and a model of a heart (Figure 3.4) processed from the original VRML 2 (“.wrl”) files (Funnell 2015) provided by the "davis3d” (Dynamic Anatomy Visualization in 3-D) project (Funnell 2013). The skull model is based on the female cryosection data obtained from the Visible Human Project (U.S. National Library of Medicine 2015) and was originally generated using locally developed Fie/Tr3 software (Funnell 2015). The heart model is based on a model developed by Christine Siegel at New York University in 1996 (Funnell 2013). 


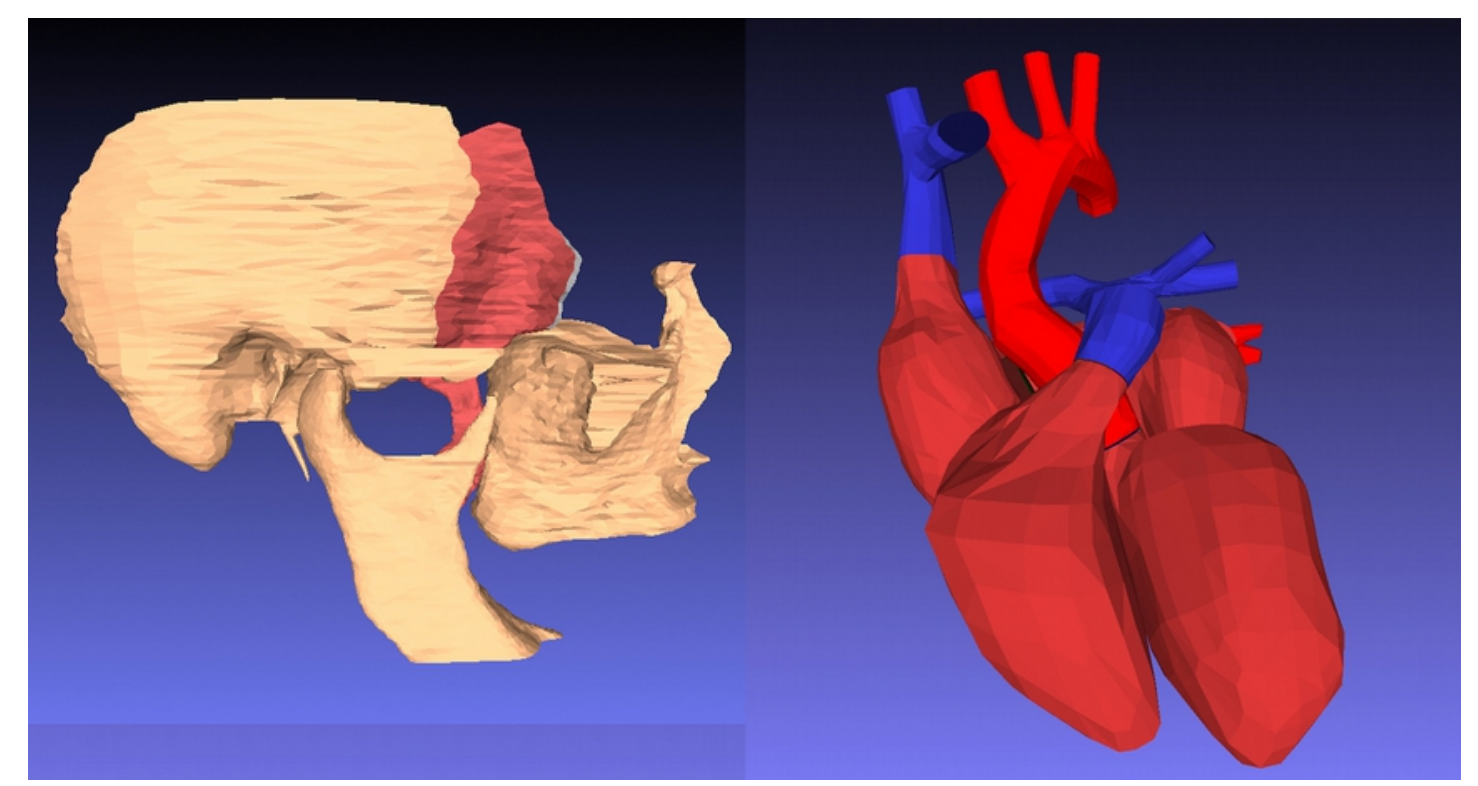

Figure 3.4: Skull model (left) with 35,013 triangles and heart model (right) with 11,812 triangles.

In order to be used within Unity, the original ".wrl" files were exported to ".obj" format using MeshConvert (Min 2015), then to ".fbx" format using FBX Converter software (Autodesk 2013).

These models were simplified using a quadric-based edge-collapse strategy in MeshLab (Cignoni 2014 ) to reduce the numbers of polygons by $70 \%$. For example, the skull model was simplified from 35,013 to 10,501 triangles (without the muscles) and the heart was simplified from 11,812 to 3,543 triangles (Figure 3.5). The need for this simplification will be explained in the evaluation chapter. 


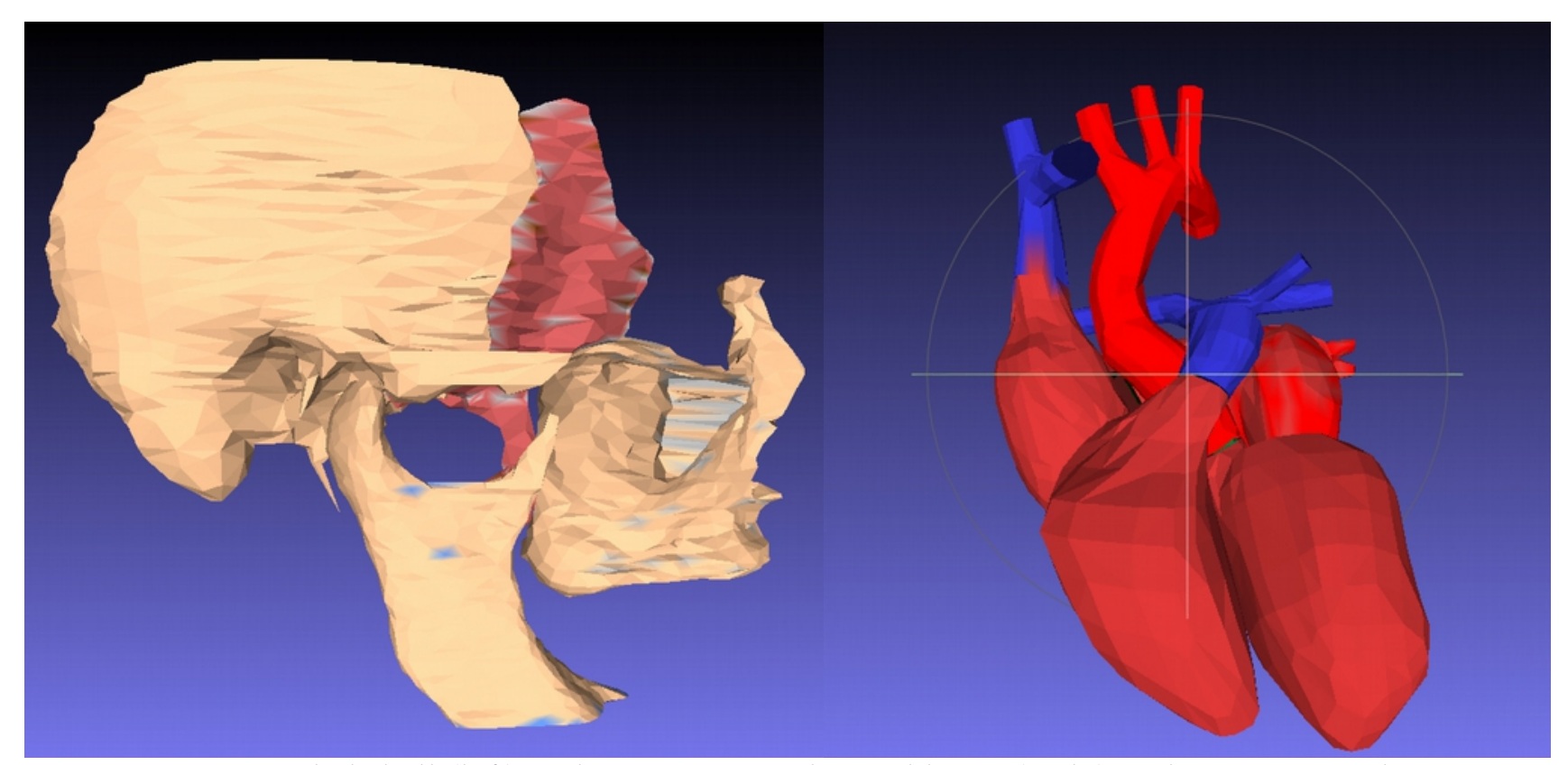

Figure 3.5: Resampled skull (left) with 10,501 triangles and heart (right) with 3,543 triangles.

\subsubsection{Operating system and computer graphics}

We developed the system on a PC running Microsoft Windows 7, configured with an Intel Core 2 Extreme X9650 3.00-GHz CPU, an NVIDIA GeForce GTX 400-series graphics card and 4 GB of RAM. During the testing phase, we switched the graphics card for an NVIDIA GeForce GTX TITAN to meet the Oculus HMD recommended system graphics specification. At the final stage of development, the system was migrated to a new PC running Microsoft Windows 10, configured with an Intel Core i7-6700K 4.00-GHz CPU, an NVIDIA GeForce GTX 960 graphics card, and 24 GB of RAM.

\subsection{Configuration and Implementation}

The system was implemented in C\# under the Unity 3D game engine using two software development tools: (1) Microsoft Visual Studio 2013 while developing under Microsoft Windows; (2) and 
MonoDevelop v5.9.6 while developing under Mac OS. In the following sections we will go through the configuration steps and system implementation.

\subsubsection{Oculus Rift setup}

Setting up the Oculus Rift on a PC requires the following: (1) download the run-time installer from https://developer.oculus.com/downloads to install the Oculus service application, configuration utility and drivers needed for the display and tracker; (2) launch the configuration utility tool to update the DK2 firmware using the Tools menu option in case the firmware shipped with the device is not the latest version; (3) set a user profile and test the Oculus Rift using the Demo Scene found in the utility tool (Figure 3.6).
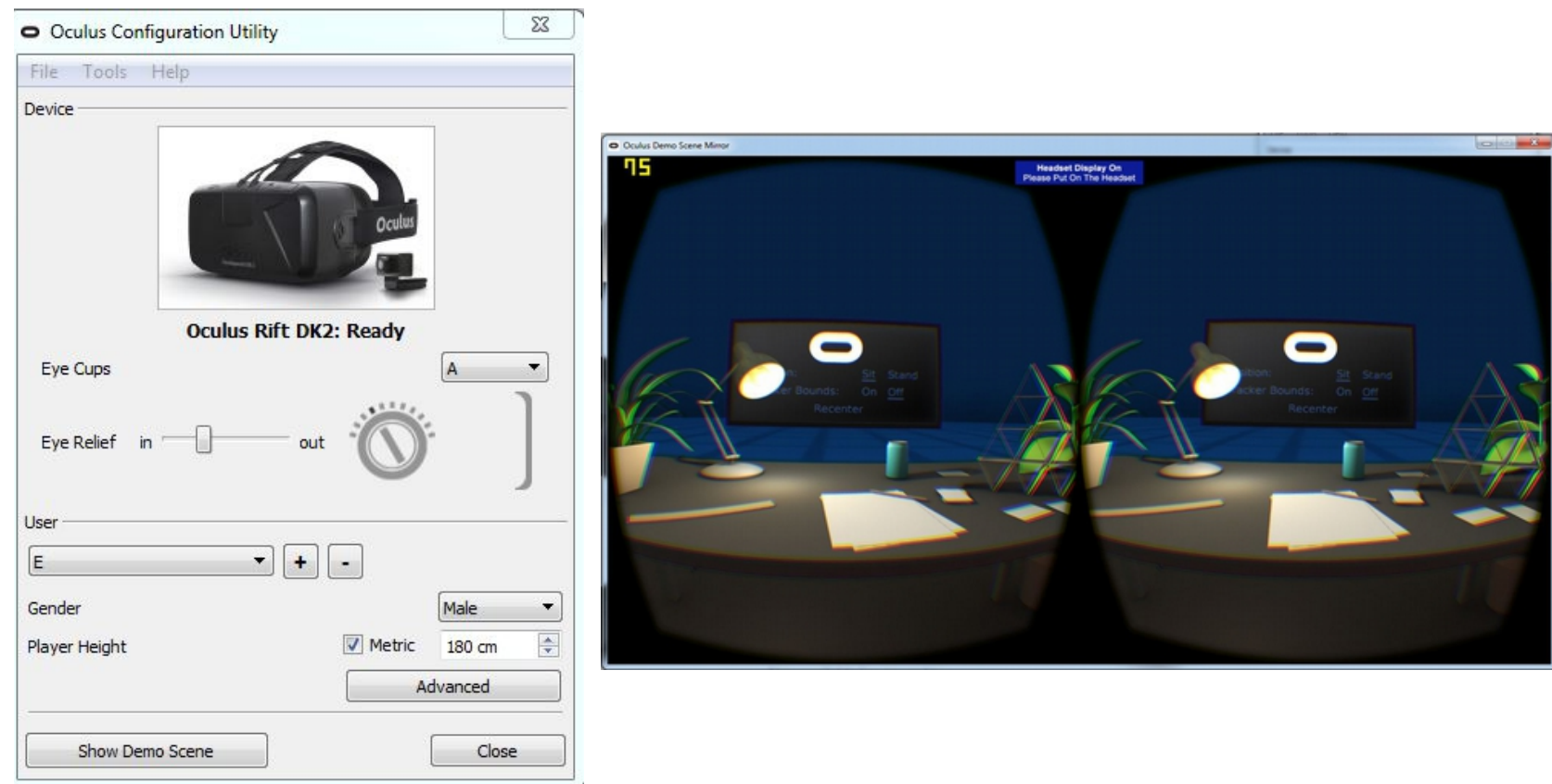

Figure 3.6: Oculus Configuration Utility main screen (left) and Demo Scene running at 75 fps (Right).

Once the Oculus is running properly, the next step is to integrate it in Unity. First, the virtual reality support should be enabled in the Unity project using the Player Settings Configuration tab. Second, the latest Oculus Utilities Package should be downloaded from https://developer.oculus.com/downloads 
and imported into Unity. This package contains basic assets and scripts needed to start using the Rift within the project. In our system we used the OVRPlayerController "prefab" to navigate in the virtual environment using a keyboard and a mouse, which will be explained in the user-interaction section below.

\subsubsection{Phantom Premium 1.5 haptic setup}

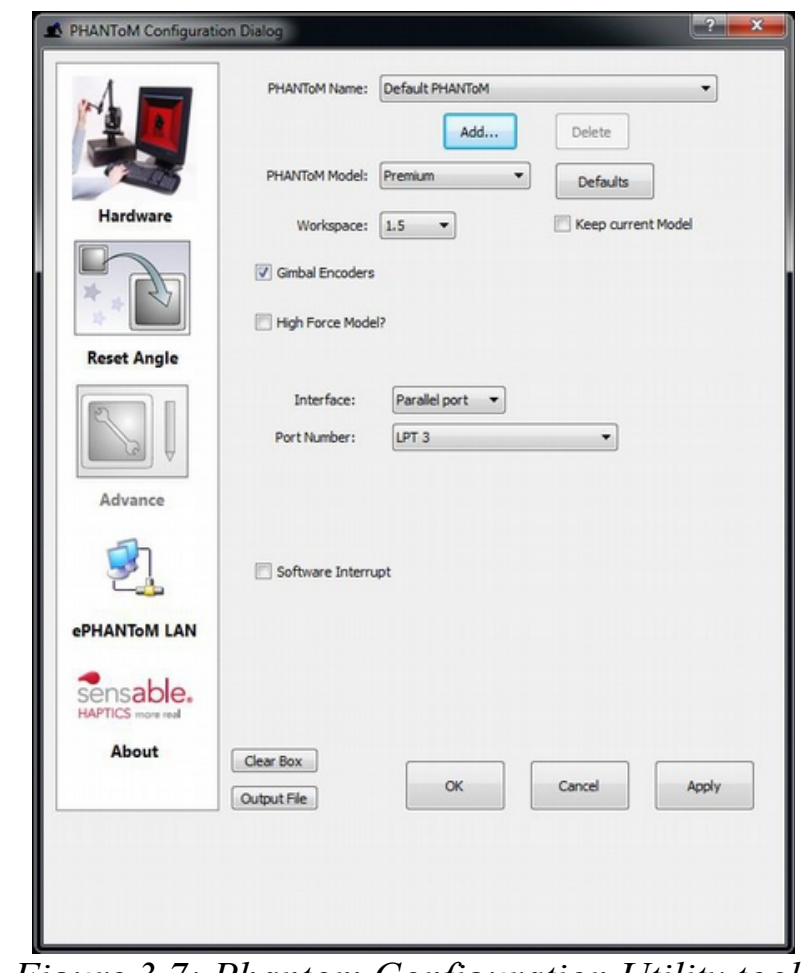

Figure 3.7: Phantom Configuration Utility tool.

First we installed the OpenHaptics toolkit v3.0 along with the required haptic drivers and tools from (OpenHaptics 2015). Then, using the PHANTOM_Configuration tool (Figure 3.7) we set up the device name and specifications. 
Using the provided test tool (Figure 3.8), we tested the machine's basic interactions such as the forcefeedback and the stylus switch. The latter stopped responding partway through the project and we had to use a mouse button instead until the switch started working again, for reasons that are not clear.

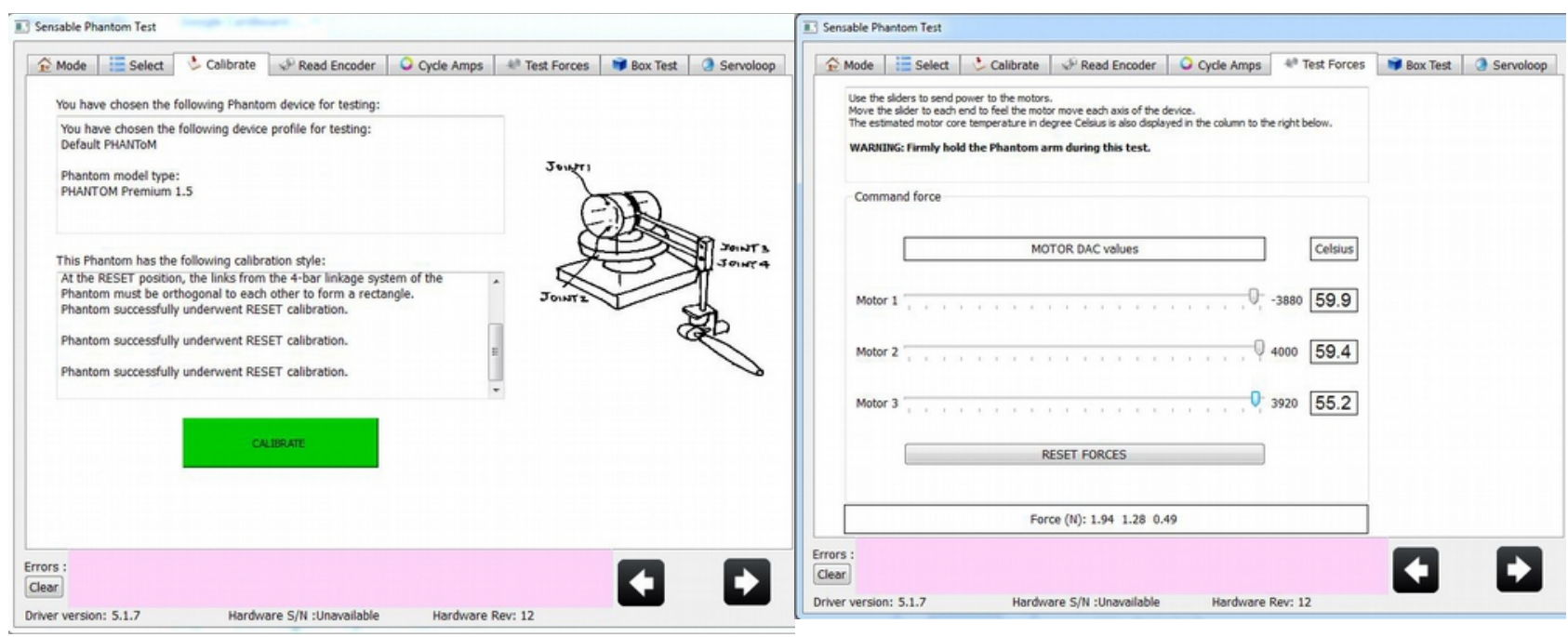

Figure 3.8: Using the Sensable Haptics Phantom test tool to calibrate the device (left) and check its forces (right) among other sanity tests.

As mentioned in the previous section, we used a haptic plugin for Unity (Poyade et al. 2014) to integrate the Phantom device into our system. First we imported the plugin to our project. Then we implemented a controller class (HapticInteractionController) responsible for initializing the haptic interaction and workspace update. Four managers were also implemented (HapticManager, SceneManager, ModelManager and StructureManager) to take care of the haptic interaction along with the scene and structure managements, such as resetting the scene, rotating the model and fading a given structure. A HapticDevice class was also implemented to define the haptic device workspace and mode. Note that the HapticManager and HapticDevice classes were based on the GenericFunctionsClass and HapticDeviceClass provided by the plugin. A UML (Larman 2005) class diagram for the haptic interaction is shown in Figure 3.9. 


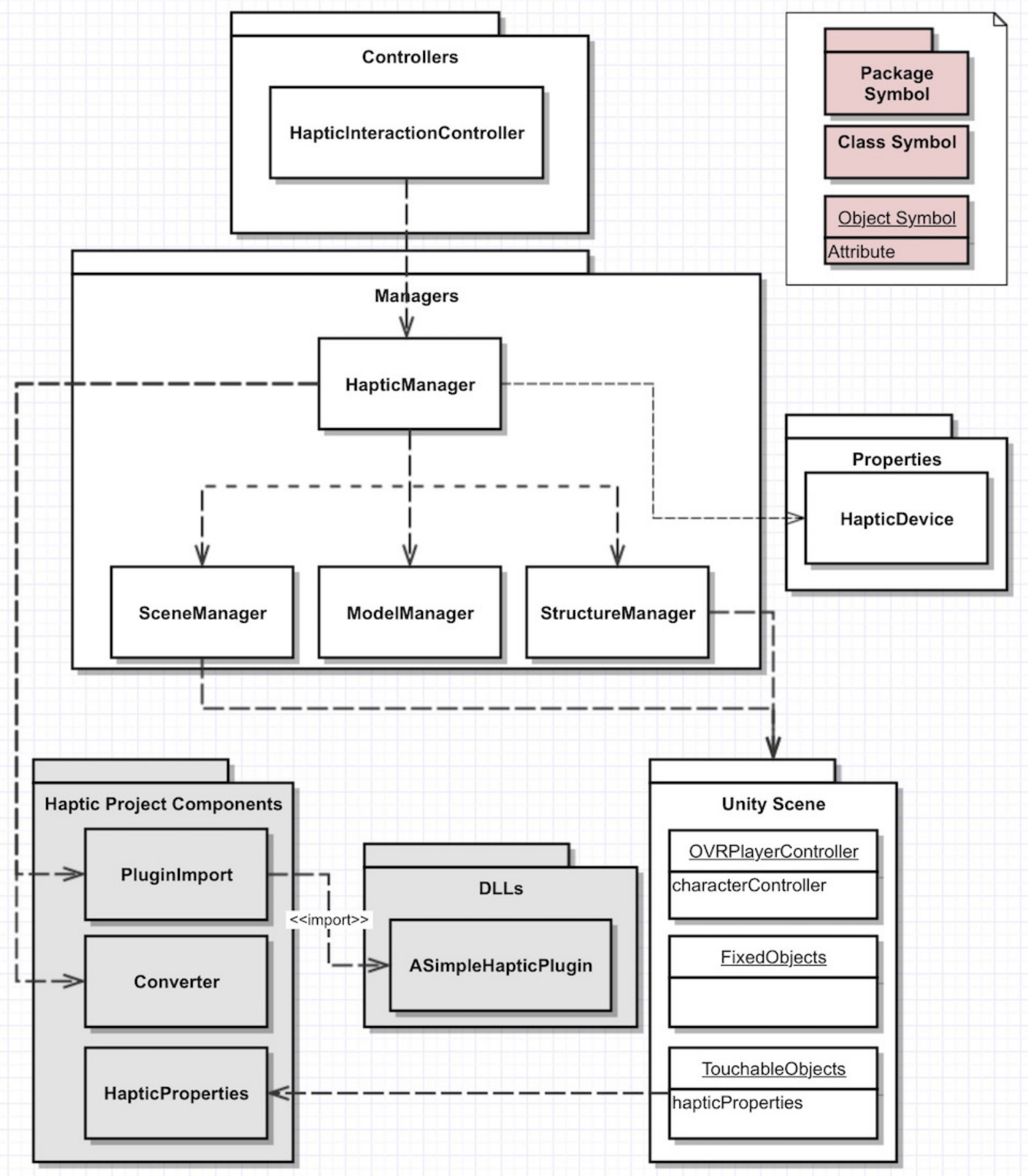

Figure 3.9: UML Class diagram showing the system haptic interaction. Note that the packages with grey background are provided by an external haptic plugin. A legend defining UML symbols is shown on the upper right. 
After successfully integrating and testing the haptic device within our system, we added more functionality related to user interaction, such as displaying the name of the structure touched by the user and changing the colour and shape of the virtual pointer when the haptic stylus button is clicked.

\subsubsection{Scene setup}

The current version of the system starts with a main screen (Figure 3.10) where the user has the option of selecting one of the three available scenes: (1) a sample scene with three simple 3D models as shown in Figure 3.11-A; (2) a skull scene with a 3D model of part of a human skull and a 2D illustrative poster as shown in Figure 3.11-B; and (3) a heart scene with a 3D model of a human heart and a 2D illustrative poster as shown in Figure 3.11-C. Each of these scenes represents a room where the 3D model is placed on a table with a colour palette on the left side and a 2D illustration of the corresponding anatomy on the right side of the scene. The 2D illustration helps in identifying the different structures of the 3D anatomical model and learning their names. By wearing the Oculus Rift HMD, the user becomes immersed in the scene and is able to interact with and colour the 3D model using the haptic device (Figure 3.14).

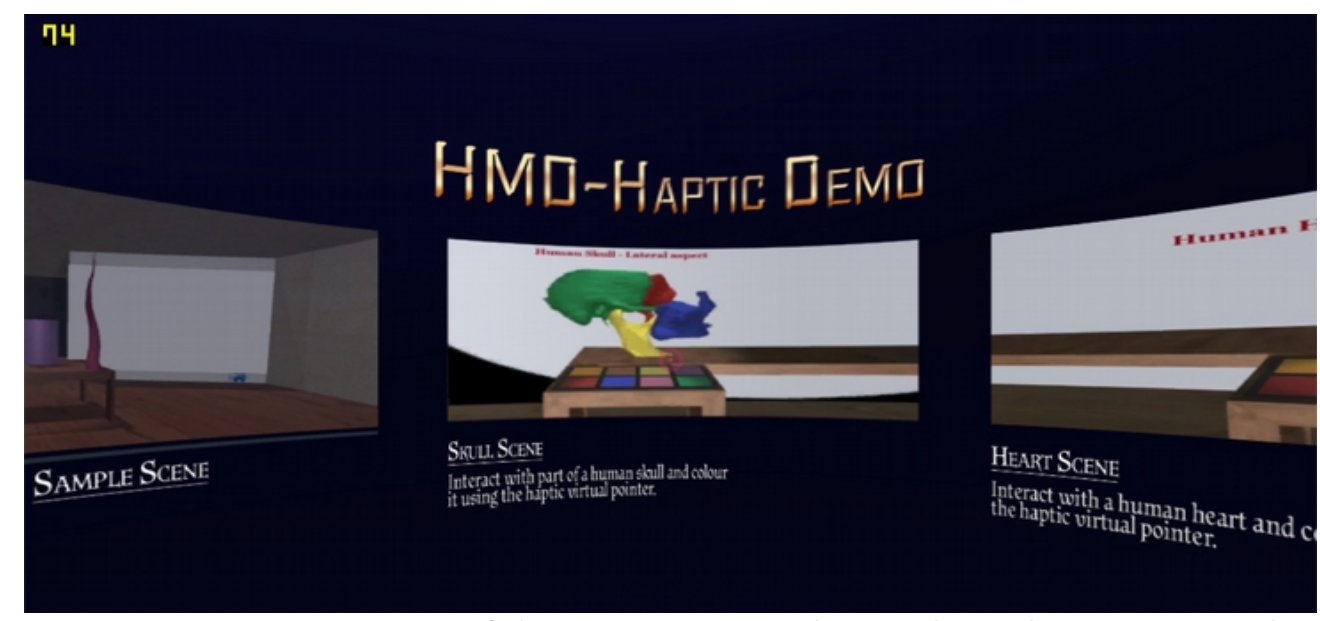

Figure 3.10: Main screen of the HMD-Haptic demo where the user can select the sample scene (left), the skull scene (middle) or the heart scene (right). 

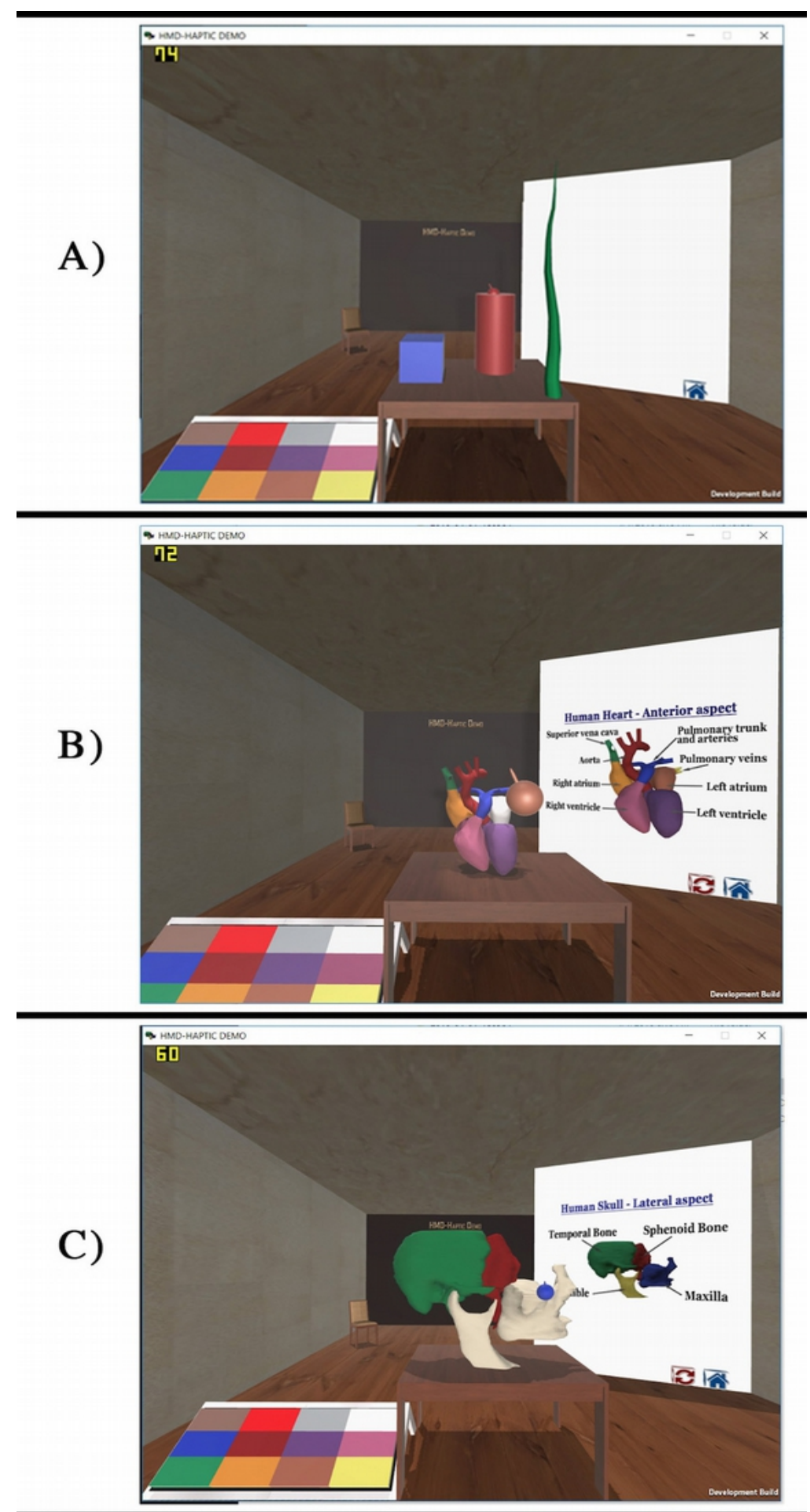

Figure 3.11: The three scenes of the system, each having a colour palette on the left side of the room to colour the model, a table with the 3D models in the middle and a 2D illustration of the corresponding anatomy to the right. A) Sample scene where the user can colour and interact with three simple 3D objects; B) Heart scene where the user can colour and interact with a 3D model of a human heart; C) Skull scene where the user can colour and interact with a $3 D$ model of part of a human skull. 
In previous versions of the system, as seen in Figure 3.12 and some other figures, the 3D model was in the middle with a 2D illustration behind it, which was less convenient, especially since we wanted the user to turn their head and benefit from the HMD's wide field of view. We also tried a scene where the heart and the skull were attached to a 3D human skeleton model. However, having both models in the same scene reduced the system's performance excessively due to the increased number of triangles.
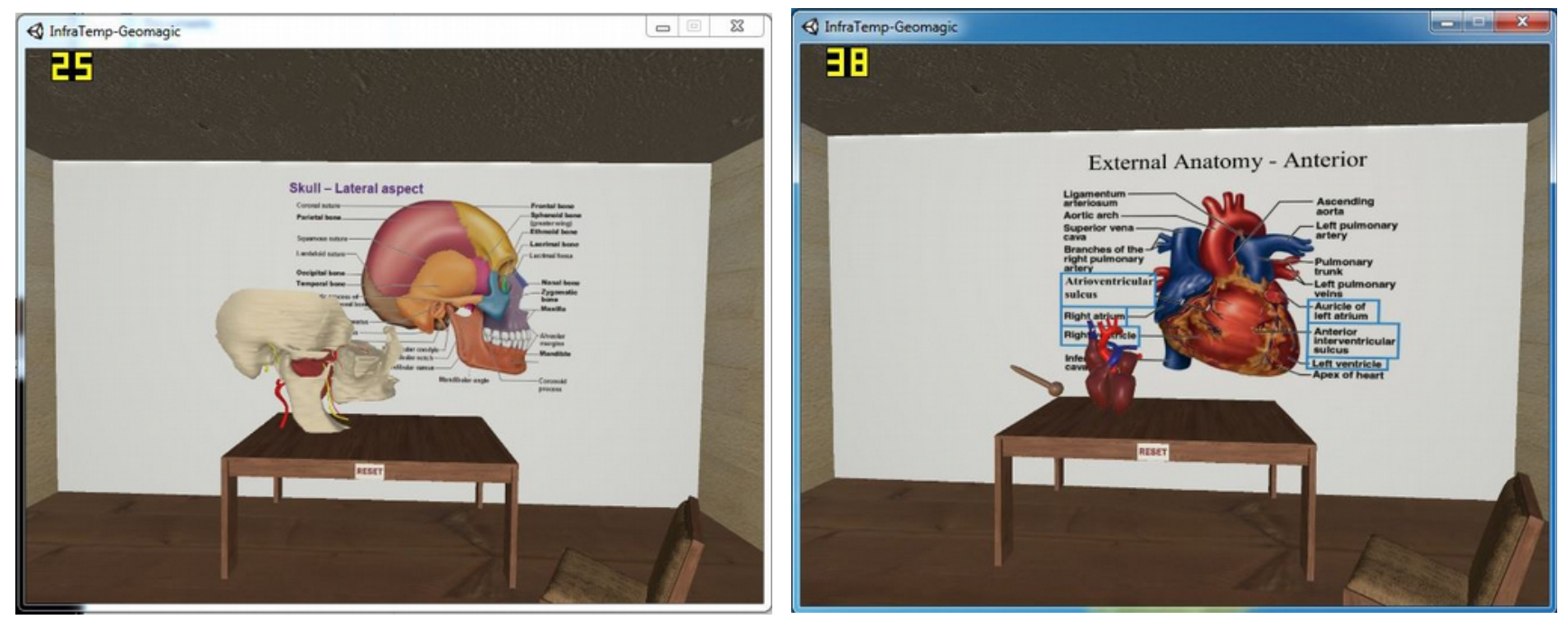

Figure 3.12: Haptic scenes showing the initial 3D models of the skull (left) and the heart (right) with a $2 D$ illustration of their corresponding anatomy. Note the frame rate of $25 \mathrm{fps}$ for the skull model running with 35,013 triangles and 38 fps for the heart model having 11,812 triangles.

When an object is added to the scene, we attach a HapticProperties script to it in order to define the material and object properties needed for haptic interaction such as stiffness, damping, friction and mass. To enable haptic interaction, the object must be tagged as "Touchable". In the current scene we made touchable the 3D model, the colour palette, the walls, the floor, and the refresh and home buttons. The user can disassemble the model (Figure 3.13) and colour each structure by selecting a colour from the palette using the haptic virtual pointer. 


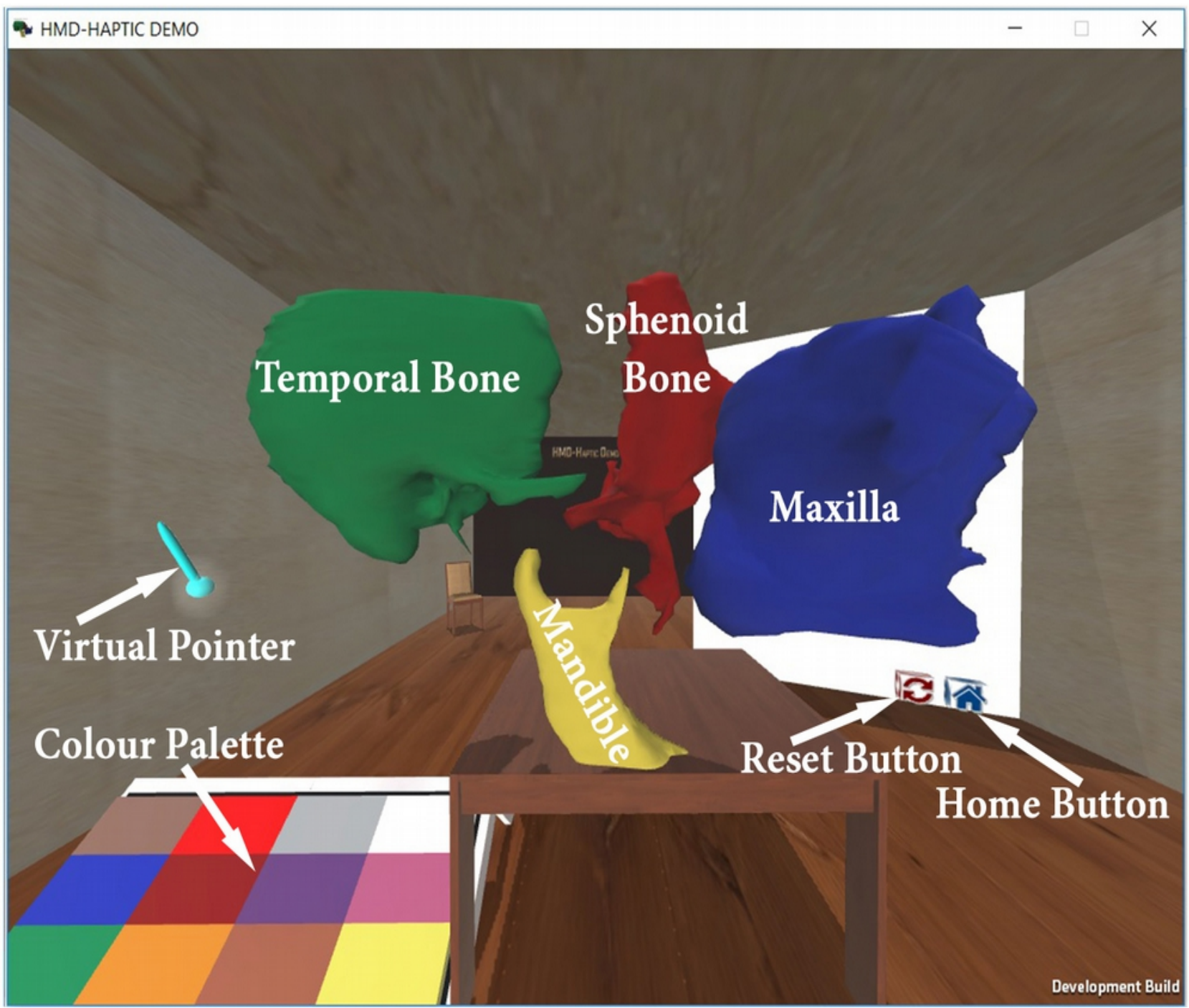

Figure 3.13: 3D skull model disassembled using the haptic device. Note that the names of the structures and other elements in the scene (in white) were manually added on this screenshot. 


\subsubsection{User interaction}

During the system development phase we tried various combinations of mouse buttons, keyboard keys, gamepad controller and the stylus switch for the user interaction. In the final version, the user selects a

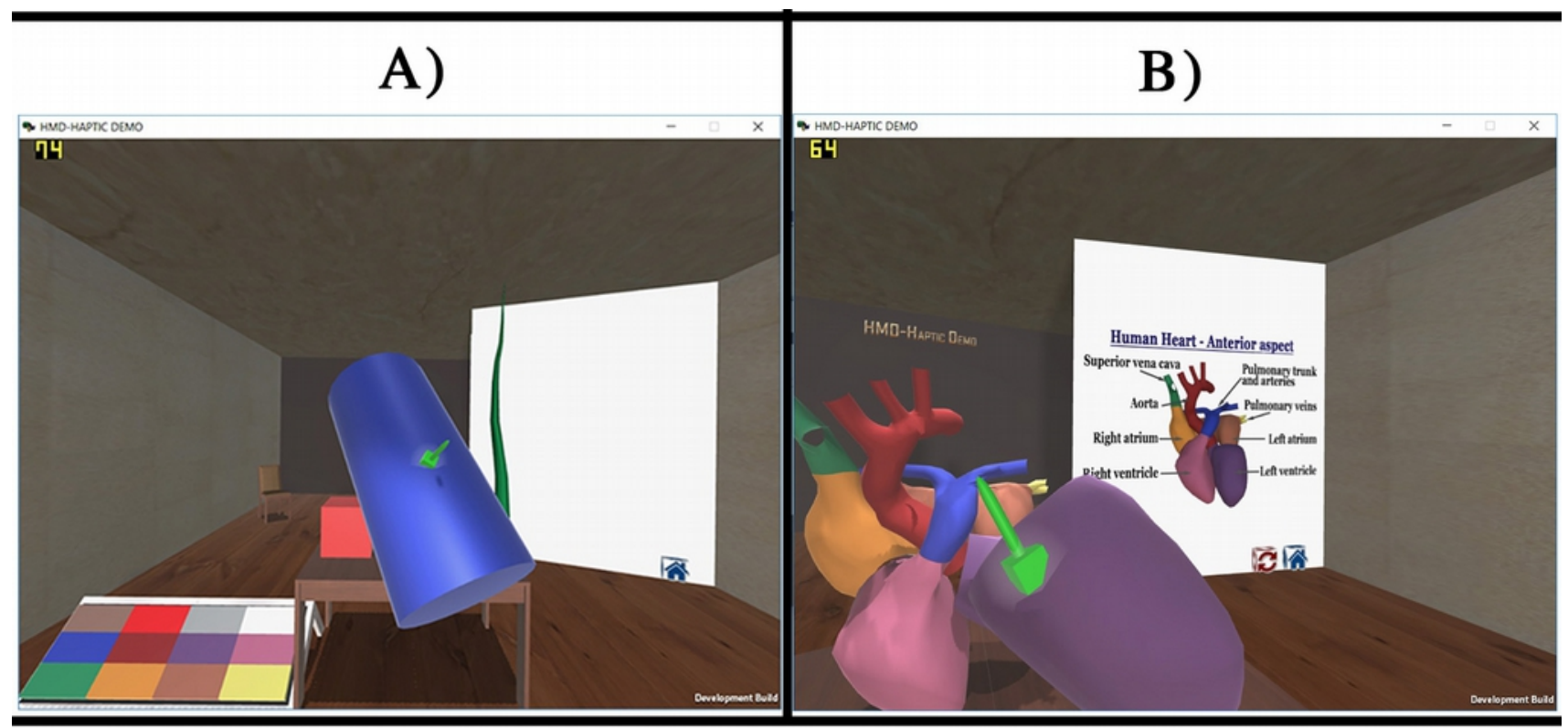

C)

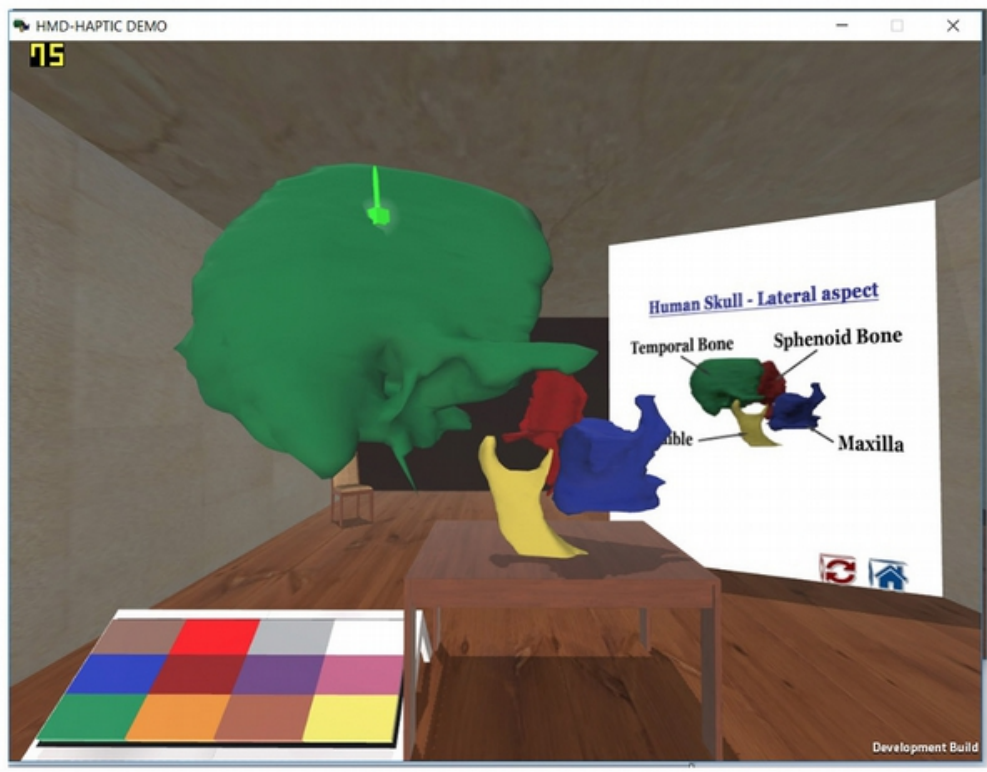

Figure 3.14: Scenes showing the user interaction with A) a cylinder while in the sample scene; B) the left ventricle while in the heart scene; and C) the temporal bone while in the skull scene. 
scene from the main screen by looking at it, thus targeting it using the Oculus HMD, and then clicking on the stylus button. Once inside a given scene, the haptic device is manipulated using the dominant hand to touch the $3 \mathrm{D}$ objects and the gamepad controller is manipulated using the non-dominant hand to move around the scene and rotate the view.

The haptic tooltip is simulated in the scene by a 6 DOF virtual pointer. When the user clicks on the stylus button, the colour of the pointer changes from cyan to green and its shape becomes a cube instead of a sphere. When the user touches an object with the virtual tool and clicks the stylus button, the selected object can be rotated and moved around the scene by moving the stylus in the desired direction (Figure 3.14). To move around the scene in the left, right, forward and backward directions, we use the keyboard's arrow keys or the gamepad controller. Left-right motion is defined by the gamepad controller joystick or the Oculus HMD tracker, which follows the user's head to define the direction of view.

Another option was implemented based on the mouse controls, with moving to the left and right done by clicking the left and right mouse buttons respectively, while moving forward and backward is done using the scroll wheel. This was not found to be easy to use, especially because it felt awkward using the mouse with the non-dominant hand.

At one point we also implemented the feature of fading the untouched structures of the model when the user is interacting with one of them, as shown in Figure 3.15. 


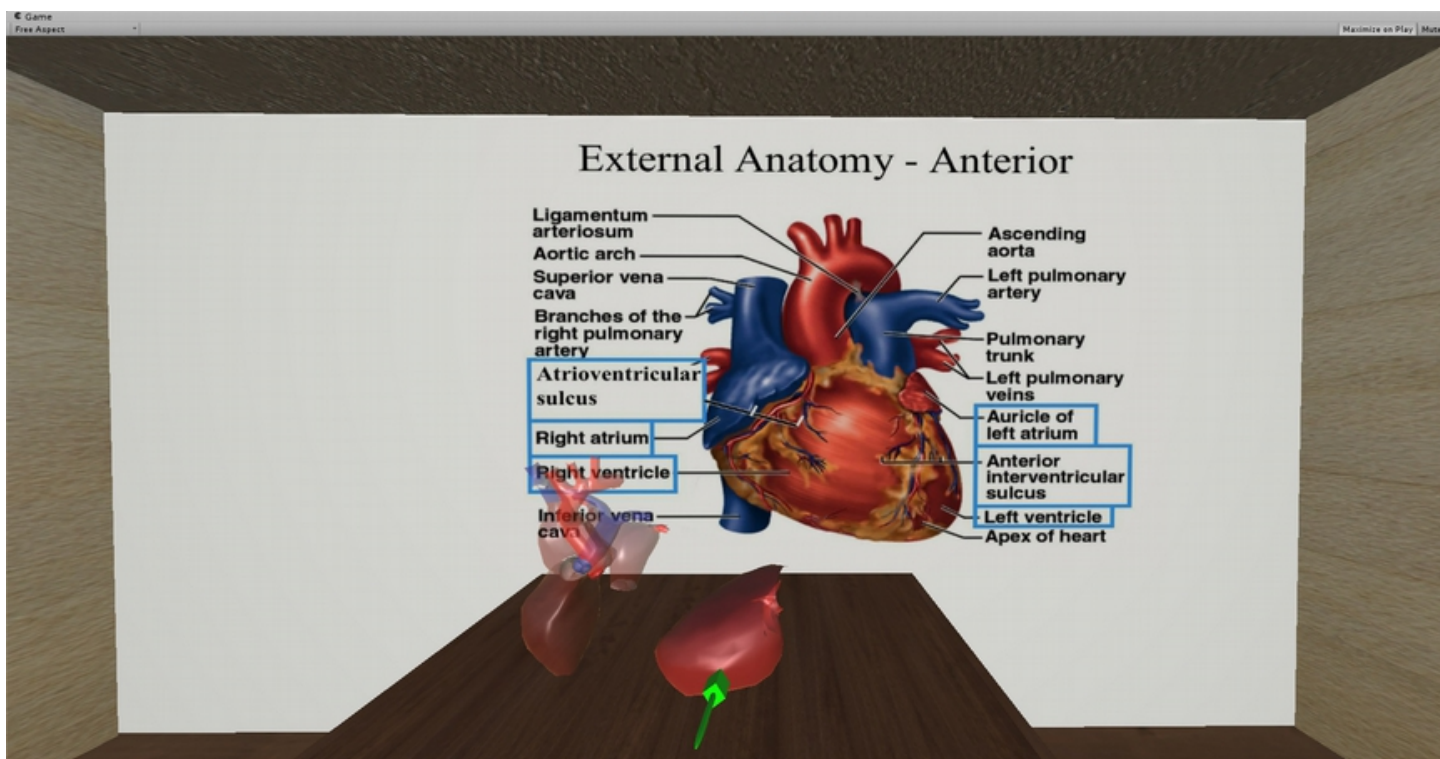

Figure 3.15: Heart scene where the user is interacting with the left ventricle structure while the remaining parts are faded (semitransparent). 


\section{System evaluation and challenges}

This chapter presents a preliminary technical-performance evaluation of the current version of our system and includes a small evaluation of user responses.

\subsection{System performance}

To obtain a good VR experience with a frame rate of 75 frames per second (fps) or more, the Oculus Rift manufacturer recommends the following: (1) an NVIDIA GTX 970 / AMD 290 graphic card or better with a driver version 358.70 or later; (2) an Intel i5-4590 CPU or better; (3) at least 8 GB of RAM; and (4) Windows 7 or a later version.

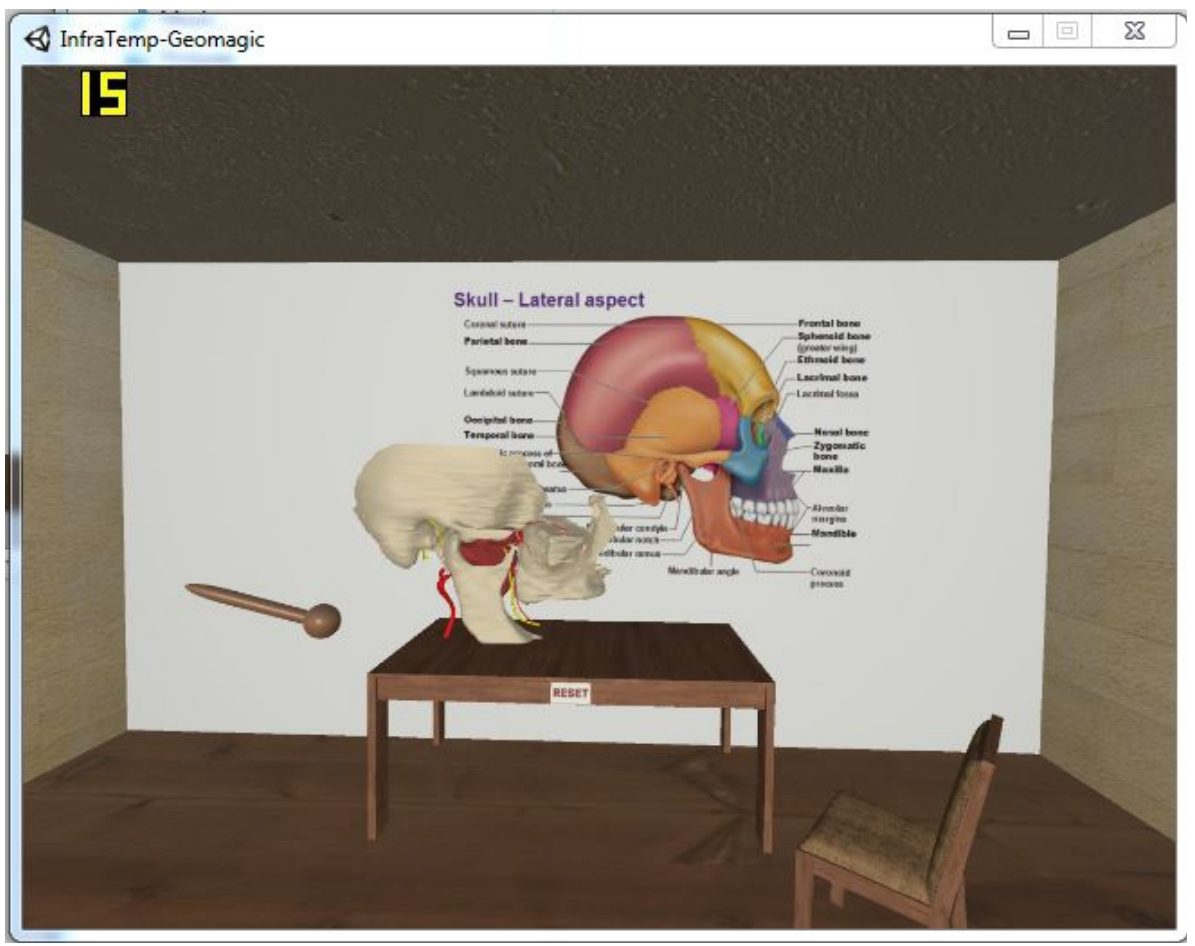

Figure 4.1: Frame rate of 15 fps when interacting with the skull model (35,021 triangles) on a PC with NVIDIA GTX 400 series graphics card. 
The PC initially used to develop and test our system did not satisfy the Rift recommendations. As we mentioned in section 3.2.5, it has an Intel Core 2 extreme CPU, a NVIDIA GTX 400 series graphics card and 4 GB of RAM.

Using Fraps, a real-time video-capture utility (Fraps 2013), we recorded the frame rates while testing the system. The rate was around 65-70 fps when using the Oculus without the Phantom Premium, and 80-90 fps when interacting with the haptic device only. However, when combining both the HMD and the haptic device, the rate was lower than what is recommended by the Rift. It went down to 15 fps when interacting with the system using complex models such as the skull (Figure 4.1) with 35,013 triangles (not counting the muscles and the arteries). The system was also tested with a heart model having 11,812 triangles which resulted in a frame rate of 25-30 fps. Testing the system using a much simpler model, such as a cube for example, resulted in only 60-65 fps, which is still lower than what is required for a good VR Rift experience with smooth interactions.
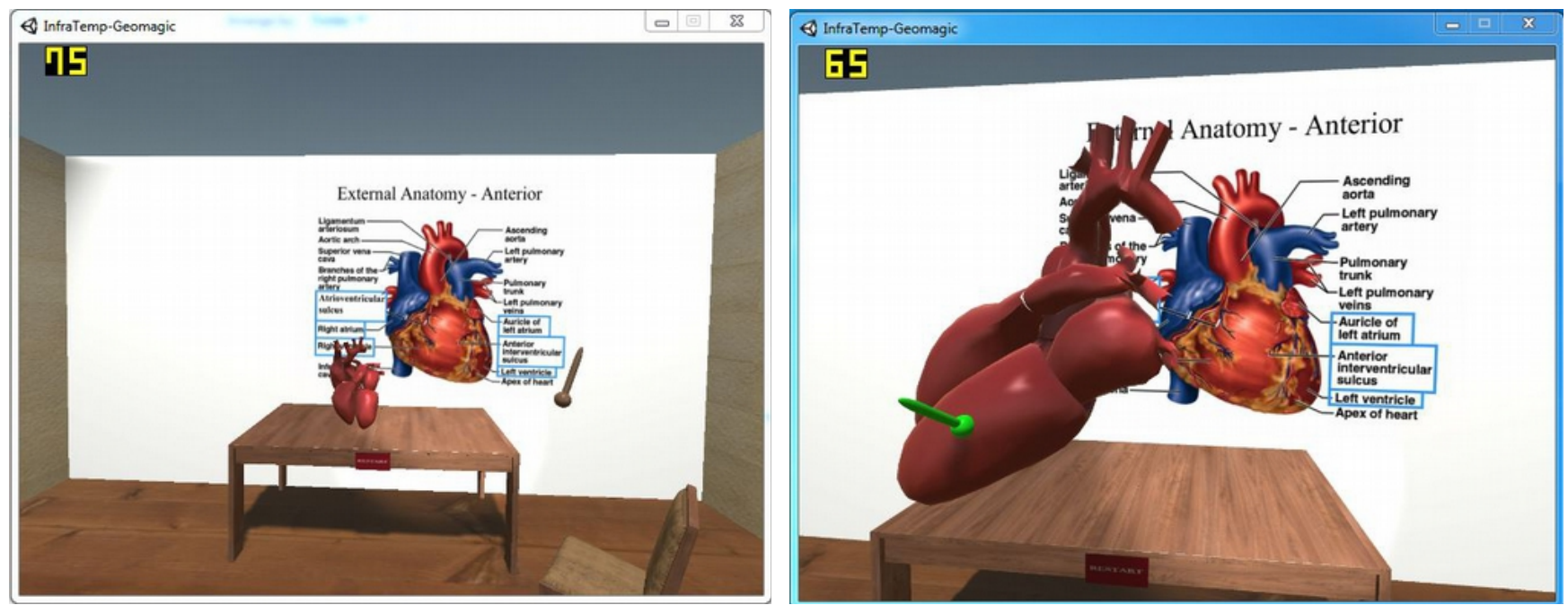

Figure 4.2: Sample scenes showing the resampled heart 3D model (3,543 polygons) with a 2D illustration of the heart anatomy in the back and a haptic tooltip which changes colour to green (right) when the user clicks on the haptic stylus button. Note the frame rate of $75 \mathrm{fps}$ (left) which goes down to $65 \mathrm{fps}$ when interacting with the heart using the haptic device (right). 
A second set of tests was done in January 2016 using the same PC but with an NVIDIA GTX TITAN graphics card. By running the Rift compatibility tool for Windows, we found that the graphics card now met the Rift requirements while the CPU and memory did not.

With this new configuration, for models with 3,500-4,000 triangles (Figure 4.2) or less, the frame rate went up to 70-75 fps, which matches the desired Oculus Rift frame rate. Increasing the number of triangles to 5,000-6,000 lowered the frame rate to $50 \mathrm{fps}$, lower than the desired rate.

Complex models such as the skull, with 35,013 triangles, are clearly not a good fit for the system using the PC we currently have. For the simplified skull with 10,521 triangles, the frame rate was around 3035 fps as shown in Figure 4.3.
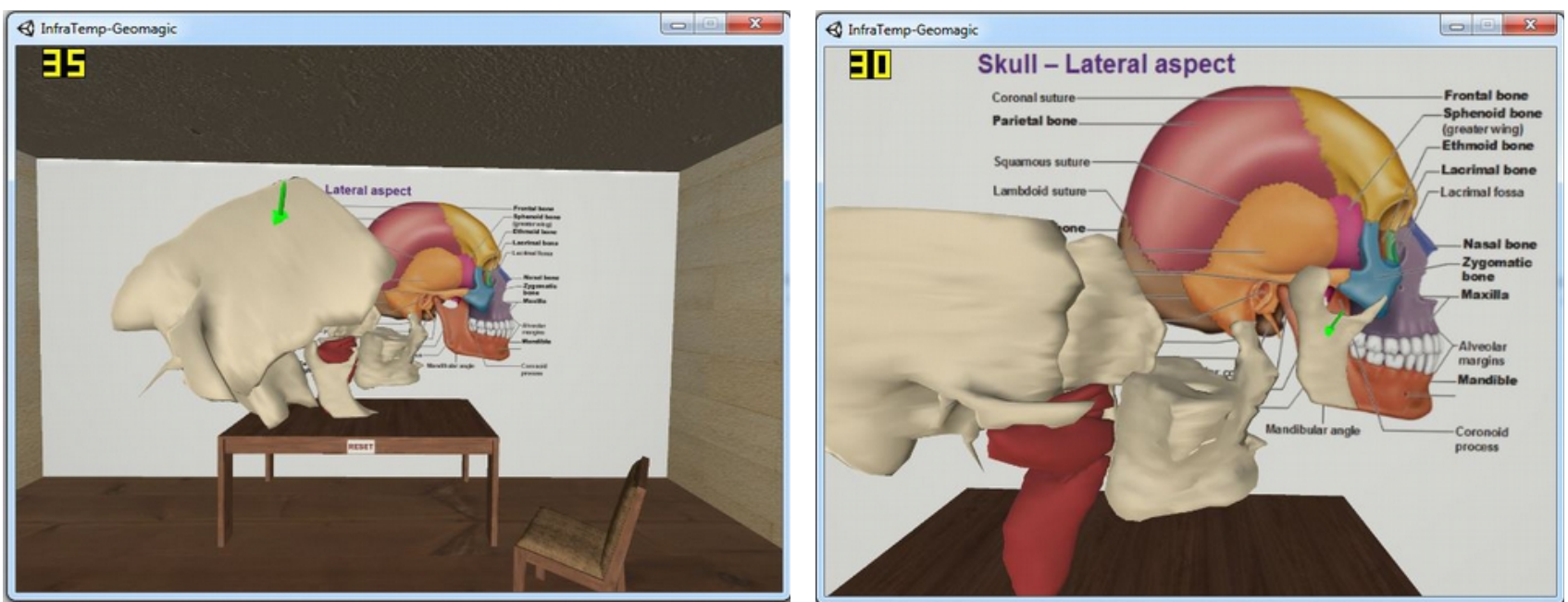

Figure 4.3: Scenes showing the user interaction with the temporal bone (upper image) and the mandible (lower image) of the $3 D$ simplified skull model using the haptic virtual pointer (in green). Note that the skull model used in this scene was simplified to 10,501 triangles which led to a frame rate of 30-35 fps.

The heart model, on the other hand, has fewer triangles to start with and, after simplifying it from 11,812 to 3,543 triangles, the frame rate was $75 \mathrm{fps}$ when starting the system and $65 \mathrm{fps}$ when interacting with the heart using the haptic device (Figure 4.2). 
In March 2016, we ran a new set of tests after migrating the system to a brand new and more powerful PC, as mentioned in section 3.2.5. Even though the graphics card of this PC, an NVIDIA GTX 960, did not satisfy the Rift requirements, the resulting frame rate was good, ranging from 60 to 75 fps when interacting with the 3D models (Figure 3.11 and Figure 3.14).

\subsection{User evaluation}

After achieving these acceptable results on the new system, we recruited five undergraduate students, who had previously taken or were taking a first-year visceral-anatomy course, to conduct a preliminary user evaluation. Two of these students were enrolled in the Physiotherapy program, two in the Kinesiology program and one in the Occupational Therapy program. The study was approved by the Institutional Review Board of McGill University (study number A04-E31-14A). Each participant signed a consent form (Appendix A) before interacting with the system. We then presented the system components using a fixed set of instructions (Appendix B). The participant started by interacting with simple 3D models to get used to the system, as shown in Figure 3.11-A and Figure 3.14-A. They were then directed to the heart scene where they had to do three timed tasks: (1) colour the heart model according to a 2D illustration on the right side of the scene (Figure 3.11-B); (2) interact with the heart by selecting a structure and moving it closer to their eyes, rotating it and then placing it back (Figure 3.14-B); and (3) moving around the scene using the gamepad controller. After completing the timed tasks, they were presented with a user-evaluation questionnaire (Appendix C). Following this, the participant was provided with the option of trying the skull scene (Figure 3.11-C and Figure 3.14-C), a more complex scene with a higher number of triangles that requires a more powerful $\mathrm{PC}$ and might cause simulation sickness related to a variable frame rate. 
As shown in Table 7, the participants reported that they use printed media along with lectures and seminars more frequently than 3D models and videos for learning anatomy. All participants reported having previously used 3D models, but only one participant reported monthly interaction with such models. All five participants agreed that a learning method based on 3D models could help them in the courses they were taking, especially for visualizing anatomical models and grasping their different structures

Table 7: Questionnaire results: Learning methods for anatomy.

\begin{tabular}{|l|l|l|l|l|l|}
\hline \multirow{2}{*}{ Learning method } & \multicolumn{4}{|c|}{ Frequency of use } \\
\cline { 3 - 6 } & Never & Seldom & Monthly & Weekly & \multicolumn{1}{c|}{ Daily } \\
\hline Printed media (books, magazines, etc.) & & & & P2 - P4 - P5 & P1 - P3 \\
\hline Digital media (ebooks, etc.) & & P1 & P3 & P2 - P4 - P5 & \\
\hline Lectures and seminars & & & & P3 - P4 & P1 - P2 - P5 \\
\hline Videos (Youtube, etc.) & & P4 & P1 - P5 & P2 - P3 & \\
\hline $\begin{array}{l}\text { 3D models (Anatomy TV, VisibleBody, } \\
\text { etc.) }\end{array}$ & & P1 - P2 - P3 - & P5 & & \\
\hline Other (please specify): & & & & & \\
\hline
\end{tabular}

Table 8 shows that participant daily computer use consists primarily of email, social media (Facebook, Twitter, Instagram, etc.), learning and Internet browsing. Only one participant reported daily computer use for playing games. The remaining participants either seldom or never use a computer for gaming purposes, indicating that they may have had little to no experience with interactive 3D scenes. Table 9 shows that (1) none of the participants have ever used a haptic device and a HMD; (2) participants three and four have never used a gamepad controller; and (3) participants two, four and five have never used 3D glasses for interacting with 3D models. 
Table 8: Questionnaire results: Computer use

\begin{tabular}{|c|c|c|c|c|c|}
\hline \multirow{2}{*}{ Computer used for: } & \multicolumn{5}{|c|}{ Frequency of use } \\
\hline & Never & Seldom & Monthly & Weekly & Daily \\
\hline Internet browsing & & & & P1 & $\begin{array}{l}\mathrm{P} 2-\mathrm{P} 3-\mathrm{P} 4- \\
\mathrm{P} 5\end{array}$ \\
\hline Emailing & & & & & $\begin{array}{l}\mathrm{P} 1-\mathrm{P} 2-\mathrm{P} 3- \\
\mathrm{P} 4-\mathrm{P} 5\end{array}$ \\
\hline $\begin{array}{l}\text { Social media (Facebook, Twitter, } \\
\text { Instagram, etc.) }\end{array}$ & & & & & $\begin{array}{l}\mathrm{P} 1-\mathrm{P} 2-\mathrm{P} 3- \\
\mathrm{P} 4-\mathrm{P} 5\end{array}$ \\
\hline Playing games & P5 & $\mathrm{P} 1-\mathrm{P} 2-\mathrm{P} 3$ & & & P4 \\
\hline Research & & & P1 & $\begin{array}{l}\mathrm{P} 2-\mathrm{P} 3-\mathrm{P} 4- \\
\mathrm{P} 5\end{array}$ & \\
\hline Learning & & & & & $\begin{array}{l}\mathrm{P} 1-\mathrm{P} 2-\mathrm{P} 3- \\
\mathrm{P} 4-\mathrm{P} 5\end{array}$ \\
\hline $\begin{array}{l}\text { Watching videos and movies for } \\
\text { entertainment }\end{array}$ & & & & $\begin{array}{l}\mathrm{P} 1-\mathrm{P} 2-\mathrm{P} 3- \\
\mathrm{P} 5\end{array}$ & P4 \\
\hline Video Conference (Skype, etc.) & & $\mathrm{P} 1-\mathrm{P} 3-\mathrm{P} 5$ & & P2 & P4 \\
\hline
\end{tabular}

Table 9: Questionnaire results: Previous interaction with 3D models

\begin{tabular}{|c|c|c|c|c|c|}
\hline \multirow{2}{*}{ Tools for interacting with 3D models } & \multicolumn{5}{|c|}{ Frequency of use } \\
\hline & Never & Seldom & Monthly & Weekly & Daily \\
\hline Conventional mouse & & $\mathrm{P} 3-\mathrm{P} 4-\mathrm{P} 5$ & & & $\mathrm{P} 1-\mathrm{P} 2$ \\
\hline Gamepad controller & $\mathrm{P} 3-\mathrm{P} 4$ & $\mathrm{P} 1-\mathrm{P} 5$ & $\mathrm{P} 2$ & & \\
\hline Haptic device (please specify): & $\begin{array}{l}\mathrm{P} 1-\mathrm{P} 2-\mathrm{P} 3- \\
\mathrm{P} 4-\mathrm{P} 5\end{array}$ & & & & \\
\hline 3D glasses (please specify): & $\mathrm{P} 2-\mathrm{P} 4-\mathrm{P} 5$ & $\mathrm{P} 1-\mathrm{P} 3$ & & & \\
\hline $\begin{array}{l}\text { Head-mounted display (please } \\
\text { specify): }=\end{array}$ & $\begin{array}{l}\mathrm{P} 1-\mathrm{P} 2-\mathrm{P} 3- \\
\mathrm{P} 4-\mathrm{P} 5\end{array}$ & & & & \\
\hline
\end{tabular}

The questionnaire results for the system evaluation presented in Figure 4.4 show that all five participants had positive feedback based on their experiences interacting with the system. Participants agreed that the system is useful and easy to use and could be used as a study tool. They also found that it was easy to navigate through the scenes, and that the tasks were clear and easy to understand. Overall, participants were satisfied with the ease of use and the amount of time for completing the tasks. The haptic component was found to be easy to use and easy to learn, and to provide a realistic 
interaction with the $3 \mathrm{D}$ models. As for the HMD component, users mostly agreed that it was easy to perform the tasks while wearing the HMD and that the field of view provided a good virtual-reality experience. However, only one user felt that the HMD's resolution was good enough. Three users felt dizzy after the experiment, which might be related to the amount of time spent interacting with the system while wearing the Oculus HMD; the three users who felt dizzy spent around 15 to 18 minutes each, while the other two spent around 12 and 14 minutes respectively. One of the three also said they had a headache and mentioned that it was caused by having the images too much 'in the face'. We did not attempt to quantify the severity of dizziness or headache.

The task times summarized in Figure 4.5 and Table 10 show that users quickly learned and began interacting with the system components. They were able to understand the system in less than 5.5 minutes and practised with the sample scene for less than 5 minutes. The individual task times for the heart scene are low, which demonstrates that the system is user friendly and easy to learn and use. All but one user spent more than 4.5 minutes interacting with the optional skull scene, signifying that they found the system interesting and engaging.

In the free-text part of the questionnaire, users provided the following written comments and recommendations: (1) the first participant mentioned dizziness ('Felt a little bit dizzy after the task. But overall very helpful and a great experience'); (2) the second participant asked for better resolution and easier rotation in all directions; (3) the third participant suggested adding collision detection between the structures to make the 3D models more realistic, and asked for forcing a slower movement to avoid dizziness while navigating in the scenes; (4) the fourth participant asked for higher resolution and more comfortable HMD which is 'lighter or easier to wear, especially for people with glasses'; and (5) the 
fifth participant suggested not having the images so much 'in the face', which causes dizziness and headache.

In addition to the written comments, one of the participants mentioned the difficulty of finding the haptic pointer in the scene sometimes. Two other participants also mentioned the difficulty of finding the gamepad controller and the haptic stylus while wearing the HMD as it blocks the user's vision.

Even once the user has found the gamepad, interaction with it is still challenging. With the eyes covered by the HMD, the dominant hand is used to manipulate the haptic device and the user is left with the non-dominant hand for using the gamepad controller and/or the keyboard without any visual feedback.

Overall, the data are consistent among the five participants and provide a preliminary indication that the combination of both HMD and haptics can be helpful for interacting with 3D models. However, a more in-depth user evaluation should be conducted to demonstrate the usability and usefulness of such a system for specific applications and as a study tool. 
The anatomical 3D models used are accurate

The Phantom Premium 1.5 Haptic Device was easy to use

The haptic interaction was easy to learn Finding the virtual pointer in the scene was easy Touching the 3D model with the virtual pointer provided a realistic interaction

The head-mounted display (HMD) is comfortable

The field-of-view of the HMD provided a good virtual-reality experience

The resolution of the HMD is good (sharp images, no fuzziness, etc.)

I find it easy to do the tasks while wearing the HMD

I feel dizzy after using the HMD

氠

I have a headache after using the HMD

I feel nauseous after using the HMD

I find it easy to use all system components together...

Overall, I find the system easy to use

It is easy to navigate through the scenes

I quickly learned how to use the system

I would easily become skillful at using such a system

The tasks (colouring, moving objects, etc.) are clear and easy to understand

Overall, I am satisfied with the ease of completing the tasks

Overall, I am satisfied with the amount of time it took to complete each task

If given access to such a system, I would use it as a study tool

Overall, I find the system useful

I would recommend the system to a friend
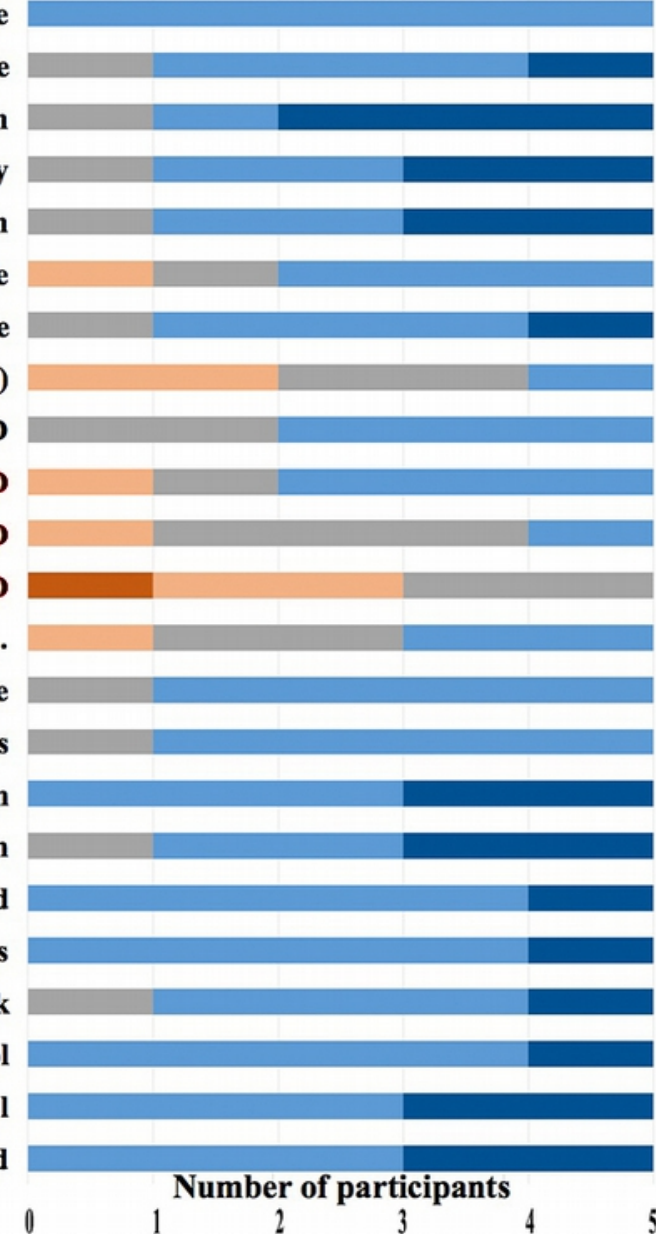

Strongly Disagree $\quad$ Disagree $\square$ Neutral $\square$ Agree $\square$ Strongly agree

Figure 4.4: Questionnaire results for the system evaluation. The three questions in red are those for which agreement indicates a negative response. 


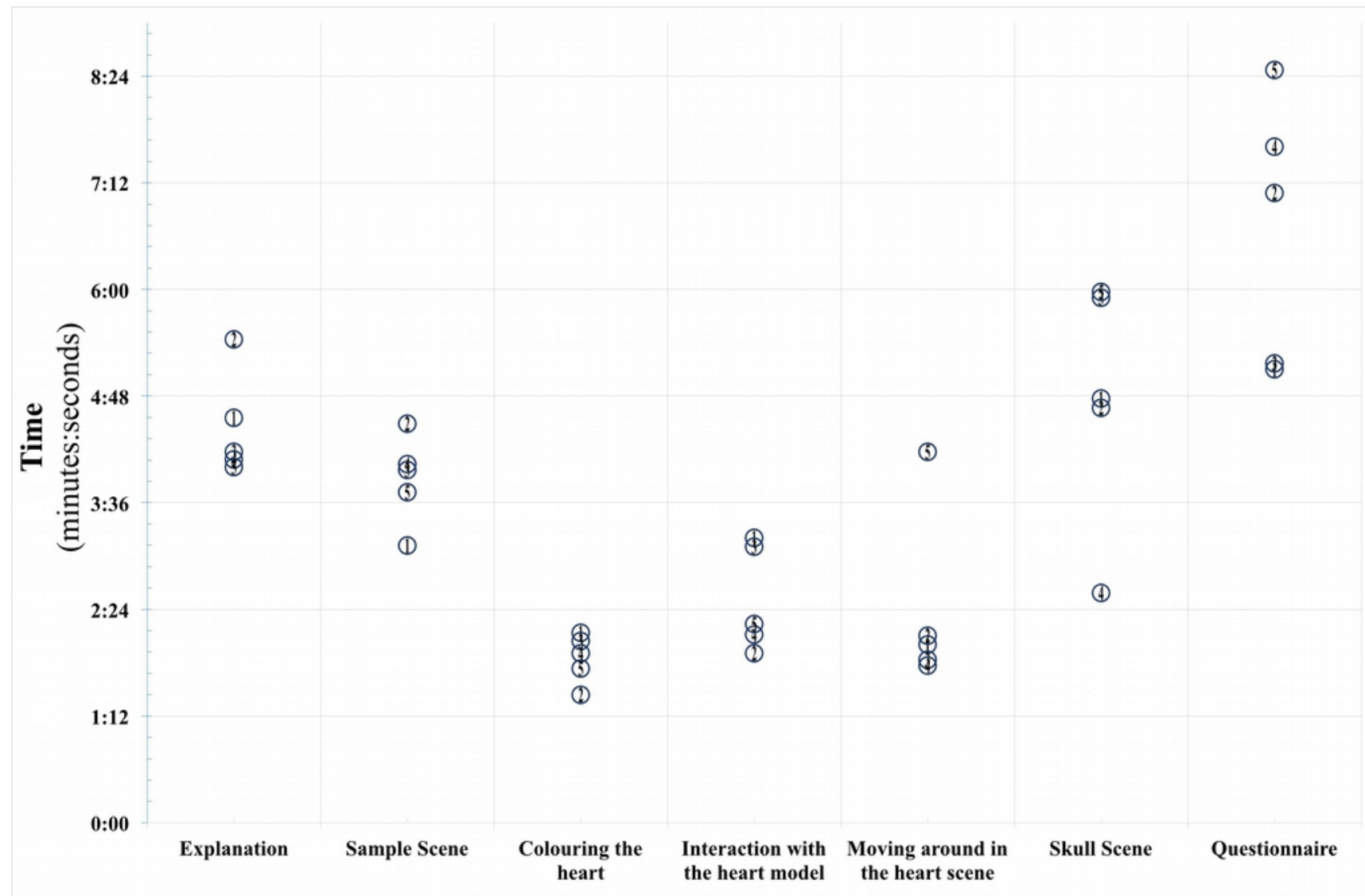

Tasks

Figure 4.5: Timings for completing the tasks for the user evaluation study.

Table 10: Individual times to complete each task for the five participants.

\begin{tabular}{|c|c|c|c|c|c|c|}
\hline \multirow[b]{2}{*}{ Tasks } & & \multicolumn{5}{|c|}{$\begin{array}{l}\text { Timings for five participants } \\
\text { (minutes:seconds) }\end{array}$} \\
\hline & & P1 & P2 & P3 & P4 & P5 \\
\hline \multicolumn{2}{|l|}{ Explanation } & $4: 33$ & $5: 26$ & $4: 10$ & $4: 05$ & $4: 00$ \\
\hline \multicolumn{2}{|c|}{ Sample Scene } & 3:07 & $4: 29$ & 3:58 & 4:02 & $3: 43$ \\
\hline \multirow{4}{*}{ Heart Scene } & Colouring the heart & $2: 08$ & $1: 26$ & 2:02 & $1: 54$ & $1: 44$ \\
\hline & $\begin{array}{l}\text { Interaction with the } \\
\text { heart model }\end{array}$ & $3: 12$ & $1: 54$ & 3:06 & $2: 07$ & $2: 14$ \\
\hline & $\begin{array}{l}\text { Moving around in the } \\
\text { heart scene }\end{array}$ & $2: 00$ & 2:06 & $1: 50$ & $1: 46$ & $4: 10$ \\
\hline & Subtotal time & $7: 20$ & $5: 26$ & $6: 58$ & $5: 47$ & $8: 08$ \\
\hline \multicolumn{2}{|l|}{ Skull Scene } & $4: 46$ & $4: 40$ & $5: 54$ & $2: 35$ & $5: 58$ \\
\hline \multicolumn{2}{|c|}{ Questionnaire } & 5:06 & $7: 05$ & $5: 10$ & $7: 36$ & $8: 28$ \\
\hline \multicolumn{2}{|l|}{ Total time } & $29: 05$ & $32: 50$ & $28: 55$ & $29: 38$ & $32: 45$ \\
\hline
\end{tabular}




\section{Conclusion and future work}

\subsection{Summary}

The senses of vision and touch play major roles in our perception of the objects in our environment. These senses are exploited by HMDs and haptics devices to immerse their users into a virtual environment and provide them with new means of interaction with 3D models besides the conventional keyboard and mouse. The resulting systems are important for many STEM applications which require the virtual world to be as close as possible to the real-world setting in order to create realistic and reliable scenes.

The main contributions of this thesis include an overview of the current state of the marketplace in HMDs and haptics, and a demonstration of the feasibility of combining HMD and haptics in one system. This system was tested with two 3D human anatomical models, a heart and a portion of a skull, as a proof of concept for 3D model visualization and interaction. Users can disassemble and colour the models using the haptic device while being immersed in the virtual environment using the HMD. Our goal was to create an enjoyable setup where the user can play while learning. This presentation of a prototype system provides a preliminary look at user interaction when using both types of device, without trying to prove the usefulness of combining such devices in a specific application.

With the emergence of increasingly powerful computer processors and graphics cards designed specifically for virtual environments, the resulting VR experience is becoming closer to the real-world setting. This can be very useful for education and training purposes. However, the technology behind 
HMDs and haptics is still under rapid development, with new prototypes, devices and systems emerging or planned for the near future (e.g., FOVE 2016; Ackerman 2016). Further advances are still required in order to provide a fully immersive VR experience.

\subsection{Future work}

Although the new computer we used to test the system did not entirely satisfy the recommended specifications for the Oculus Rift HMD, it did result in an acceptable VR experience for our scenes. As an alternative to upgrading the computer hardware, the frame rates could also be improved by activating the haptic properties of a given structure only when the user clicks on it, or perhaps when the virtual pointer is in its proximity. This would reduce the number of triangles for haptic rendering, but would not entirely solve the issue when the selected structure itself has a very high number of triangles.

Another extension of the system should include more complex features such as material deformation and cutting, which are useful for many STEM applications, like surgical training for example. The question remains whether the Unity game engine is the best choice for such types of simulations. It may be worth considering another real-time simulation framework such as SOFA (INRIA 2015), which has an emphasis on medical simulation.

A more in-depth study should be conducted to evaluate the usability of this system, addressing many issues such as (1) the position of the haptic device, in front of the screen or on the side of the user's dominant hand; and (2) the user interaction, to make better use of the gamepad controller, the keyboard and the mouse. It would also be interesting to test more sophisticated devices in order to make better use of the non-dominant hand. Such devices might include the 6 DOF 3dconnexion SpaceNavigator (3DConnexion 2015); a motion-sensing game controller such as the Wii remote (Nintendo 2015); or a second haptic device. Devices like the Leap Motion hand-and-finger motion sensor (Leap Motion 
2016) or haptic gloves (e.g., Foottit et al. 2014; CyberGlove Systems 2015) are also an interesting consideration. Furthermore, the power of the HMD's head tracking might be better exploited by using a portable haptic device like the Haplet (Gallacher et al. 2016).

Other studies will also be needed to evaluate the usefulness of such a system for specific applications such as anatomy teaching (e.g., Nicholson, Funnell, and Daniel 2006; Kinnison et al. 2009), surgical training (e.g., Varshney et al. 2014) and physical rehabilitation (e.g., Sveistrup 2004). In particular, it would be interesting to evaluate the usefulness of combining both HMD and haptics into one system, especially since most haptic devices require a "sit still" setup which severely limits the use of the HMD.

Finally, it is worth mentioning that creating a cross-device and cross-platform system would be useful. It would permit testing multiple devices for a given application, as mentioned in section 2.3.7. Unity is already a cross-platform game engine, while the Oculus Rift is only compatible with the Microsoft Windows platform and the Geomagic OpenHaptics API is compatible with Windows and Linux. As a next system iteration we could use a cross-platform haptic device from Force Dimension (2015) along with the recently released cross-platform OSVR Hacker development kit HMD (OSVR 2015). However, none of these options is cross-device for both HMD and haptics. 


\section{References}

3DConnexion. 2015. SpaceNavigator, Advanced 3D Navigation for Everyone. United States. http://www.3dconnexion.com/products/spacemouse/spacenavigator.html.

3D Systems Corporation. 2013a. "Geomagic Phantom Haptic Devices: Phantom Premium 1.0, 1.5, 1.5 HF Device Guide." Device guide R 7: 4/29/13. U S . http://dl.geomagic.com/binaries/support/downloads/Sensable/3DS/Premium1.0_1.5_HF_Devic e_guide.pdf.

. 2013b. "Geomagic Phantom Haptic Devices: Phantom Premium 3.0 6 DOF Device Guide." Device guide P/N - $02598 \quad$ R3: 4/29/13. US A. http://dl.geomagic.com/binaries/support/downloads/Sensable/3DS/Prem3.06DOF_Device_guid e.pdf.

- 2013c. "Geomagic Phantom Haptic Devices: Phantom Premium 3.0 Device Guide." Device guide $\quad \mathrm{P} / \mathrm{N} \quad-\quad 02536 \quad$ R3: 4/29/13. U A . http://dl.geomagic.com/binaries/support/downloads/Sensable/3DS/Prem3.0_Device_guide.pdf.

. 2015. "Haptic Devices That Add the Sense of Touch to Your Digital World: Touch 3D Stylus, Geomagic ${ }^{\circledR}$ Touch and Geomagic ${ }^{\circledR}$ Touch X." Product brochure. USA. http://www.geomagic.com/files/6114/3940/9416/Haptic_Device_brochure-8-2015-final.pdf.

Ackerman, Evan. 2016. "Hands-On with Ultrahaptics' Invisible, Touchable Controls." IEEE Spectrum, January 14. http://spectrum.ieee.org/tech-talk/consumer-electronics/gadgets/handson-withultrahaptics-invisible-touchable-controls?utm_campaign=Weekly $\% 20$ Notification- $\% 20$ IEEE $\% 20$ Spectrum $\% 20$ Tech

$\% 20 A l e r t \& u t m \_s o u r c e=$ boomtrain\&utm_medium=email\&utm_term=555a972628fbca1d260da 1ba\&utm_content $=$ Hands-On\%20with\%20Ultrahaptics.

Adams, Richard J., and Blake Hannaford. 1999. "Stable Haptic Interaction with Virtual Environments." IEEE Transactions on Robotics and Automation 15 (3): 465-74.

Apple. 2015. Taptic Engine. http://www.apple.com/ca/.

Autodesk. 2013. FBX 2013.3 Converter. Autodesk. http://autodesk.com.

Auweraer, Herman Van der, Stijn Donders, Peter Mas, and Karl Janssens. 2008. "Breakthrough Technologies for Virtual Prototyping of Automotive and Aerospace Structures." In Product Engineering, edited by Doru Talaba and Angelos Amditis, 397-418. Springer Netherlands. http://dx.doi.org/10.1007/978-1-4020-8200-9_20. 
Avusoglu, M. Cenk C., Winthrop Williams, Frank Tendick, and Shankar Sastry. 2001. "Robotics for Telesurgery: Second Generation Berkeley/UCSF Laparoscopic Telesurgical Workstation and Looking towards the Future Applications." INDUSTRIAL ROBOT 30 ( 1 ). doi:10.1108/01439910310457670.

Basdogan, C., S. De, J. Kim, Manivannan Muniyandi, H. Kim, and M.A. Srinivasan. 2004. "Haptics in Minimally Invasive Surgical Simulation and Training." Computer Graphics and Applications, IEEE 24 (2): 56-64. doi:10.1109/MCG.2004.1274062.

Bayer, Michael A., Clarence E. Rash, and James H. Brindle. 2009. “3- Introduction to Helmet-Mounted Displays." In Helmet-Mounted Displays: Sensation, Perception and Cognition Issues, 54-58. U S A : U.S. Army A eromedical Research Laboratory. http://www.usaarl.army.mil/publications/HMD_Book09/.

Blade, Richard A., and Mary Lou Padgett. 2015. "2- Virtual Environments Standards and Terminology." In Handbook of Virtual Environments: Design, Implementation, and Applications, edited by Kelly S. Hale and Kay M. Stanney, Second, 25-34. USA: CRC Press. https://books.google.ca/books?id=7zzSBQAAQBAJ.

Bracewell, R.Martyn, AndrewS. Wimperis, and AlanM. Wing. 2008. "Brain Mechanisms of Haptic Perception." In The Sense of Touch and Its Rendering, edited by Antonio Bicchi, Martin Buss, MarcO. Ernst, and Angelika Peer, 45:26-29. Springer Tracts in Advanced Robotics. Springer Berlin Heidelberg. http://dx.doi.org/10.1007/978-3-540-79035-8_3.

"Braille." 2015. Encyclopcedia Britannica Online. http://www.britannica.com/topic/Braille-writingsystem.

Bresciani, Jean-Pierre, Knut Drewing, and MarcO. Ernst. 2008. "Human Haptic Perception and the Design of Haptic-Enhanced Virtual Environments." In The Sense of Touch and Its Rendering, edited by Antonio Bicchi, Martin Buss, MarcO. Ernst, and Angelika Peer, 45:61-70. Springer Tracts in Advanced Robotics. Springer Berlin Heidelberg. http://dx.doi.org/10.1007/978-3-54079035-8_5.

Butterfly Haptics. 2014. Maglev 200. http://butterflyhaptics.com/products/.

CAE Healthcare. 2015. CAE Interventional Simulators for Performing Minimally Invasive Procedures: EndoVR, LapVR and CathLabVR. http://caehealthcare.com/eng/interventional-simulators.

Changeon, Gwénaël, Delphine Graeff, Margarita Anastassova, and José Lozada. 2012. "Tactile Emotions: A Vibrotactile Tactile Gamepad for Transmitting Emotional Messages to Children with Autism." In Haptics: Perception, Devices, Mobility, and Communication, edited by Poika Isokoski and Jukka Springare, 7282:79-90. Lecture Notes in Computer Science. Springer Berlin Heidelberg. http://dx.doi.org/10.1007/978-3-642-31401-8_8.

Chouvardas, V.G., A.N. Miliou, and M.K. Hatalis. 2008. "Tactile Displays: Overview and Recent Advances." Displays 29 (3): 185-94. doi:10.1016/j.displa.2007.07.003.

Cignoni, Paolo. 2014. MeshLab, a Processing System for 3D Triangular Meshes (version 1.3.3). 3DCoForm Project. http://meshlab.sourceforge.net. 
Coles, Timothy R., Dwight Meglan, and Nigel W. John. 2011. "The Role of Haptics in Medical Training Simulators: A Survey of the State of the Art." Haptics, IEEE Transactions on 4 (1): 51-66. doi:10.1109/TOH.2010.19.

Crytek. 2015. CryEngine Game Engine (version 3). http://cryengine.com.

CyberGlove Systems. 2015. CyberTouch. http://www.cyberglovesystems.com/cybertouch.

Entact. 2015. W3D and W6D Haptic Devices. http://www.quanser.com.

Epic Games. 2015. Unreal Game Engine (version 4). http://www.unrealengine.com.

Fidopiastis, Cali M., Albert A. Rizzo, and Jannick P. Rolland. 2010. "User-Centered Virtual Environment Design for Virtual Rehabilitation." Journal of NeuroEngineering and Rehabilitation 7 (1): 1-12. doi:10.1186/1743-0003-7-11.

Foottit, Jacques, Dave Brown, Stefan Marks, and Andy M. Connor. 2014. "An Intuitive Tangible Game Controller." In Proceedings of the 2014 Conference on Interactive Entertainment, 1-7. Newcastle, NSW, Australia: ACM.

Force Dimension. 2015. Haptic Device Products. http://www.forcedimension.com/products.

FOVE. 2016. THE WORLD'S FIRST EYE TRACKING VIRTUAL REALITY HEADSET. http://www.getfove.com.

Fraps. 2013. Real-Time Video Capture \& Benchmarking (version 3.5.99). http://www.fraps.com.

Fritschi, Michael, Hasan Esen, Martin Buss, and MarcO. Ernst. 2008. "Multi-Modal VR Systems." In The Sense of Touch and Its Rendering, edited by Antonio Bicchi, Martin Buss, MarcO. Ernst, and Angelika Peer, 45:179-88. Springer Tracts in Advanced Robotics. Springer Berlin Heidelberg. http://dx.doi.org/10.1007/978-3-540-79035-8_9.

Fujii, Yasuhisa, Kazunori Kihara, Soichiro Yoshida, Junichiro Ishioka, Yoh Matsuoka, Noboru Numao, and Kazutaka Saito. 2014. "A Three-Dimensional Head-Mounted Display System (RoboSurgeon System) for Gasless Laparoendoscopic Single-Port Partial Cystectomy." Videosurgery and Other Mini Invasive Techniques 9 (4): $638-43$. doi:10.5114/wiitm.2014.44407.

Funnell, W. Robert J. 2013. davis3d: Dynamic Anatomy Visualization in 3-D. Montreal, Canada. http://audilab.bme.mcgill.ca/ funnell/davis3d/.

———. 2015 . Fabrication D'imagerie Extraordinaire (FIE). Montreal, Canada. http://audilab.bme.mcgill.ca/ funnell/AudiLab/sw/fie.html.

Gallacher, Colin, Arash Mohtat, Morgane Ciot, and Steven Ding. 2016. Haply Robotics. Montreal, Qc, Canada. http://www.haply.co.

GeForce. 2016. VR-Ready Graphics Cards GEFORCE GTX. USA: NVIDIA. http://www.geforce.com/hardware/technology/vr/where-to-buy.

Geomagic. $\quad 2015$. Geomagic ${ }^{\circledR} \quad$ Phantom ${ }^{\circledR}$ Premium ${ }^{T M}$ Haptic Devices. http://www.geomagic.com/en/products/phantom-premium/overview/. 
Gigante, Michael A. 1993. "1- Virtual Reality: Definitions, History and Applications." In Virtual Reality Systems, 3-14. Boston: Academic Press. http://www.sciencedirect.com/science/article/pii/B9780122277481500093.

Google. 2015. Google Cardboard (version 1.0). http://www.google.com/get/cardboard/.

Haption. 2015 .Virtuose $3 D$ and 6 D Haptic Interfaces. http://www.haption.com/site/index.php/en/products-menu-en/hardware-menu-en.

Hezel, Paul J., and Harry Veron. 1993. "Head Mounted Displays for Virtual Reality." Military M 93 B 0000015 . Bed ford, Massachussets: M T RE Corporation. http://www.dtic.mil/dtic/tr/fulltext/u2/a263498.pdf.

HTC. 2015. HTC Vive. HTC. http://www.htcvr.com.

INRIA. 2015. Simulation Open Framework Architecture (SOFA) (version 15.12). Windows. https://www.sofa-framework.org.

Jansson, Gunnar. 2008. "Haptics as a Substitute for Vision." In Assistive Technology for Visually Impaired and Blind People, edited by Marion A. Hersh and Michael A. Johnson, 135-66. Springer London. http://dx.doi.org/10.1007/978-1-84628-867-8_4.

Kaczmarek KA, Webster JG, Bach-y-Rita P, and Tompkins WJ. 1991. "Electrotactile and Vibrotactile Displays for Sensory Substitution Systems." IEEE Transactions on Bio-Medical Engineering 38 (1): $1-16$.

Kayatt, Pedro, and Ricardo Nakamura. 2015. "Influence of a Head-Mounted Display on User Experience and Performance in a Virtual Reality-Based Sports Application." In Proceedings of the Latin American Conference on Human Computer Interaction, 1-6. Cordoba, Argentina: ACM.

Keller, Kurtis, Andrei State, and Henry Fuchs. 2008. "Head Mounted Displays for Medical Use." Journal of Display Technology 4 (4): 468-72. doi:10.1109/JDT.2008.2001577.

Kinnison, Tierney, Neil Forrest, Stephen Philip Frean, and Sarah Baillie. 2009. "Teaching Bovine Abdominal Anatomy: Use of a Haptic Simulator." ANATOMICAL SCIENCES EDUCATION 2 (6): 280-85. doi:10.1002/ase.109.

Kolarsick, Paul A. J., Maria Ann Kolarsick, and Carolyn Goodwin. 2011. "Anatomy and Physiology of the Skin." Journal of the Dermatology Nurses' Association Journal of the Dermatology Nurses' Association 3 (4): 203-13.

Kress, Bernard, and Thad Starner. 2013. "A Review of Head-Mounted Displays (HMD) Technologies and Applications for Consumer Electronics." In Proc. SPIE, 8720:87200A - 87200A - 13. doi:10.1117/12.2015654.

Larman, Craig. 2005. Applying UML and Patterns : An Introduction to Object-Oriented Analysis and Design and Iterative Development. Upper Saddle River, N.J.: Prentice Hall PTR.

Leap Motion. 2016. Leap Motion for Virtual Reality. https://www.leapmotion.com. 
Lederman, Susan J., and Roberta L. Klatzky. 1999. "Sensing and Displaying Spatially Distributed Fingertip Forces in Haptic Interfaces for Teleoperator and Virtual Environment Systems." Presence: Teleoper. Virtual Environ. 8 (1): 86-103.

Lenarčič, Jadran, Tadej Bajd, and MichaelM. Stanišić. 2013. "2- Mechanisms \& 7- Parallel Mechanisms." In Robot Mechanisms, 60:65-71 \& 239-44. Intelligent Systems, Control and Automation: Science and Engineering. Springer Netherlands. http://dx.doi.org/10.1007/978-94007-4522-3_7.

Liddell, Henry George, and Robert Scott. 1990. A Lexicon Abridged from Liddell and Scott's GreekEnglish Lexicon. Oxford: Oxford University Press.

Mako Surgical Corp. 2015. Rio Robotic Arm Interactive Orthopedic System. Immersion. http://www.makosurgical.com/physicians/products/rio.

Marshall, Gerald F. 1989. "Back From The Past: The Helmet Integrated System Of Albert Bacon Pratt (1916).” In Proc. SPIE, 1116:2-13. doi:10.1117/12.960891.

Melzer, James E. 2001. “5- Head-Mounted Displays.” In The Avionics Handbook. New York: CRC Press. http://www.davi.ws/avionics/TheAvionicsHandbook_Cap_5.pdf.

Melzer, James E., Frederick T. Brozoski, Tomasz R. Letowski, Thomas H. Harding, and Clarence E. Rash. 2009. "17- Guidelines for HMD Design." In Helmet-Mounted Displays: Sensation, Perception and Cognition Issues, 810-11. USA: U.S. Army Aeromedical Research Laboratory. http://www.usaarl.army.mil/publications/HMD_Book09/.

Mihelj, Matjaž, Domen Novak, and Samo Begus. 2014. "Haptic Modality in Virtual Reality." In Virtual Reality Technology and Applications, 68:161-94. Intelligent Systems, Control and Automation: Science and Engineering. Springer Netherlands. http://dx.doi.org/10.1007/978-94007-6910-6_7.

Min, Patrick. 2015. [meshconv] 3D Model Converter. United States: Princeton University. http://www.cs.princeton.edu/ min/meshconv/.

MPB Technologies. 2014. Haptic Interfaces Freedom 6S and 7S. http://www.mpb-technologies.ca.

Nicholson, DT, WRJ Funnell, and SJ Daniel. 2006. "A Randomized Controlled Study of a ComputerGenerated Three-Dimensional Model for Teaching Ear Anatomy." Medical Education 40: $1081-87$.

Nintendo. 2015. Wii Remote. http://www.nintendo.com/wiiu.

Novint Technologies Inc. $2012 \mathrm{a}$. Novint Falcon 3 D Touch Device. http://www.novint.com/index.php/novintfalcon.

- - $2012 \mathrm{~b}$. Novint Xio: Adding the Sense of Touch to Motion Control. http://www.novint.com/index.php/novintxio.

Oculus. 2015. Oculus Head-Mounted Display. http://www.oculus.com.

OpenHaptics. 2015 . Haptic Device Drivers (version 3.4). Geomagic. http://support1.geomagic.com/link/portal/5605/5668/Article/2377/Haptic-Device-Drivers. 
OSVR. 2015. Open Source Virtual Reality Hacker Kit. http://www.osvr.com.

Pamungkas, D.S., and K. Ward. 2016. "Electro-Tactile Feedback System to Enhance Virtual Reality Experience." International Journal of Computer Theory and Engineering 8 (6): 465-70. doi:DOI: 10.7763/IJCTE.2016.V8.1090.

Panëels, Sabrina A., Panagiotis D. Ritsos, Peter J. Rodgers, and Jonathan C. Roberts. 2013. "Prototyping 3D Haptic Data Visualizations." Computers \& Graphics 37 (3): 179-92. doi:10.1016/j.cag.2013.01.009.

Peli, Eli, Gang Luo, Alex Bowers, and Noa Rensing. 2007. "Applications of Augmented Vision HeadMounted Systems in Vision Rehabilitation." Journal of the Society for Information Display 15 (12): 1037-45. doi:10.1889/1.2825088.

PlayStation. 2015. Project Morpheus. Sony. http://www.playstation.com.

Poyade, M., V. Kargas, and V. Portela. 2014. Haptic Plug-In for Unity. Glasgow, United Kingdom: Digital Design Studio (DDS), Glasgow School of Art.

Pressure Profile Systems. 2015.FingerTPS Pressure Sensor System. P P . http://www.pressureprofile.com/fingertps.

Proske, Uwe, and Simon C Gandevia. 2009. "The Kinaesthetic Senses.” The Journal of Physiology 587 (Pt 17): 4139-46. doi:10.1113/jphysiol.2009.175372.

Purves, Dale, George J. Augustine, David Fitzpatrick, Lawrence C. Katz, Anthony-Samuel LaMantia, James O. McNamara, and S Mark Williams, eds. 2001. Neuroscience. 2nd ed. Sunderland (MA): Sinauer Associates. http://www.ncbi.nlm.nih.gov/books/NBK10986/figure/A1105/.

Pyo, Dongbum, Semin Ryu, Seung-Chan Kim, and Dong-Soo Kwon. 2015. "Haptic Interaction on a Touch Surface." In Haptic Interaction, edited by Hiroyuki Kajimoto, Hideyuki Ando, and KiUk Kyung, 277:109-11. Lecture Notes in Electrical Engineering. Springer Japan. http://dx.doi.org/10.1007/978-4-431-55690-9_20.

Quanser. 2015. HD ${ }^{2}$ High Definition Haptic Device. http://www.quanser.com/products/hd2.

Razer. 2015. Razer Edge - Gamepad Controller. Immersion.

Riener, Robert, and Matthias Harders. 2012. "Haptic Aspects." In Virtual Reality in Medicine, 79-107. Springer London. http://dx.doi.org/10.1007/978-1-4471-4011-5_4.

Rolland, Jannick, and Hong Hua. 2005. "Head-Mounted Display Systems." In Encyclopedia of Optical Engineering, 1-14. Taylor \& Francis. doi:10.1081/E-EOE-120009801.

Samur, Evren. 2012. "State of the Art." In Performance Metrics for Haptic Interfaces, 9-26. Springer Series on Touch and Haptic Systems. Springer London. http://dx.doi.org/10.1007/978-1-44714225-6_2.

Sensable technologies. 2007. New 7 DOF Option for PHANTOM® 6 DOF Devices. Geomagic. http://www.geomagic.com/files/9913/4859/1209/Sensable_7DOFOption_Jan2008.pdf.

Senseg. 2015. Electrostatic Haptic Feedback. Senseg. http://www.senseg.com. 
Sony. 2015.HMS-3000MT 3D Head-Mounted Display System: Visualise Endoscopic and Laparoscopic Images in Stereoscopic 3D. Sony. http://www.sony.co.uk/pro/product/medical-3dmedical-products/hms-3000mt/.

Soukal, Roman, Václav Purchart, and Ivana Kolingerová. 2014. "Surface Point Location by Walking Algorithm for Haptic Visualization of Triangulated 3D Models." Advances in Engineering Software 75 (September): 58-67. doi:10.1016/j.advengsoft.2014.05.004.

Sveistrup, Heidi. 2004. "Motor Rehabilitation Using Virtual Reality." Journal of NeuroEngineering and Rehabilitation 1: 10-10. doi:10.1186/1743-0003-1-10.

Talabă, Doru. 2008. "A Concept for a Multipurpose, Multi-Modal Interface for Product Engineering Applications." In Product Engineering, edited by Doru Talaba and Angelos Amditis, 65-86. Springer Netherlands. http://dx.doi.org/10.1007/978-1-4020-8200-9_3.

Thrustmaster. 2015. Thrustmaster TX Racing Wheel Ferrari 458 Italia Edition. Immersion. $\mathrm{http}: / / \mathrm{www}$.thrustmaster.com/en_US/products/tx-racing-wheel-ferrari-458-italia-edition.

Ueberle, M., N. Mock, and M. Buss. 2004. "VISHARD10, a Novel Hyper-Redundant Haptic Interface." In Haptic Interfaces for Virtual Environment and Teleoperator Systems, 2004. HAPTICS '04. Proceedings. 12th International Symposium on, 58-65. doi:10.1109/HAPTIC.2004.1287178.

Unity. 2015. Unity Game Engine (version 5). http://unity3d.com.

U.S. National Library of Medicine. 2015. The Visible Human Project. https://www.nlm.nih.gov/research/visible/.

Varshney, Rickul, Saul Frenkiel, Lily H. P. Nguyen, Meredith Young, Rolando Del Maestro, Anthony Zeitouni, Elias Saad, W. Robert J. Funnell, and Marc A. Tewfik. 2014. "The McGill Simulator for Endoscopic Sinus Surgery (MSESS): A Validation Study." Journal of Otolaryngology Head \& Neck Surgery = Le Journal D'oto-Rhino-Laryngologie et de Chirurgie CervicoFaciale 43: 40. doi:10.1186/s40463-014-0040-8.

Vrvana. 2015. Vrvana Totem. http://www.vrvana.com.

Xu, Cheng, Ali Israr, Ivan Poupyrev, Olivier Bau, and Chris Harrison. 2011. "Tactile Display for the Visually Impaired Using TeslaTouch.” In CHI '11 Extended Abstracts on Human Factors in Computing Systems, 317-22. Vancouver, BC, Canada: ACM.

Yong Fu, N. Kottenstette, Yingming Chen, Chenyang Lu, X.D. Koutsoukos, and Hongan Wang. 2010. "Feedback Thermal Control for Real-Time Systems." In Real-Time and Embedded Technology and Applications Symposium (RTAS), 2010 16th IEEE, 111-20. doi:10.1109/RTAS.2010.9.

Zachmann, Gabriel. 1998. "VR-Techniques for Industrial Applications." In Virtual Reality for Industrial Applications, edited by Fan Dai, 13-38. Computer Graphics: Systems and Applications. Springer Berlin Heidelberg. http://dx.doi.org/10.1007/978-3-642-46847-6_2. 


\section{Appendix A: Consent Form}

Title of study: Use of 3-D models for learning anatomy

Institution: McGill University

Introduction: You are being asked to participate in this study, whose purpose is to evaluate the usefulness of a 3-D model for learning anatomy.

Study Procedures: If you agree to participate, you will be asked to interact with the 3-D computer-generated model. Your interactions will be observed with the intention of identifying strengths and weaknesses of the model and how it's used, not of evaluating your own knowledge or skills. Afterward you will be asked to fill out a questionnaire about the model and its use.

Benefits and Risks: There is no direct benefit to you of your participation in the study, nor is there any risk in your participation in the study. Your participation (or non-participation) will in no way affect your academic grades or evaluations.

Withdrawal from Study: You may withdraw from the study at any time, without prejudicing or otherwise influencing your subsequent education, training or career at McGill or elsewhere.

Compensation: You will not be financially compensated for taking part in the study.

Subject Rights: As a research subject, your participation in the study is voluntary. Refusal to participate in or withdrawal from the study will involve no penalty or loss of benefits to which you are otherwise entitled. You are entitled to ask questions about the study at any time.

Confidentiality: Your participation in the study will remain confidential. Your choice to participate or not to participate will only be known to the investigators (Prof. Robert Funnell and his collaborators and students involved in the study) and will not be shared with others.

Contact: If questions or problems arise at any time during the study, you are encouraged to contact Prof. Funnell by e-mail (robert.funnell@mcgill.ca).

Signature: The purpose and procedures of this study have been explained to me, and my questions have been answered satisfactorily. I have received a copy of this consent form. I agree to participate in this study.

Signature of subject

Date

Investigator

Date

Witness

Date

2015 Oct 28 


\section{Appendix B: Instructions for using the HMD-Haptics Demo Instructions for using the HMD-Haptics Demo}

1. Have participant read and sign consent.

2. Introduce the Phantom Premium 1.5 haptic device to the participant:

- Ask if they have used such a device before

- Briefly explain the force-feedback mechanism

- Let them interact with the stylus and its switch using their dominant hand.

3. Introduce the Oculus Rift HMD and the head tracker to the participant:

- Ask if they have used such a device before

- Let them wear and properly adjust the HMD to become comfortable

- Mention the possibility of nausea and dizziness, and that they can stop if uncomfortable

4. Introduce the gamepad controller to the participant and let them try it with their nondominant hand.

5. Run the HMD-Haptics demo and ask the participant to wear the Oculus HMD.

6. Explain the main screen:

- Ask participant to look at the sample scene menu item by moving their head until the red circle (target) is on that scene

- Tell participant to click on the stylus switch to start the scene

7. Give the participant 3 minutes to interact with the sample $3 \mathrm{D}$ models. Interaction should include:

- Colouring objects in scene

- Rotating objects in scene

- Moving objects in scene

- Moving in the scene with gamepad controller 
8. Ask the participant to click on the home button to return to the main screen

9. Have participant select the Heart scene by looking at it and clicking with stylus.

10. Ask the participant to colour the 3D heart model to match the poster found to the right of the screen (note the time taken)

11. Ask the participant to interact with the heart model using the haptic device to touch, rotate and move a given part closer to their head.

12. Give the participant 2-3 minutes to move around the scene using a gamepad controller.

13. Have participant return to home screen.

14. Ask the participant how they feel and give them the questionnaire to fill out.

15. Ask the participant if they are interested in trying another scene, the Skull scene, which has a more complex 3D model. If they are interested, tell them to wear the HMD and select the Skull scene.

16. After 5 minutes, ask the participant their opinion about the scene and write that down.

17. Thank the participant.

Take notes for each participant: how they used the system, the time spent on the colouring task and whether they wanted to try the skull scene or not. 


\section{Appendix C: Questionnaire for participants}

\section{Questionnaire on the virtual-reality system for interacting with 3-D models using a haptic device and a head-mounted display}

The following survey takes approximately 5 minutes to complete. Your participation is voluntary and your responses are strictly confidential. Should you wish to withdraw from participation, you may do so at any point in time.

Note: when uncertain about answering a given question, you can skip it and, optionally, give a brief explanation of why you are uncertain.

\section{Identification}

Age (optional):

Date:

Gender (optional): $\square$ Male $\square$ Female

Degree program:

\section{Learning methods for anatomy}

Please rate each of the following learning methods according to your frequency of use.

\begin{tabular}{|l|l|l|l|l|l|}
\hline \multirow{2}{*}{ Learning method } & \multicolumn{5}{|c|}{ Frequency of use } \\
\cline { 2 - 6 } & Never & Seldom & Monthly & Weekly & Daily \\
\hline Printed media (books, magazines, etc.) & & & & & \\
\hline Digital media (ebooks, etc.) & & & & & \\
\hline Lectures and seminars & & & & & \\
\hline Videos (Youtube, etc.) & & & & & \\
\hline 3D models (Anatomy TV, VisibleBody, etc.) & & & & & \\
\hline Other (please specify): & & & & & \\
\hline
\end{tabular}

Do you think that a learning method based on 3D models could help you in any of the course(s) you are currently registered in? If yes, please explain. 


\section{Computer use}

\begin{tabular}{|l|l|l|l|l|l|}
\hline \multirow{2}{*}{ Computer used for: } & \multicolumn{5}{|c|}{ Frequency of use } \\
\hline & Never & Seldom & Monthly & Weekly & Daily \\
\hline Internet browsing & & & & & \\
\hline Emailing & & & & & \\
\hline Social media (Facebook, Twitter, Instagram, etc.) & & & & & \\
\hline Playing games & & & & & \\
\hline Research & & & & & \\
\hline Learning & & & & & \\
\hline Watching videos and movies for entertainment & & & & & \\
\hline Video Conference (Skype, etc.) & & & & & \\
\hline
\end{tabular}

\section{Previous interaction with 3D models}

Please specify whether you have previously used one of the following tools for interacting with 3D models.

\begin{tabular}{|l|l|l|l|l|l|}
\hline \multirow{2}{*}{ Tools for interacting with 3D models } & \multicolumn{5}{|c|}{ Frequency of use } \\
\hline & Never & Seldom & Monthly & Weekly & Daily \\
\hline Conventional mouse & & & & & \\
\hline Gamepad controller & & & & & \\
\hline Haptic device (please specify): & & & & & \\
\hline 3D glasses (please specify): & & & & & \\
\hline Head-mounted display (please specify): & & & & & \\
\hline
\end{tabular}

\section{Anatomical background}

Please list the anatomy courses that you have taken or are currently registered in, if any. 


\section{System evaluation}

Please answer the following questions.

\begin{tabular}{|c|c|c|c|c|c|}
\hline \multirow[b]{2}{*}{ Question } & \multicolumn{5}{|c|}{ Scale } \\
\hline & 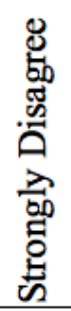 & 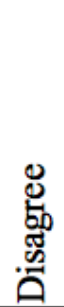 & 焉 & 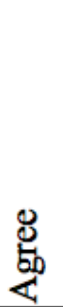 & 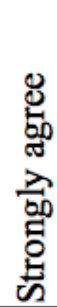 \\
\hline The anatomical 3D models used are accurate & 1 & 2 & 3 & 4 & 5 \\
\hline The Phantom Premium 1.5 Haptic Device was easy to use & 1 & 2 & 3 & 4 & 5 \\
\hline The haptic interaction was easy to learn & 1 & 2 & 3 & 4 & 5 \\
\hline Finding the virtual pointer in the scene was easy & 1 & 2 & 3 & 4 & 5 \\
\hline $\begin{array}{l}\text { Touching the } 3 \mathrm{D} \text { model with the virtual pointer provided a realistic } \\
\text { interaction }\end{array}$ & 1 & 2 & 3 & 4 & 5 \\
\hline The head-mounted display (HMD) is comfortable & 1 & 2 & 3 & 4 & 5 \\
\hline The field-of-view of the HMD provided a good virtual-reality experience & 1 & 2 & 3 & 4 & 5 \\
\hline The resolution of the HMD is good (sharp images, no fuzziness, etc.) & 1 & 2 & 3 & 4 & 5 \\
\hline I find it easy to do the tasks while wearing the HMD & 1 & 2 & 3 & 4 & 5 \\
\hline I feel dizzy after using the HMD & 1 & 2 & 3 & 4 & 5 \\
\hline I have a headache after using the HMD & 1 & 2 & 3 & 4 & 5 \\
\hline I feel nauseous after using the HMD & 1 & 2 & 3 & 4 & 5 \\
\hline $\begin{array}{l}\text { I find it easy to use all system components together: the haptic device, the } \\
\text { HMD and the gamepad controller (or the mouse) }\end{array}$ & 1 & 2 & 3 & 4 & 5 \\
\hline Overall, I find the system easy to use & 1 & 2 & 3 & 4 & 5 \\
\hline It is easy to navigate through the scenes & 1 & 2 & 3 & 4 & 5 \\
\hline I quickly learned how to use the system & 1 & 2 & 3 & 4 & 5 \\
\hline I would easily become skillful at using such a system & 1 & 2 & 3 & 4 & 5 \\
\hline The tasks (colouring, moving objects, etc.) are clear and easy to understand & 1 & 2 & 3 & 4 & 5 \\
\hline Overall, I am satisfied with the ease of completing the tasks & 1 & 2 & 3 & 4 & 5 \\
\hline Overall, I am satisfied with the amount of time it took to complete each task & 1 & 2 & 3 & 4 & 5 \\
\hline If given access to such a system, I would use it as a study tool & 1 & 2 & 3 & 4 & 5 \\
\hline Overall, I find the system useful & 1 & 2 & 3 & 4 & 5 \\
\hline I would recommend the system to a friend & 1 & 2 & 3 & 4 & 5 \\
\hline
\end{tabular}


Do you have any suggestions or recommendations for future developments of this system?

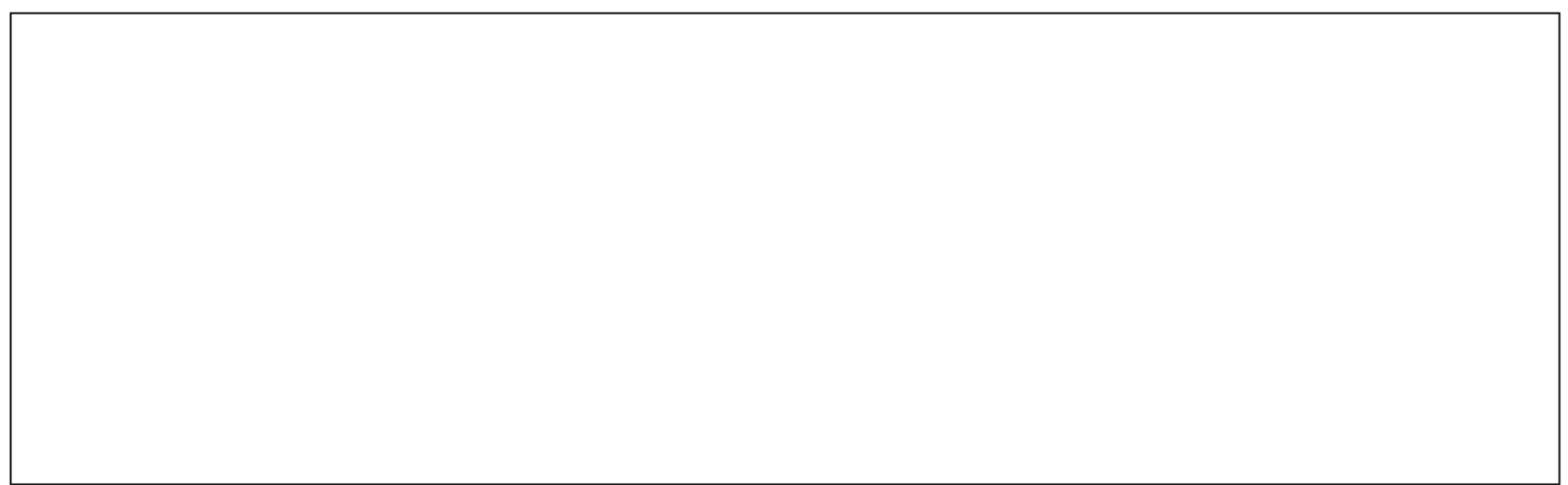

